\title{
ANALYSIS OF DIABLO CANYON SITE RESPONSE SPECTRA
}

\author{
D. L. Bernreuter \\ L. H. Wight
}

June 24, 1977

\section{MASTER}

Prepared for U.S. Energy Research \& Development Administration under contract No. W-7405-En $5-48$

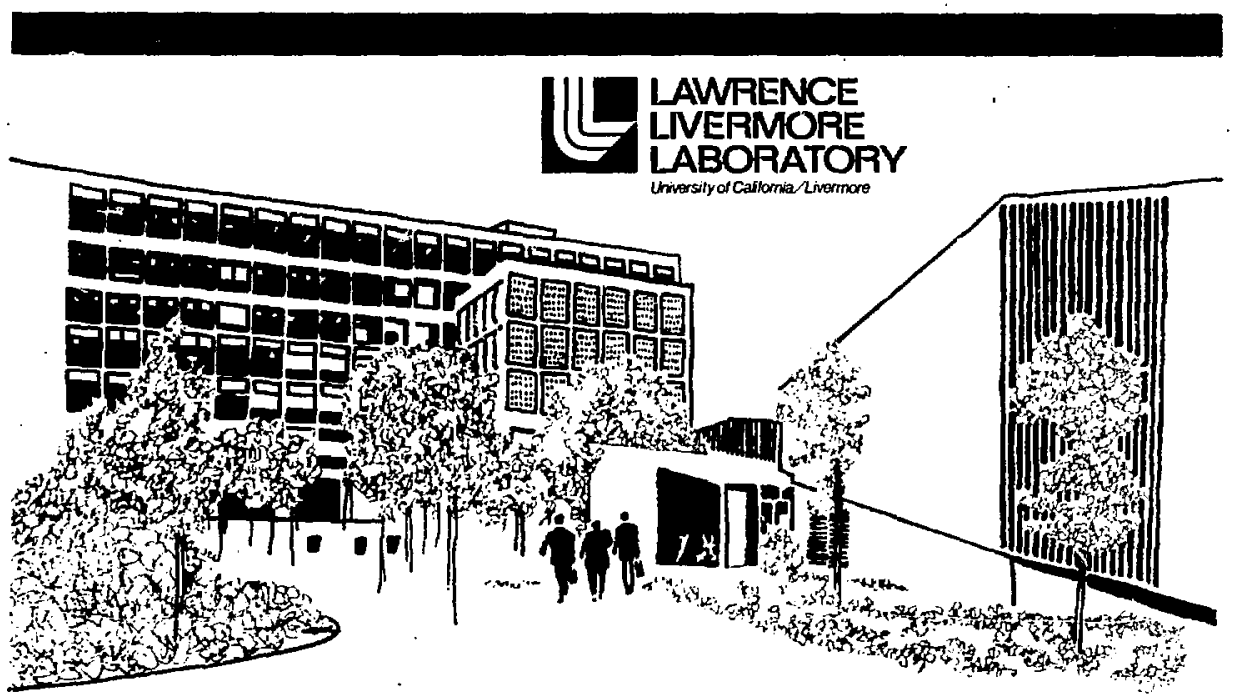




\section{NOTICE}

This report was prepared as an account of work sponsored by the United States Govemment. Neither the Uniled States nor the United States Energy Research 2 Development Administration, nar any of their employec:, nor any of their contractors, subcontractors, or their employees, makes any warnanty, exp :es of Implied, or axumes any legil liability us responsibility for the aceiracy, completeriess or usefulness of any information, waparatus, product or process disclosed, or represents that its 11 wo would not infringe privately owned rights.

\section{NOTICE}

Reference to a company or product name does not imply approval or recommendation of the product by the University of California or the U.S. Energy Research a Development Administration to the exciusion of others that may be suitable.

Printed in the United States of America Available from

Notional Technical Information Service

U.S. Depurtment of Commerce

$\$ 285$ Port Royal Road

Springlield, VA 22161

Price: Printed Copy \$ : Microfiche $\$ 3.00$

\begin{tabular}{|c|c|c|c|}
\hline Page Range & $\begin{array}{c}\text { Domestic } \\
\text { Price }\end{array}$ & Page Range & $\begin{array}{c}\text { Domestic } \\
\text { Price }\end{array}$ \\
\hline $001-025$ & $\$ 3.50$ & $326-350$ & 10.00 \\
\hline $026-050$ & 4.00 & $351-375$ & 10.50 \\
\hline $051-075$ & 4.50 & $3 / 6-400$ & 10.75 \\
\hline $076-100$ & 5.00 & $40 !-425$ & 11.00 \\
\hline $101-125$ & 5.50 & $426-450$ & 11.75 \\
\hline $126-150$ & 6.00 & $451-475$ & 12.00 \\
\hline $151-175$ & 6,75 & $476-500$ & 12.50 \\
\hline $176-200$ & 7.50 & $501-525$ & 12.75 \\
\hline $201-225$ & 7.75 & $526-550$ & 13.00 \\
\hline $226-250$ & 8,00 & $55 t-575$ & 13.50 \\
\hline $251-275$ & 9.00 & $576-600$ & 13.75 \\
\hline $276-300$ & 9.25 & $60\}-u p$ & 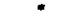 \\
\hline $301-325$ & 9.75 & & \\
\hline
\end{tabular}

Add \$2.50 for each addilional lon page incremient from 601 to 1,000 pags: add $\$ 4.50$ for eact additimal 100 page increment over 1,000 pages. 


\section{近 \\ LAWRENCE LNERMORE LABORATORY}

Uhiversitycf Cahtornia Livermore, Calfornia 94550

\section{UCRL-52263 \\ ANALYSIS OF DIABLO CANYON SITE RESPONSE SPECTRA}

D. L. Bernreuter

L. H. Wight ${ }^{*}$

MS. date: June 24, 1977

*Now with Teknekron Energy Resource Analysts Corp. Berkeley, California

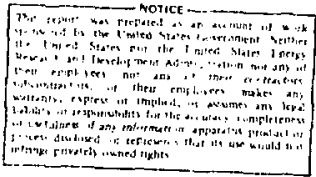




\section{Contents}

Abstract . . . . . . . . . . . . . . . . . . . . . . 1

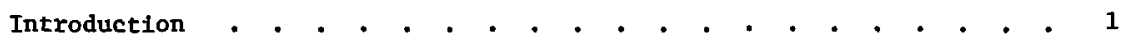

Relation Between Peak Velocity and Acceleration . . . . . . . . . 2

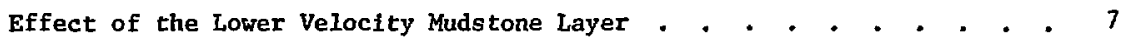

Dynamic Amplification Factors . . . . . . . . . . . . . . . 13

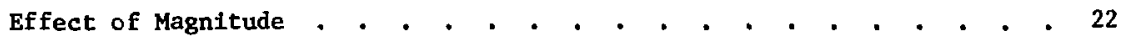

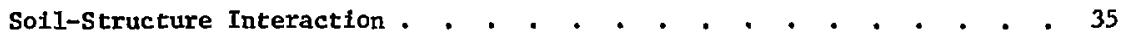

Lush Calculations . . . . . . . . . . . . . . . . . . . 36

Effect of Selsmic Wave Passage on the Response of

Large Basemat Structures . . . . . . . . . . . . . . . 46

Conclusion . . . . . . . . . . . . . . . . . . 58

Acknowledgments . . . . . . . . . . . . . . . . 58

References . . . . . . . . . . . . . . . . . . . . . 59 


\title{
ANALYSIS OF DIABLO CANYON SITE RESPONSE SPECTRA
}

\begin{abstract}
The Diablo Canyon Nuclear Power Plant, located on the central California coast, is nearing completion. Recent geologic and seismological investigations have indicated that the nearby Hosgri fault may be part of a major fault system. If so, the original Design Basis Eartiquake (DBE) may be inadequate for Diablo Canyon. Therefore, we have examined several factors that could significantly affect the design response spectra for the site. We find that, because of the area's geology,

significant site effects enuld occur that would reduce ground motion; possible soil-structure interaction would also reduce the seismic motion at the basemat of the main structure as compared to the free-fleld motion. Studies of wave-passage effects have show that they are complicated and cannot be easily predicted. We conclude that an increased-magnitude $\mathrm{DBE}$ should have little effect on the reactor design if the increase is caused by increased stress drop rather than greater fault rupture length.
\end{abstract}

\section{Introduction}

The Diablo Canyon Nuclear Power Plant, located near San Luis Obispo on the central California coast, is in final stages of completion. Recent geologic and seismological investigations have indicated that the nearby Hosgri fault may be part of a major fault system and, if so, the original Design Basis Earthquake (DBE) for Diablo Canyon may be inadequate.
Because the plant is nearing completion, major changes in the seismic design basis would be exceedingly costly. Hence, the final design response spectra must be carefully developed.

A problem arises from the fact that the currently proposed Safe Shutdown Earthquake (SSF) for Diablo Canyon is much larger and nearer the site thein anticipated by the original 
DBE. No data exist in the near field of such a large event; little data exist in the near field of any size earthquake. So, at present, there is no adequate technical basis for predicting appropriate design response speitra for the Diablo Canyon site.

In this report we summarize our studies to improve the technical basis, which will ald the Nuclear Regulatory Commission (NRC) In formulating appropriate seismic destgn specifications. Our effort has been directed toward defining spectra for the particular geologic and seismological conditions at the Diablo Canyon site. We have attempted to:

- Establish a relation between peak velocity and peak acceleration for rock and soil sites.
- Determine how low shear velocity in the underlying mudstone layer affects the possible peak accelerations and spectra.

- Derive appropriate dynamic amplification factors to define the response spectra for near-field, high-g-level eerthquakes.

- Determine appropriate scaling of the response spectra for earthquakes of large magnitude.

- Identify the effects of massive structures (in weight, size, and stiffness) on the free-field ground motion.

- Determine the scope of the possible effects of seismic wave passage on the response of buildings with large basemats.

\section{Relation Between Peak Velocity and Acceleration}

Newmark et al. 1 have studied 14 of the earthquake records used to define the spectra of Regulatory Guide 1.60, finding that, In the frequency range 0.5 to $2 \mathrm{~Hz}$, the amplification factors best defining the spectral shape should be based on a scalir.g of peak ground velocity. This scaling, they report, should be applied to the relative velocity spectra. In the highfrequency range (greater than $2 \mathrm{~Hz}$ ), amplification should be related to the paak ground acceleration and the scaling applied to the acceleration spectra. The spectra can then be mated using three-way $\log$ paper. McGuire, ${ }^{2}$ studying more earthquakes with more far-field records, reaches somewhat different conclusions. Velocity is not the most important parameter, he reports, mainly because the peak velocity attenuates more rapidly than the spectral amplitudes in the middle frequency range. We have considered his argument but concluded that, 
because the Diablo Canyon site is near the Hosgri fault, the attenuation effect is not significant. For this reason, we believe the Newmark approach is valid for Diablo Canyon.

Because peak velocity at the site plays such an important role in this approach, it is important to se able to estimate the peak velocity anticipated for a given earthquake. Figures 1 and 2 show peak acceleration and velocity as functions of epicentral range for firm-rock recording sites. The values plotted here are vector values; that is, the two horizontal components and the

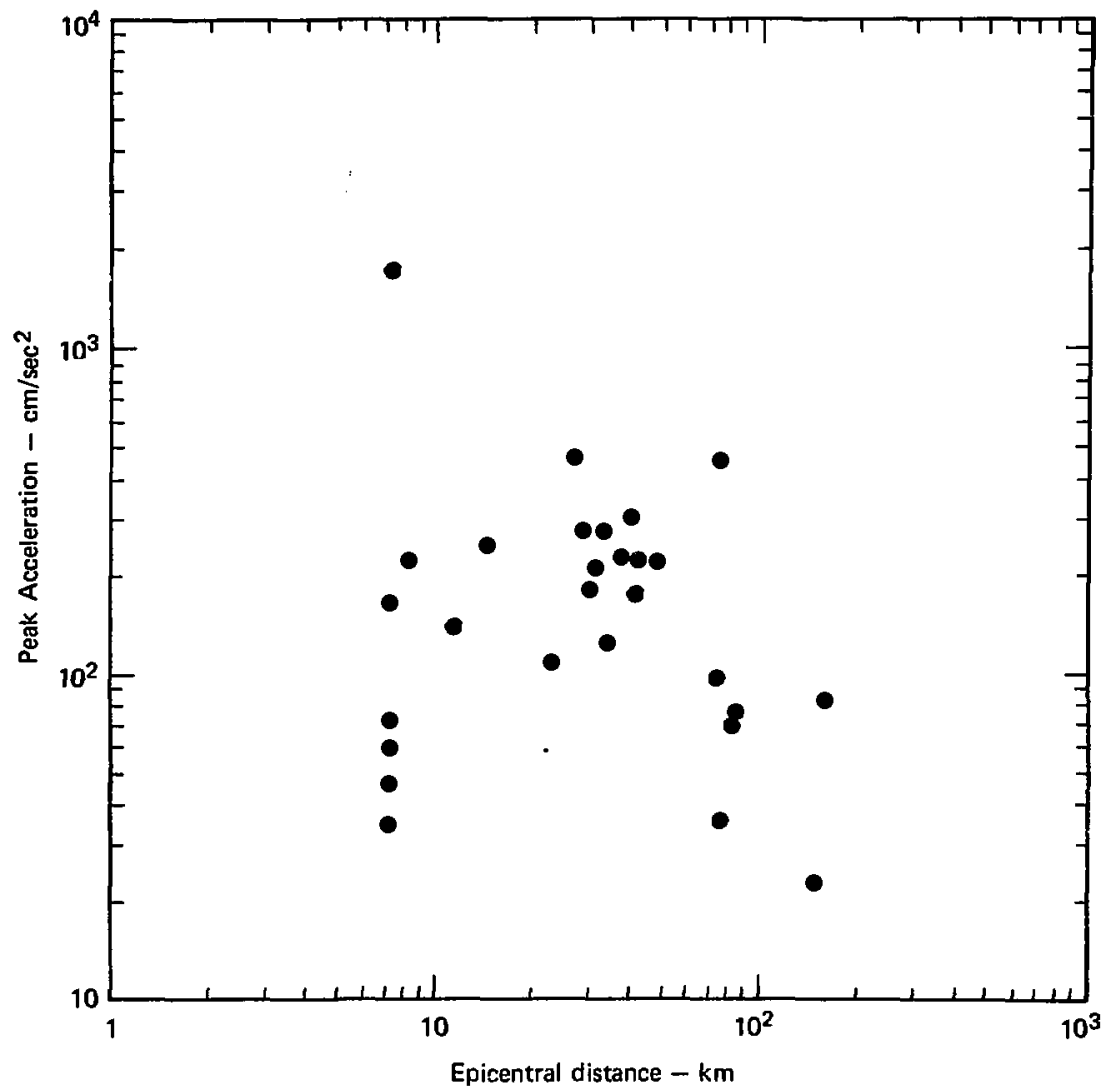

Fig. 1. Peak acceleration as a function of epicentral range for firm-rock recording sites. 


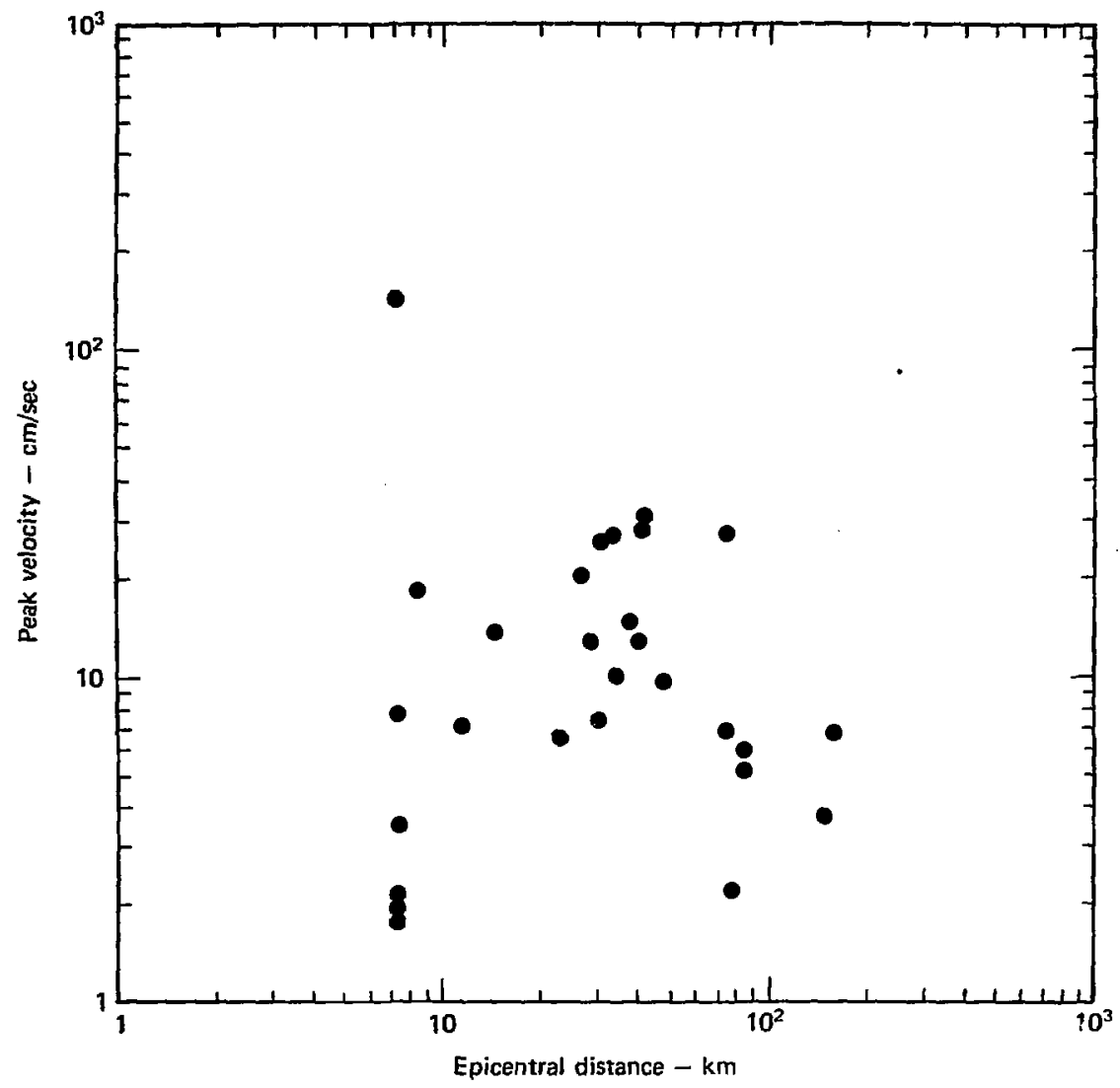

Fig. 2. Peak velocity as a function of epicentral range for firm-rock recording sites.

vertical component are combined by square root of the sum of the components' squares. This is done to reduce the data scatter that occurs when the components are plotted singly. Although the peaks do not generally occur at the same time, combined plots are felt to produce a more accurate measure of ground motion observed at a site than individual plots. These figures show considerable data scatter. Similar if not worse scatter occurs if the data are plotted in other ways (see Trifunac ${ }^{3}$ for example). Figure 3 shows peak velncity vs peak acceleration for rock sites. Figure 4 shows the same plot for softer soil sites. 


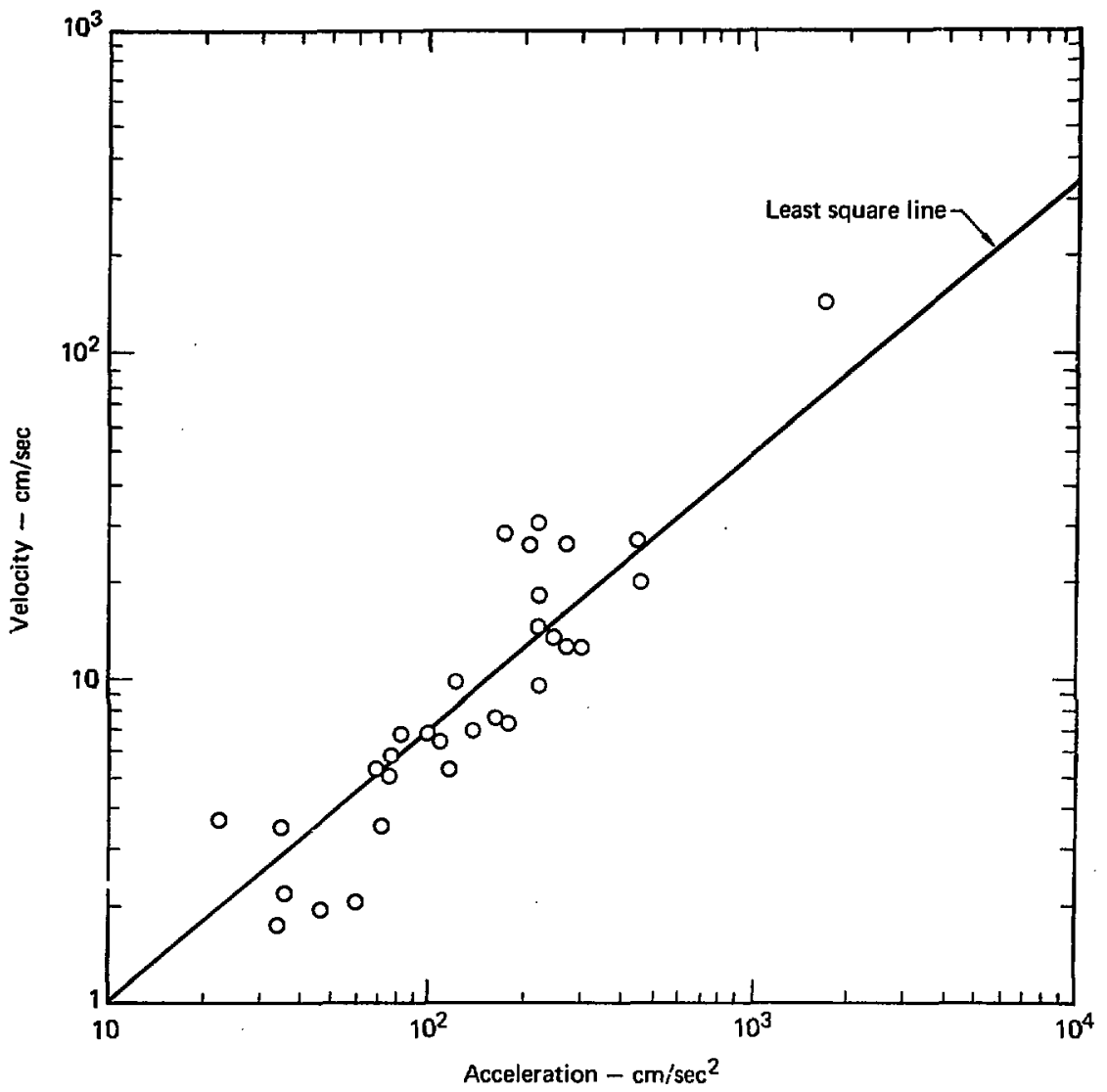

Fig. 3. Peak velocity vs peak acceleration for rock sites,

These data appear to correlate somewhat better than plots of peak acceleration and velocity vs distance.

The real difficulty at Diablo Canyon; as noted, is the fact that the site is near the fault. Thus, extrapolations based on Figs. 1 and 2 are difficult because near-field data are lacking. Also, the peak velocity recorded in the near field is not purely a function of magnitude. This is one reason why such data scatter exists for magnitude peak ground motion - epicentraldistance correlations. However, Figs. 3 and 4 show some reasonable 


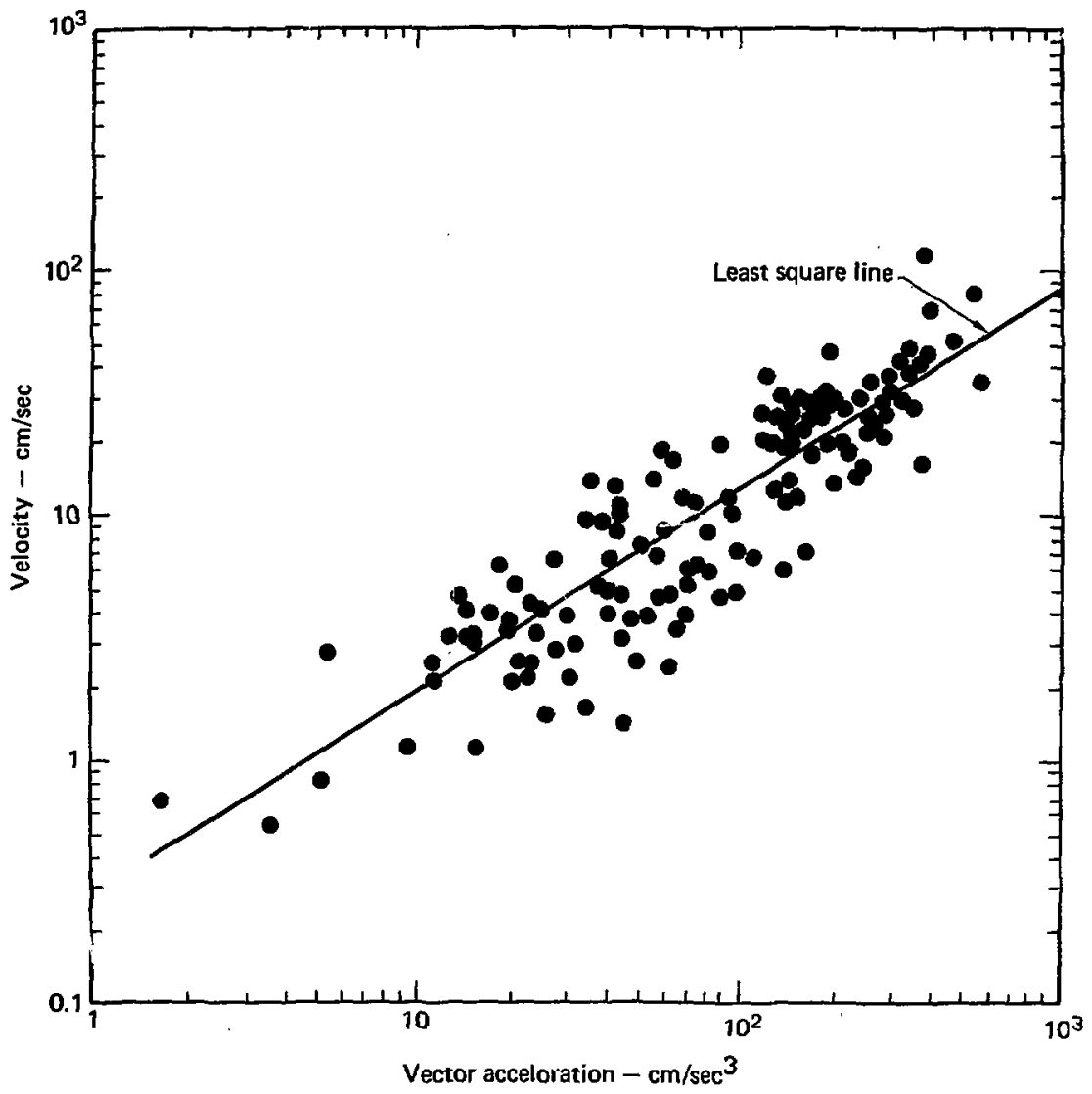

Fig. 4. Peak velocity vs peak acceleration for soil sites.

determination of the peak velocity once the peak acceleration is estimated. They also allow a reasonable basis for comparing response spectra differe.ces in soil and rock sites. Various lines can be drawn through the data, however, and for a simple comparison between rock and softer soil sites, a least-squares line on $\log -\log$ paper can be used. The equations of the various relations between acceleration and velocity are:

- Hard rook $\log V=-0.92+0.872 \log A(1)$

- Soft soil $\log V=-0.6+0.846 \log A$ 
- A2l data

$\log V=-0.65+0.845 \log A(3)$

where

$$
\begin{aligned}
& \mathrm{V} \sim \mathrm{cm} / \mathrm{sec} \\
& A \sim \mathrm{cm} / \mathrm{sec}^{2} .
\end{aligned}
$$

Table 1 gives typical values for each curve,

A similar correlation was rum between peak horizontal accelerat:nn and velocity. The equations of the fit are:

- Hard rock

$\log V=-1.07+0.939 \log A(4)$

- Alz data

$\log V=-0.68+0.846 \log A .(5)$

Table 2 gives typical values for Eqs. (4) and (5).

Table 1. Average velocities (vector) as a function of acceleration (vector) and site conditions.

\begin{tabular}{rrrr}
\hline $\begin{array}{l}\text { Hard } \\
\mathrm{cm} / \mathrm{sec}^{2}\end{array}$ & $\begin{array}{l}\text { Soft } \\
\mathrm{V} \text { cm/sec }\end{array}$ & $\begin{array}{l}\text { soil, } \\
\mathrm{cm} / \mathrm{sec}\end{array}$ & $\begin{array}{l}\text { All data, } \\
\mathrm{V} \mathrm{cm} / \mathrm{sec}\end{array}$ \\
\hline $100 \mathrm{j}$ & 50 & 87 & 77 \\
100 & 6.7 & 12 & 11 \\
10 & 0.9 & 1.8 & 1.5 \\
\hline
\end{tabular}

Table 2. Peak horizontal acceleration vs velocity.

\begin{tabular}{rcc}
\hline $\begin{array}{l}\text { Accel, } \\
\mathrm{cm} / \mathrm{sec}^{2}\end{array}$ & $\begin{array}{r}\text { Hard rock, } \\
\text { V cm/sec }\end{array}$ & $\begin{array}{c}\text { N11 rata, } \\
\text { V cmisec }\end{array}$ \\
\hline 1000 & 56 & 72 \\
100 & 6.4 & 10 \\
10 & 0.7 & 1.5 \\
\hline
\end{tabular}

The results show that, on the average, the velocity at a soil site is 1.6 to 1,7 times greater than at a firm-rock site for the same peak acculeration. This result can then be used, for example, to modify Regulatory Gulde 1.60 spectra in the frequency range 0.2 to $2.5 \mathrm{~Hz}$.

The slope of the correlation for rock data is larger than for soil sites. The importance of this can be seen by comparing the fit using the data from Figs. 3 and 4, which show that the line through the soil data is skewed toward the low side at higher accelerations. Thus, using the above correlations at high $g$ values would result in a smaller estimate ratio of

$$
(v / a)_{\text {soil }} /(v / a)_{\text {rock }}
$$

than would typically be recorded.

\section{Effect of the Lower Velocity Mudstone Layer}

The sandstone at the site is underlafd by a layer of less competent mudstone. This could signifi- cantly affect both the peak $g$ value that could occur at the site and the shape of the response spectra. If we 
assume that the major release of shear energy is well below the shallow mudstone layer, then the SHAKE computer program ${ }^{4}$ may be used to predict the maximum motion for this site. There is considerable slope to the underlying rock formations, and this could have a significant effect on the results. A complex two dimensional analysis was not used because of the time and effort required to model the underlying geo- logical structure. Such effects can be modeled, but the results are rather sensitive to the geometric parameters and frequency content of the motion. For an example, see Wong and Jennings. 5

i'igure 5 compares three models of the site. Model $\mathrm{S}$ has the mudstone shear wave velocity of half the sandstone, Model $M$ has the mudstone shear velocity midway between Model $S$ and the sandstone, and Model $H$ has a

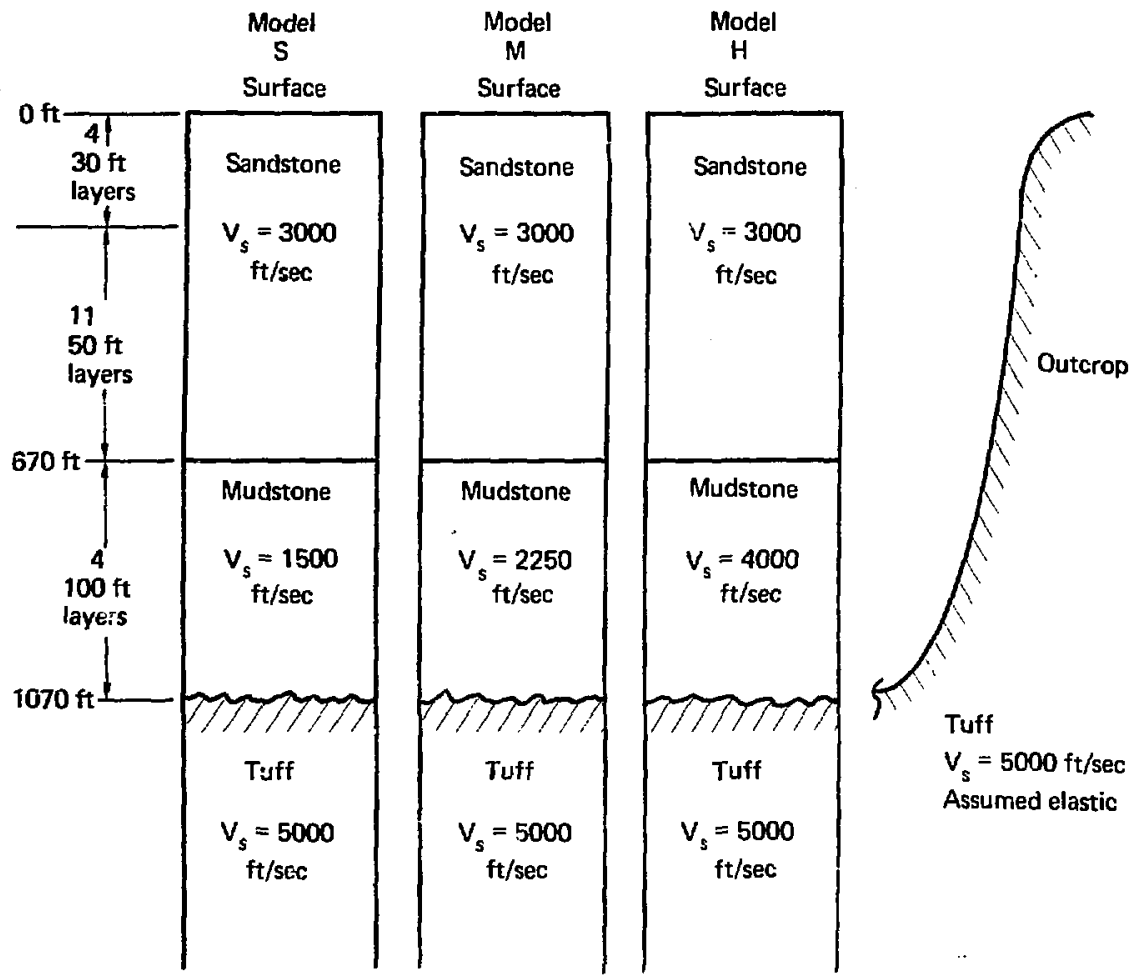

Fig. 5. Comparison of three models of the Diablo Canyon Site. 
harder layer of rock midway between the underlying tuff and the sandstone. Model $\mathrm{H}$ is used as the basis of comparison because it has no soft layer.

The racoima Dam Record, Sl6E, was used as the input ground motion scaled to $3 / 4 \mathrm{~g}$. To cover a range of cases, we calculated the response of each of the above soil models with this input applied to various locations. The $3 / 4-\mathrm{g}$ value is reasonable because it reduces the nonlinear effect somewhat, and, because the validity of our equation-of-state of the sandstone and mudstone is uncertain, we felt that severe nonlinear effects should be avoided.

In Fig. 6 we compare the surface response spectra of the three models when the input motion is at the turfmudstone interface. (The spectra of the input motion is shown for reference.) Figure 7 shows a comparison of the models when the input motion is applied at an outcrop of the tuff. SHAKE then corrects the input record for free surface effects as well as the down-traveling waves for each model. Thus the input spectra at the tuff-mudstone interface is somewhat different for each model. Also shown on Fig. 7 is the spectra of the time history at the tuff outcrop. When Figs. 6 and 7 are compared, both spectra (base motion, Fig. 6 and cutcrop motion, Fig. 7) are the same. The location of the motion input has a significant ef fect on the result, particularly when the spectral peak is in the period range of 1.2-1.6 sec. This difference is due to the spectral shape modification of the driving-time history that is caused by both the free surface effect and the down-traveling wave effect at the given site. Figure 8 illustrates this for site $\mathrm{H}$ and also shows frequencies at which maximum amplification occurs for the model and the values of the amplification factors.

The mudstone layer is important because it reduces the peak $g$ leve 1 that might be expected at the site. The shear wave velocity of the mudstone has a considerable impact on this reduction. A study of this effect was made in which the mudstone was given a shear velocity of $3000 \mathrm{ft} / \mathrm{sec}$, the same as the sandstone. The results of this study are given in Table 3 for Model H-I. It should be recalled that for Model $\mathrm{H}$ the mudstone had a shear wave velocity of $4000 \mathrm{ft} / \mathrm{sec}$, and therefore the mudstone must have a lower velocity than the sandstone if the peak surface acceleration is to be reduced. Although the comparisons were made at the surface, there is very little difference between the surfí _e motion and the free-field motion at a depth of $30 \mathrm{ft}$. 


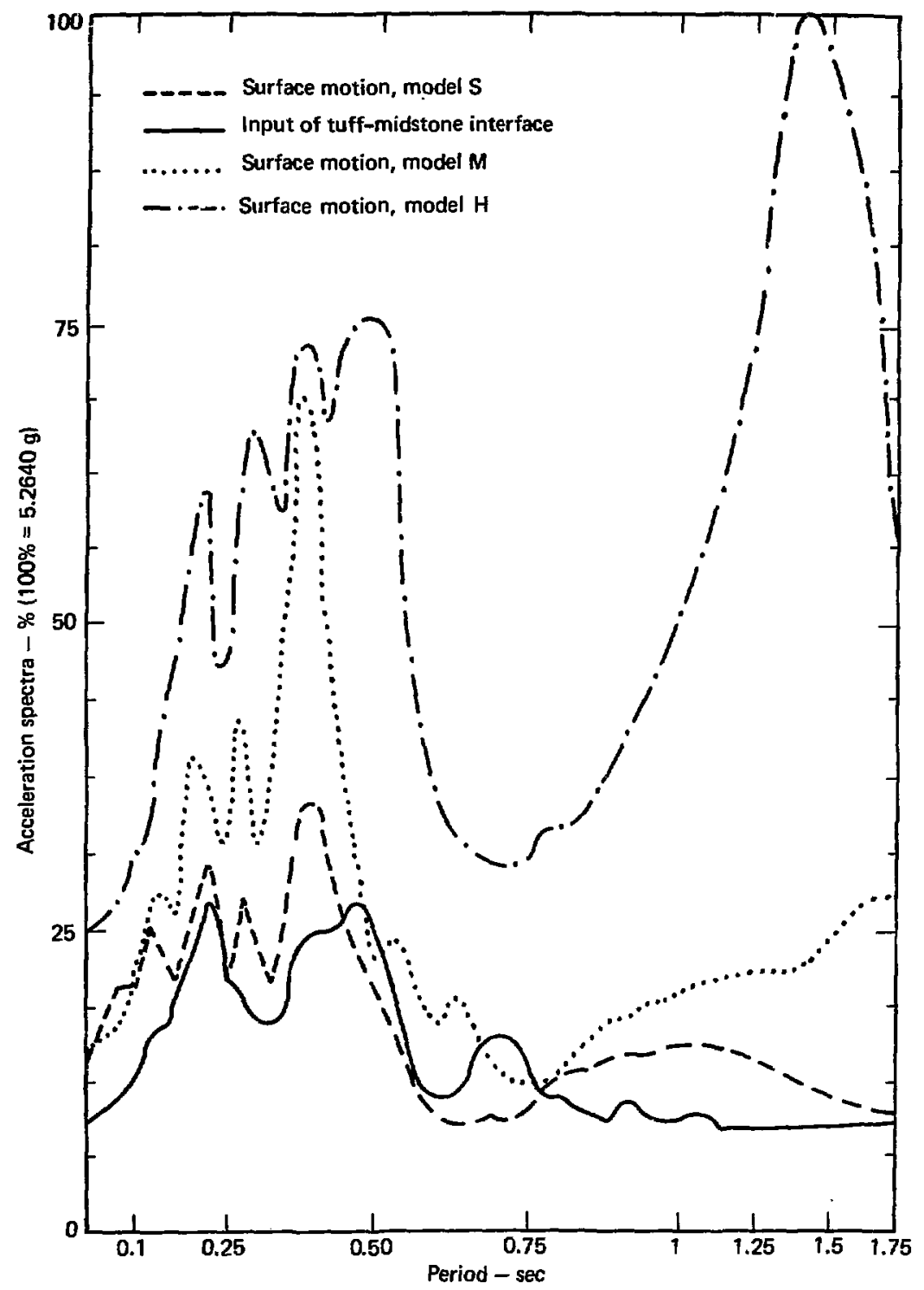

Fi. 6. Comparison of the acceleration response spectrum for three models of the Diabio Canyon. Site when input motion is at the tuff-mudstone interface. 


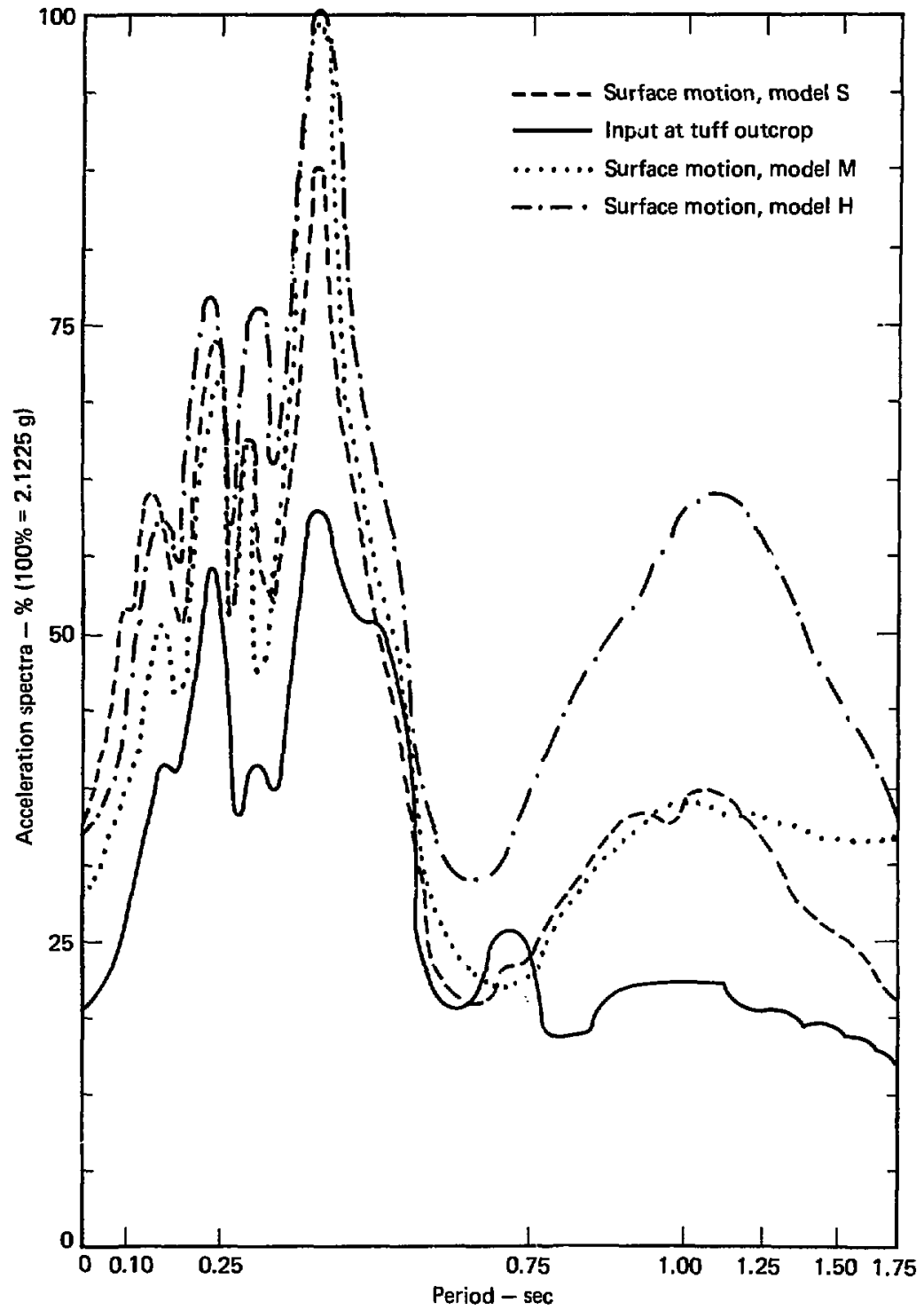

Fig. 7. Comparison of the acceleration response spectrum for three models of the Diablo Canyon Site when input motion is applied at a tuff outcrop. 


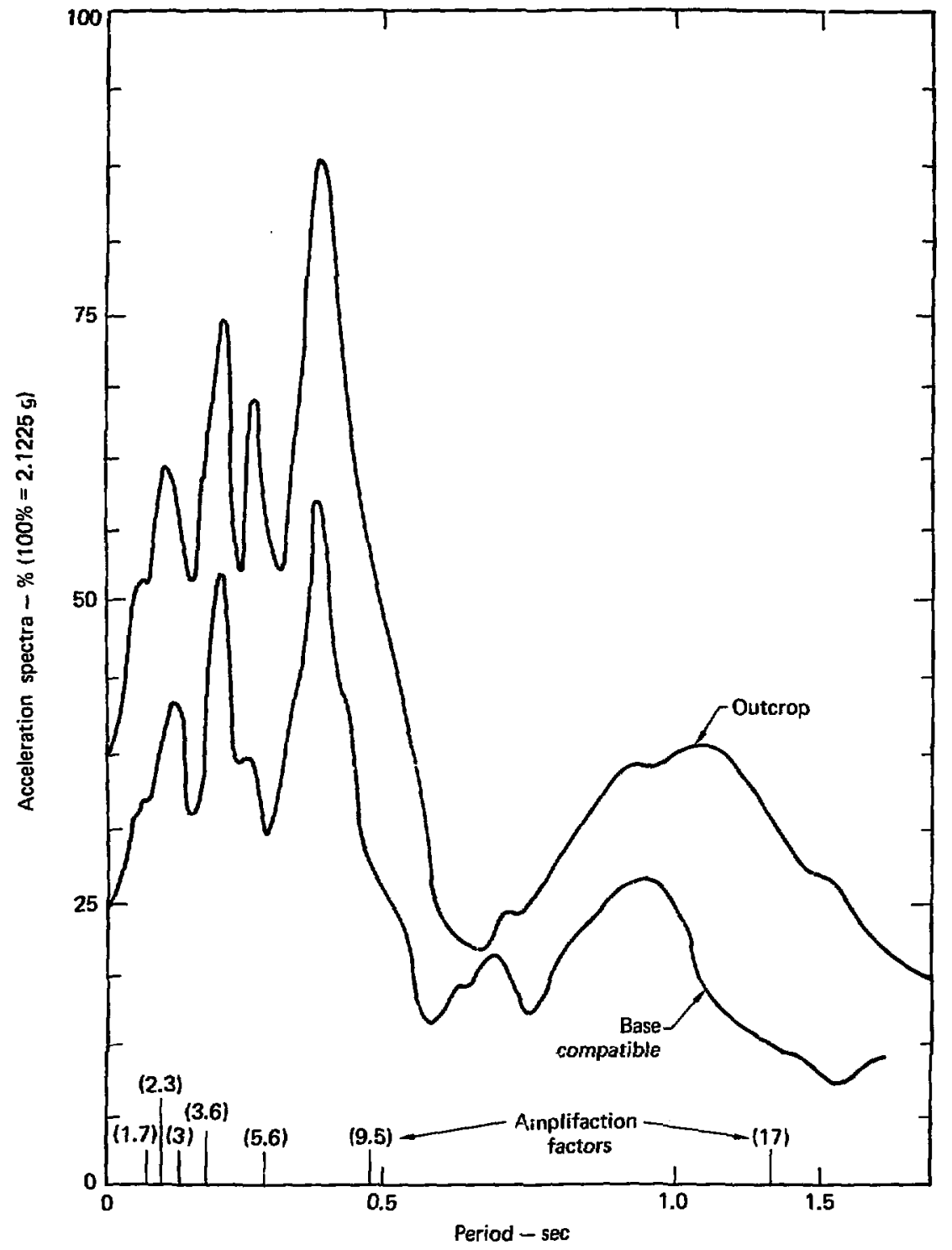

Fig. 8. Spectral shape modification of the deconvolved driving-time history and maximum amplification frequencles for Model $\mathrm{H}$. 
Table 3. A comparison of input peak accelerations and surface accelerations.

\begin{tabular}{lllll}
\hline Mode1 & $\begin{array}{c}\text { Loc. of } \\
\text { input }\end{array}$ & $\begin{array}{c}\text { Peak acceleration at } \\
\text { tuff mudstone interface }\end{array}$ & $\begin{array}{l}\text { Peak accel. } \\
\text { at surface }\end{array}$ & $\begin{array}{l}\text { Ratio } \\
\text { S/base }\end{array}$ \\
\hline S & base & 0.75 & 0.48 & 0.64 \\
S & outcrop & 0.6 & 0.43 & 0.72 \\
M & base & 0.75 & 0.78 & 1.04 \\
M & outcrop & 0.53 & 0.62 & 1.17 \\
H & base & 0.75 & 1.22 & 1.63 \\
H & outcrop & 0.48 & 0.71 & 1.48 \\
H-I & base & 0.75 & 1.22 & 1.63 \\
\hline
\end{tabular}

We conclude that the location of the input significantly affects the results. We also feel that the results for the motion input in the cutcrop are the most realistic (FIg. 7). They show the importance of the shear wave velocity variation in the sandstone as well as the contrast between the mudstone and sandstone. If the contrast is sufficient, the level of shaking at the surface of the site is considerably reduced.

\section{Dynamic Amplification Factors}

Nuclear power plants are typically designed with the spectral shape defined in Regulatory Guide 1.60. This envelope spectra is mainly composed of records of many earthquakes with peak $g$ values much less than the peak $g$ value predicted for the Diablo Canyon Site. Because the predicted ground motion at the Diablo Canyon site is sufficiently large to cause nonlinear effects, it might be expected that the spectral dynamic amplification factors would be reduced compared to the lower-level earthquake motion that was used to define Regulatory Guide 1.60 spectra. It is difficult to test this hypothesis because few records exist with high peak $g$ values. To make the problem more complex, the spectral content of the motion is a function of both the epicentral distance of the recording site and the earthquake magnitude.

Figure 9 illustrates the effect that magnitude has on the ground motion spectral shape. Shown is a comparison of the response spectra of the SI6E component of the Pacoima Dam record for both the main shock 


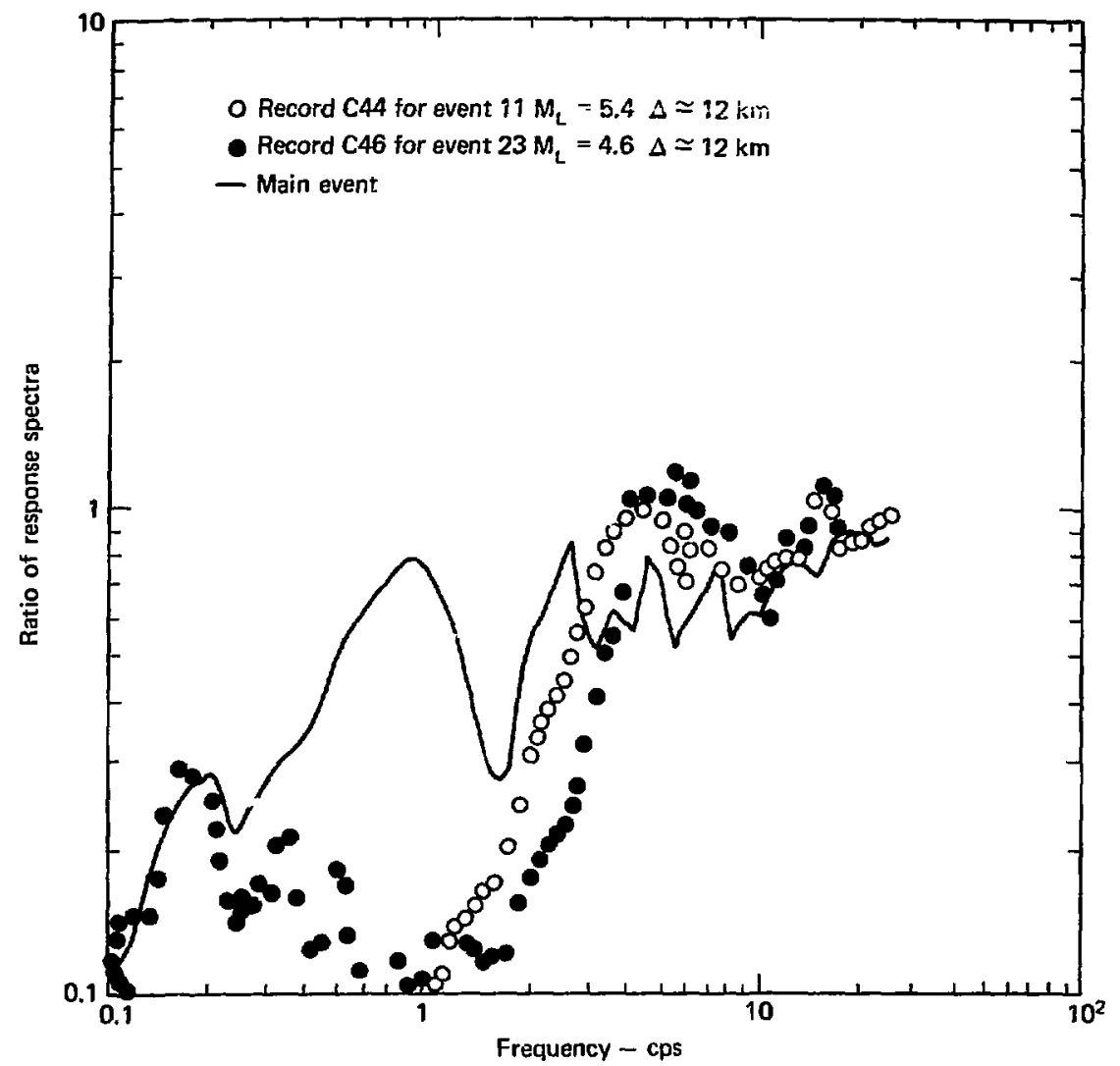

Fig. 5. Effect of magnitude on the ratio of the recorded response spectrum to Regulatory Guide 1.60 .

and several aftershocks. They are all scaled to the same peak $g$ value and divided by Regulatory Guide 1.60 spectra that is also scaled to the same peak $g$ value. It is seen that there is considerable difference in spectral shape in the lower-frequency end, which is partly caused by the difference in the length of faulting involved. Figure 10 shows the rat:o of the larger after shock 044 to the S16E record of the main shock. This illustrates the differences more clearly. A sinilar comparison of a series of small earthq̨uakes about $27 \mathrm{~km}$ from the E1 Centro site ${ }^{6}$ shows a similar trend (Fig. 11). The smaller earthquakes have higher 


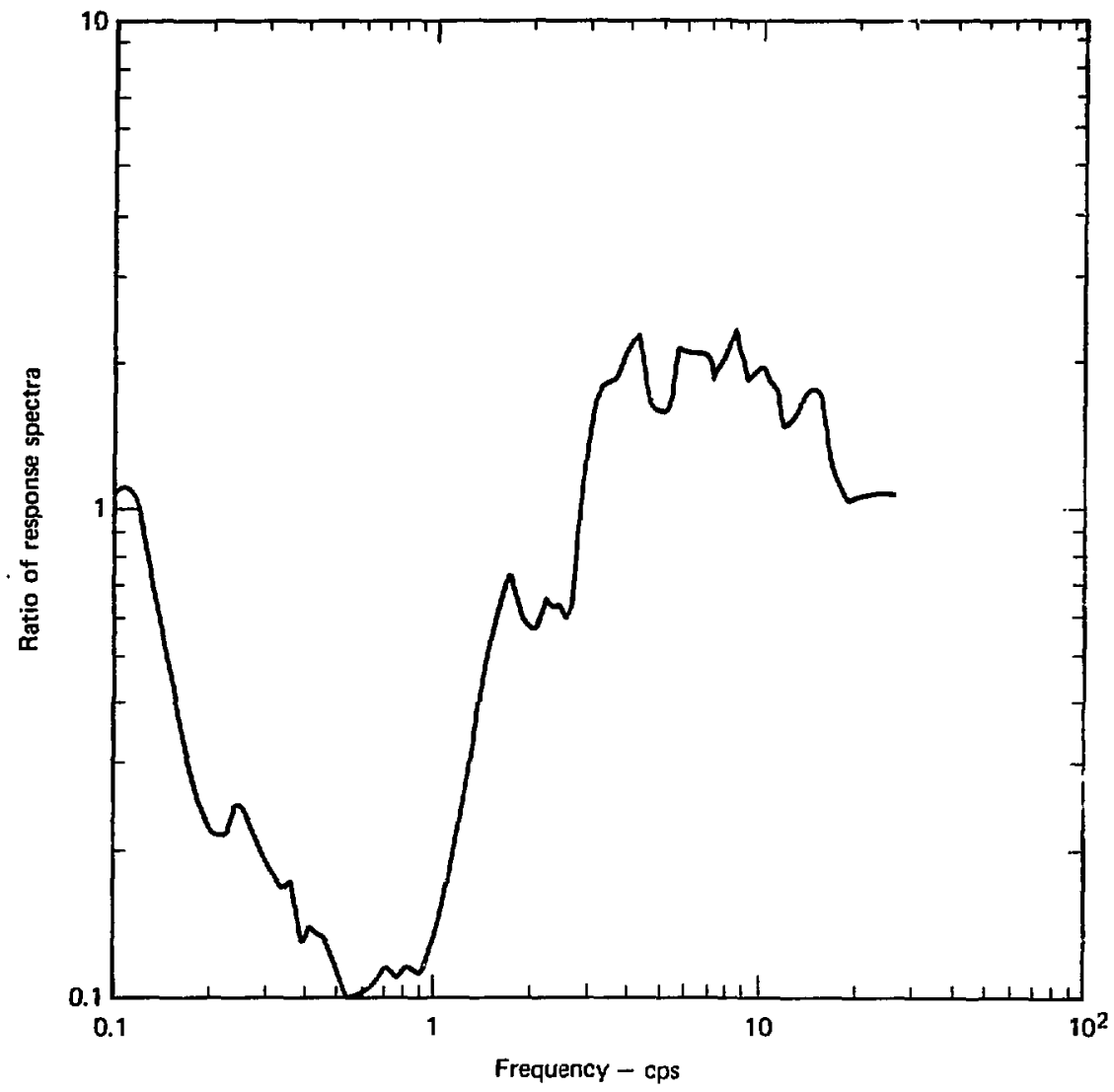

FIg. 10. Response spectra ratio of the C44 aftershock (Event 11) to the S16E record of the main shock of the San Fernando Valley earthquake.

amplification factors in the highfrequency range, and lower factors In the lower-frequency range. Two possible conclusions emerge from this comparison. First, one should not average large and small earthquake spectra because of the differences in amplification factors. Second, the higher g-value earthquakes have smaller amplification factors than lower g-value earthquakes. However, on Figs. 9 and 10 the record C44 (max $g=0.1$ ) has larger amplification factors than $\mathrm{C} 46$ (max $g=0.03)$. Because there is a considerable difference between maximum velocity and acceleration at rock and soll sites, it appears that rock and 


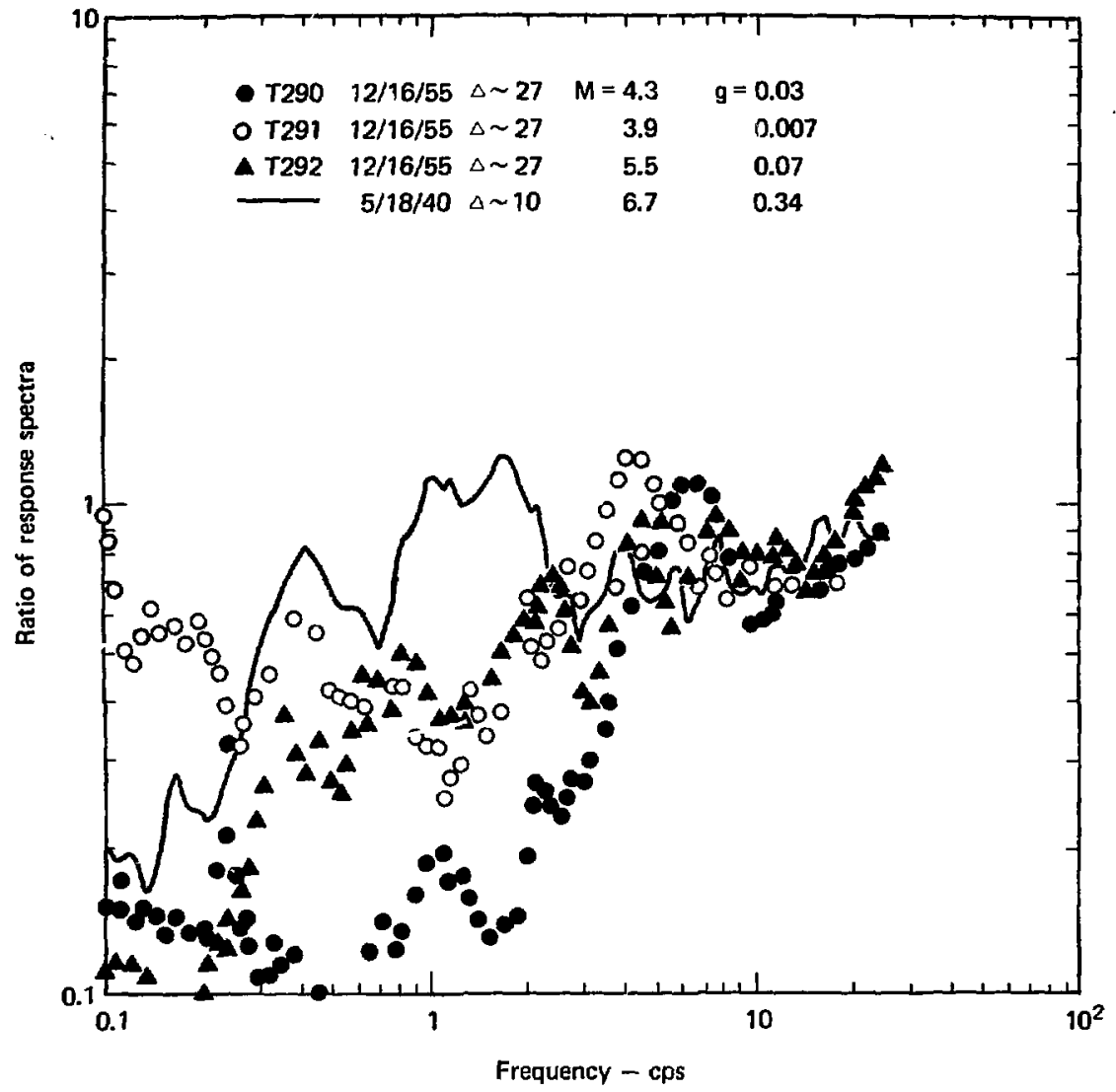

Fig. 11. Comparison of the ratio of the response spectra of several small earthquakes near the El Centro site to Regulatory Guide 1.60 spectra.

soil spectra should not be intermixed.

We must consider how the amplification factors for rock sites are affected by both high and low g values. We must also determine appropriate amplification factors for the construction of rock-site spectra in the near fleld of a large magnitude earth- quake. Because only a few earthquakes have rock-site recordings near their epicenters, very 1ittle data are available to answer these questions. The data that do exist are presented in Table 4.

Figures 12 and 13 show a comparison of the spectra from Helena, Pacoima Dam, Tremblor, and Golden Gate divided 
Table 4. Rock site recordings from several earthquakes.

\begin{tabular}{lllcc}
\hline Earthquake & $\mathrm{M}$ & Rock sites & $\begin{array}{c}\text { Epicentral } \\
\text { distance, km }\end{array}$ & $\begin{array}{c}\text { Peak g } \\
\text { value }\end{array}$ \\
\hline Helena & 6.0 & Helena & 6.5 & 0.14 \\
San Francisco & 5.3 & Golden Gate & 11.0 & 0.1 \\
Parkfield & 5.6 & Tremblor & 11.0 & 0.34 \\
San Fernando & 6.4 & Pacolma Dam & 7.0 & 1.15 \\
\hline
\end{tabular}

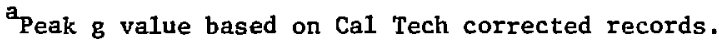

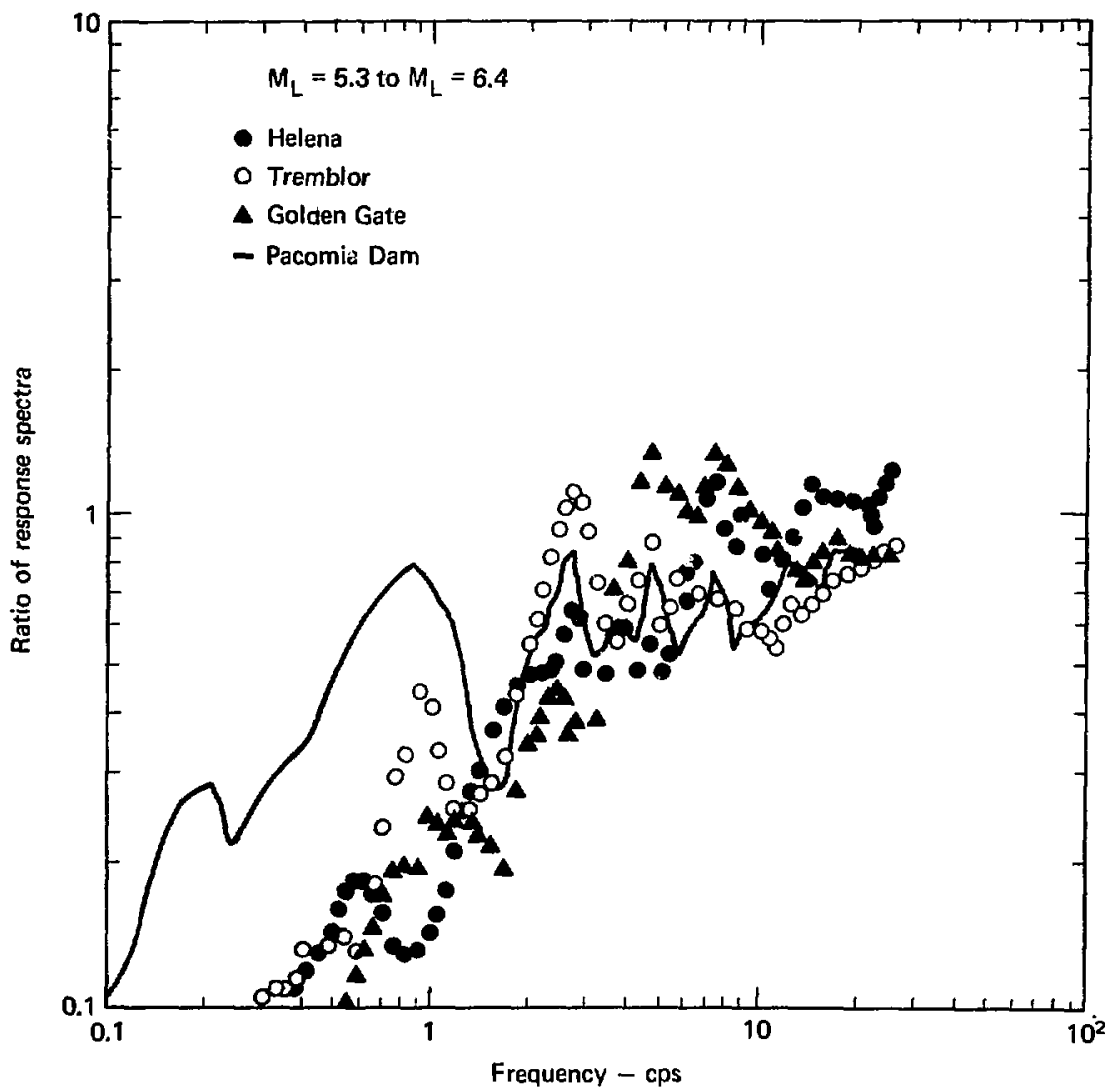

Fig. 12. Comparison of the ratio of Helena, Tremblor, and Golden Gate response spectra to Regulatory Guide 1.60 spectra. 


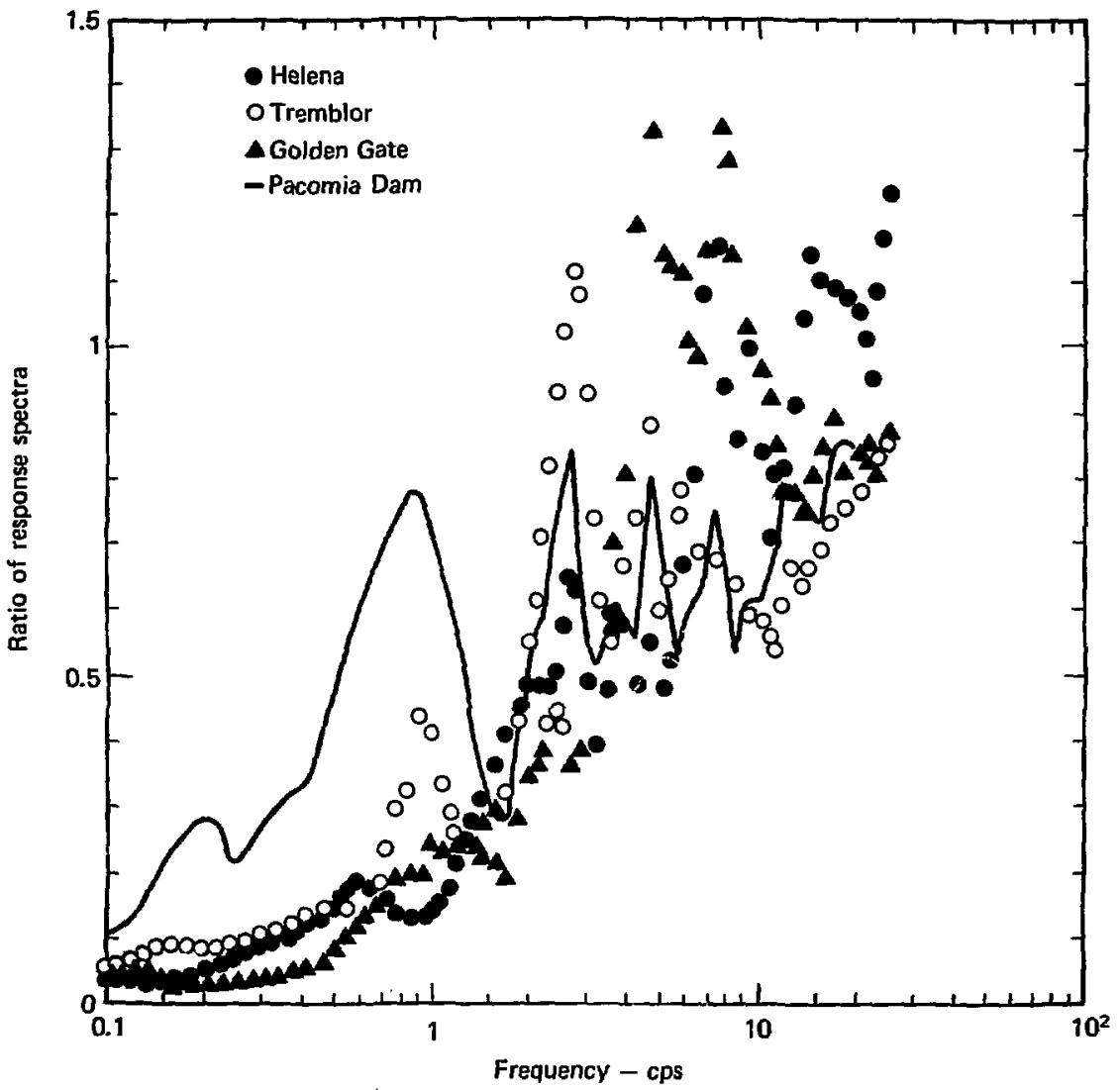

Fig. 13. Linear-log comparison of the ratio of Helena, Tremblor, and Golden Gate response spectra to Regulatory Guide 1.60 spectra.

by Regulatory GuIde 1.60 spectra. It quency range from 0.2 to $2.5 \mathrm{~Hz}$, can be seen that these earthquakes Regulatory Guide 1.60 is controlled have very similar shapes. For freby velocity based on soll sites of quencies greater than $1 \mathrm{~Hz}$ they are similar to Regulatory Guide 1.60, $48 \mathrm{In.} / \mathrm{sec} / \mathrm{g}$, which $1 \mathrm{~s}$ much higher than observed for rock sites. On the however, it is evident that at longer pe Iods, Regulatory Guide 1.60 is average, rock sites have a V/a ratio 1.6 to 1.7 times smaller than soil sites and, therefore, a value of 28 


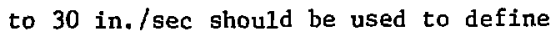
the response spectra in this frequency range. For frequencies greater than $2.5 \mathrm{~Hz}$ we must examine amplification factors based on acceletation, and we must also determine the appropriate amplification factors in this range for an earthquake with a large peak $g$ value. Both the Tremblor and Pacoima Dam spectra have lesser amplificatIons than the Helena and Regulatory Gulde 1.60 spectra, although these two spectra have large peak $g$ values.

Comparisons were made between the Pacoima Dam spectra and several rock sites (1ist in Table 5) for the San Fernando earthquake to determine whether the apparently low values of spectral amplification for the Pacoima Dam record are caused by nonlinear effects or whether they are simply a function of the source.

Figures 14, 15, and 16 give these comparisons. Record $J 141$ is con- siderably different from J142. Although station J141 is typically listed as a rock site, it is, in fact, located within the San indreas fault zone. This explains why the spectra appears spurious. It can be seen from these figures that the amplifications of the P.ıcoima Dam record are, on the average, smaller than for the other sites. This strongly suggests that one would expect lower amplifications for high $g$ value records, i.e., where nonlinear effects are important. The study of site amplification previously discussed indicated that an input of $3 / 4$ to $1 \mathrm{~g}$ causes the rock to move in a nonlinear fashion and indicates that the shear modulus might change from 10 to $12 \%$.

The E1 Centro record ( $0.34 \mathrm{~g})$ shows tha: for frequencies greater than $2.5 \mathrm{~Hz}$, the amplification factors are depressed (Fig. 11).

Table 5. Couparison of epicentral distance and peak $g$ level for several earthquakes.

\begin{tabular}{lccc}
\hline \multicolumn{1}{c}{ Site } & $\begin{array}{c}\text { Epicentral } \\
\text { distance, km }\end{array}$ & $\begin{array}{c}\text { Peak } \\
\text { g level }\end{array}$ & $\begin{array}{r}\text { Record } \\
\text { number }\end{array}$ \\
\hline Seis. Lab. C.I.T. & 38 & 0.19 & G106 \\
Griffith Park Obs. & 33 & 0.18 & 0198 \\
Santa Anita Res. & 48 & 0.17 & P221 \\
Sta. 1 Lake Hughes & 31 & 0.15 & $\mathrm{~J} 141$ \\
Sta. 2 Lake Hughes & 28 & 0.18 & $\mathrm{~J} 1.42$ \\
\hline
\end{tabular}




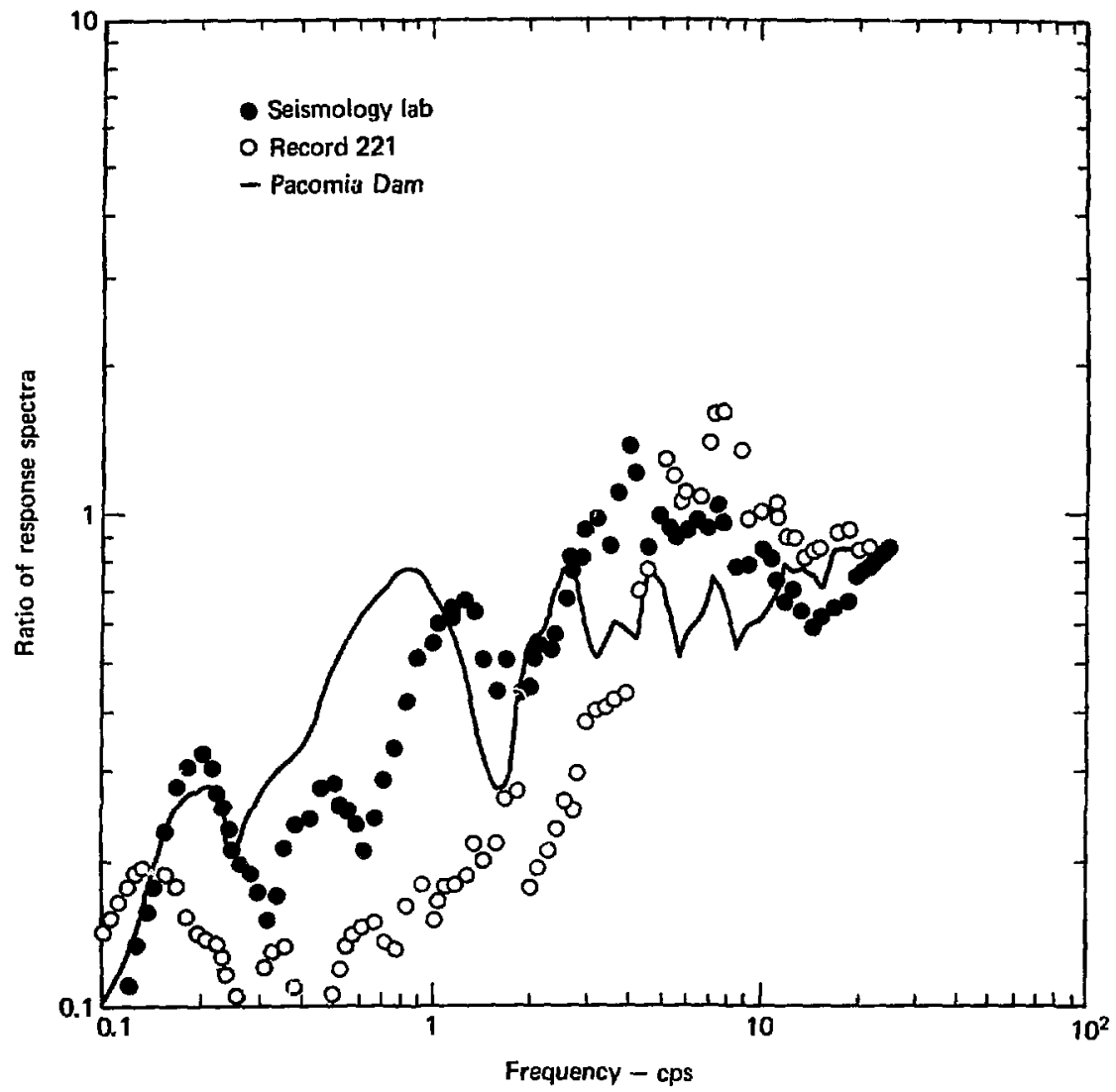

Fig. 14. Comparison of rock-stte amplification factors at lower g levelsSan Fernando earthquake, Pacoima Dam Record (normalized by Regulatory Guide 1.60 spectra). 


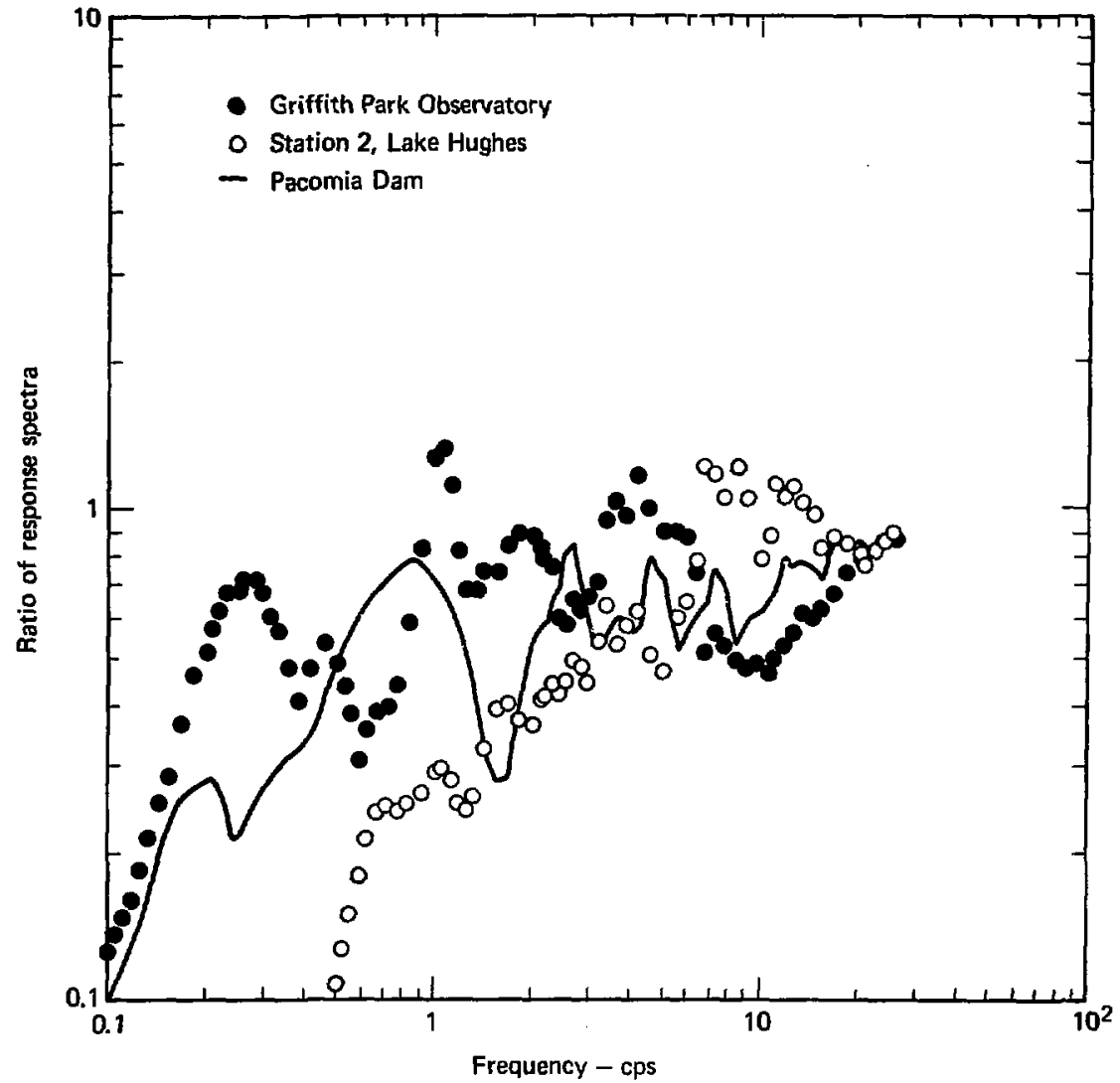

FIg. 15. Comparison of rock-site ampliftcation factors at lower g levelsPacolma Dam, Griffith Park Observatory, and Station 2, Lake Hughes (normalized by Regulatory Gulde 1.60 spectra). 


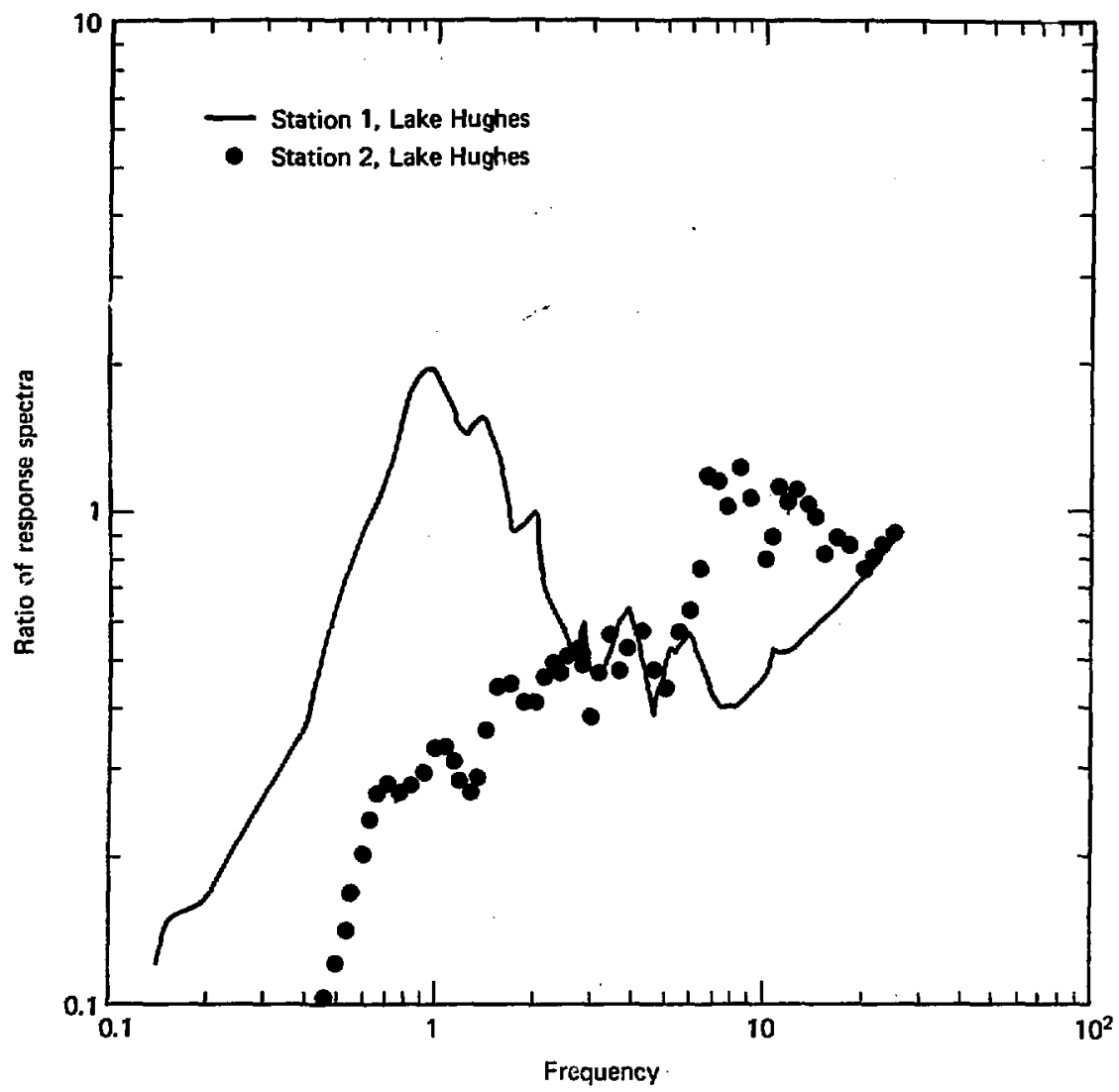

Fig. 16. Comparison of rock-site amplification factors at lower $g$ levelsStations 1 and 2, Lake Hughes (normalized by Regulatory Guide 1.60 spectra).

\section{Effect of Magnitude}

The SSE for the Diablo Canyon Site is set at $M_{L}=7.5$. The spectra previously used for compartson were for smaller magnitude earthquakes, and $i t$ is clear from the comparison that there is a magnitude effect. The smaller magnitude earthquakes appear to be somewhat richer in high frequencies (although part of this effect is also a function of the 
level of motion and nonlinear attenuation). It is clear from our comparisons that both the lower frequency in the spectra and the peak spectral level are a strong function of earthquake magnitude. However, studies show that earthquake magnitude is not the best index of earthquake size. ${ }^{7}$ The Fourier amplitude spectra of the acceleration and the relative velocity spectra can be characterized by three main engineering parameters in the near field. These are the peak acceleration, the peak velocity at the site, and the causative fault rupture length.

To relate the above parameters, an appropriate earthquake source model must be used. There are several different models available for use in the far field, such as Aki, and Brune. ${ }^{8,9}$ However, only Brune's 10 model has been used to any extent in the near field. It gives the Fourier Amplitude Spectrum of the ground displacement as

$\Omega_{\mathrm{NF}}(\omega)=\frac{\sigma \beta}{\mu} \frac{1}{\omega\left(\omega^{2}+\mathrm{f}_{c}^{2}\right)^{1 / 2}}$

where $\sigma=$ stress drop, $B=$ shear wave velocity, $\mu=$ Lamé constant, $\omega$

= circular frequency, $f_{e}=$ corner frequency $=r_{i} B / r, r=$ appropriate fault dimension, and $\eta=$ appropriate constant. (See Trifunac ${ }^{11}$ for a discussion of appropriate values of $r$ and $\eta$.)
For our purposes, we prefer to work with the Fourier Amplitude Spectra. These are simply related by $A(\omega)=\omega^{2} \Omega \quad(\omega)$. Thus Eq. 6 becoties displ

$\hat{N F}(\omega)=\frac{\sigma \beta}{\mu} \frac{\omega}{\left(\omega^{2}+\mathrm{f}_{\mathrm{c}}^{2}\right)^{1 / 2}}$.

Although we are primarily interested in the relative-velocity spectra, we will also use the Fourler Amplitude Spectra because the source models are defined relative to the Fourier spectra. Hudson ${ }^{12}$ showed that the Fourier Amplitude Spectra of the acceleration is closely related to zero damped relative spectra. He also showed that

$$
s_{\mathrm{d}} \approx \mathrm{s}_{\mathrm{v}} / \mathrm{w}
$$

and

$$
\mathrm{S}_{\mathrm{a}} \approx \omega \mathrm{S}_{\mathrm{v}}
$$

where $\mathrm{S}_{\mathrm{v}}$ is the damped relative velocity spectra, $s_{d}$ is the relative displacement spectra, and $\mathrm{s}_{a}$ is the pseudo absolute acceleration spectra. Thus once $S_{v}$, or the Fourier spectra, is defined, then the other quantities of interest are approximately defined. For our purposes, i.e., gross scaling of the spectra relative to the earthquake source, we can intermix comparisons of vartous types of spectra.

Figure 17 shows a comparison of Brune's ${ }^{10}$ model (Eq. (7)) with the Fourier Amplitude Spectra of the 


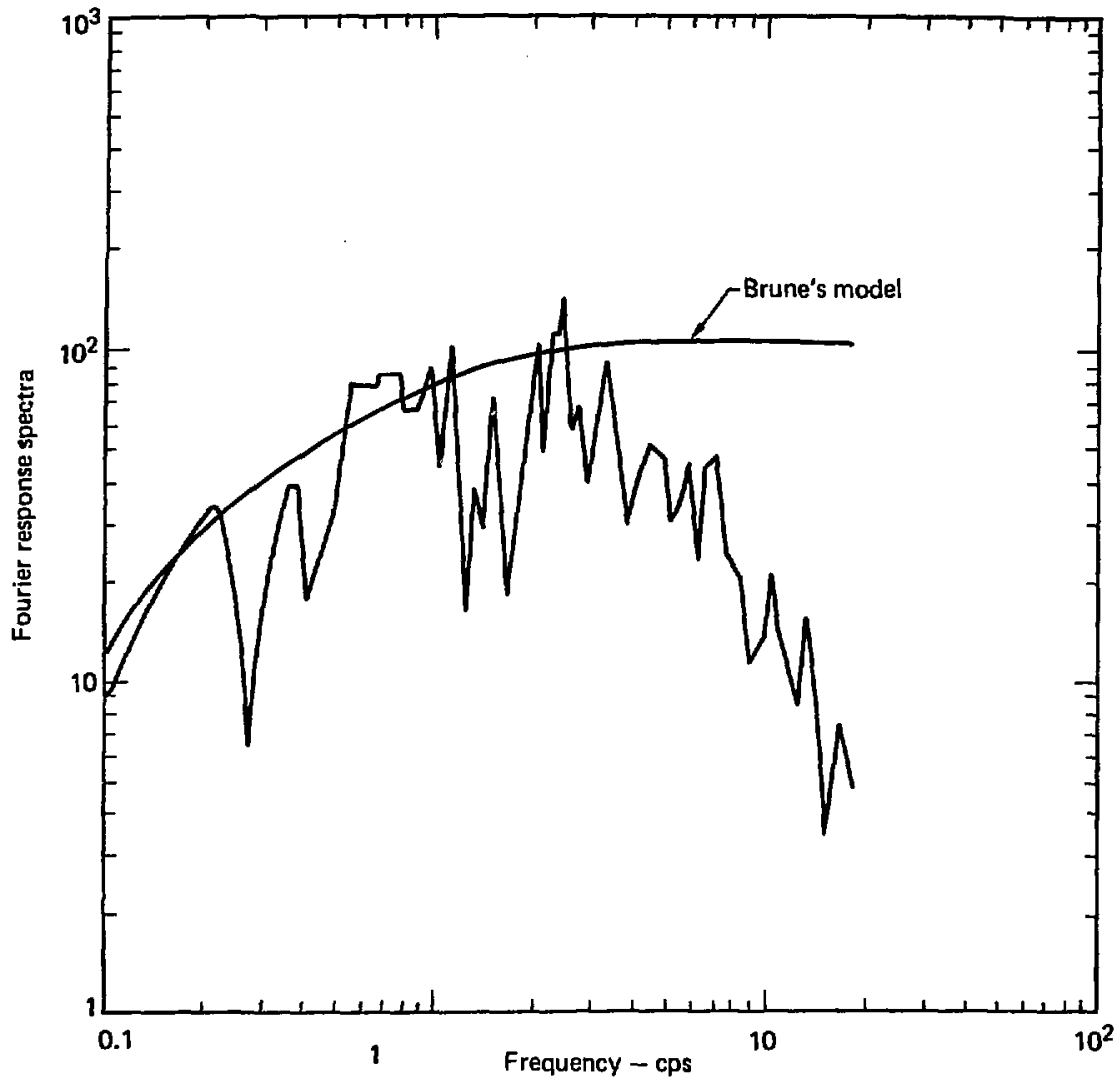

Fig. 17. Comparison of Brune's model with the Fourier amplitude spectra of the Pacoima Dam Record,

Pacoima Dam record. Both components have been averaged. The Fourier Amplitude Spectra is characterized by three regions, a low-frequency region where the spectral level decays as $w$, an intermediate range where it is constant, and a highfrequency region where the spectra amplitude decays as $1 / \omega^{2}$. These dif- ferent regions intersect at corner frequencles. The quantities of interest are the spectral level of the intermediate frequency region and the corner frequencies.

It should be noted that Brune's $s^{10}$ model only has one corner frequency, when it is evident that there is a high-frequency corner frequency (HFCF) 


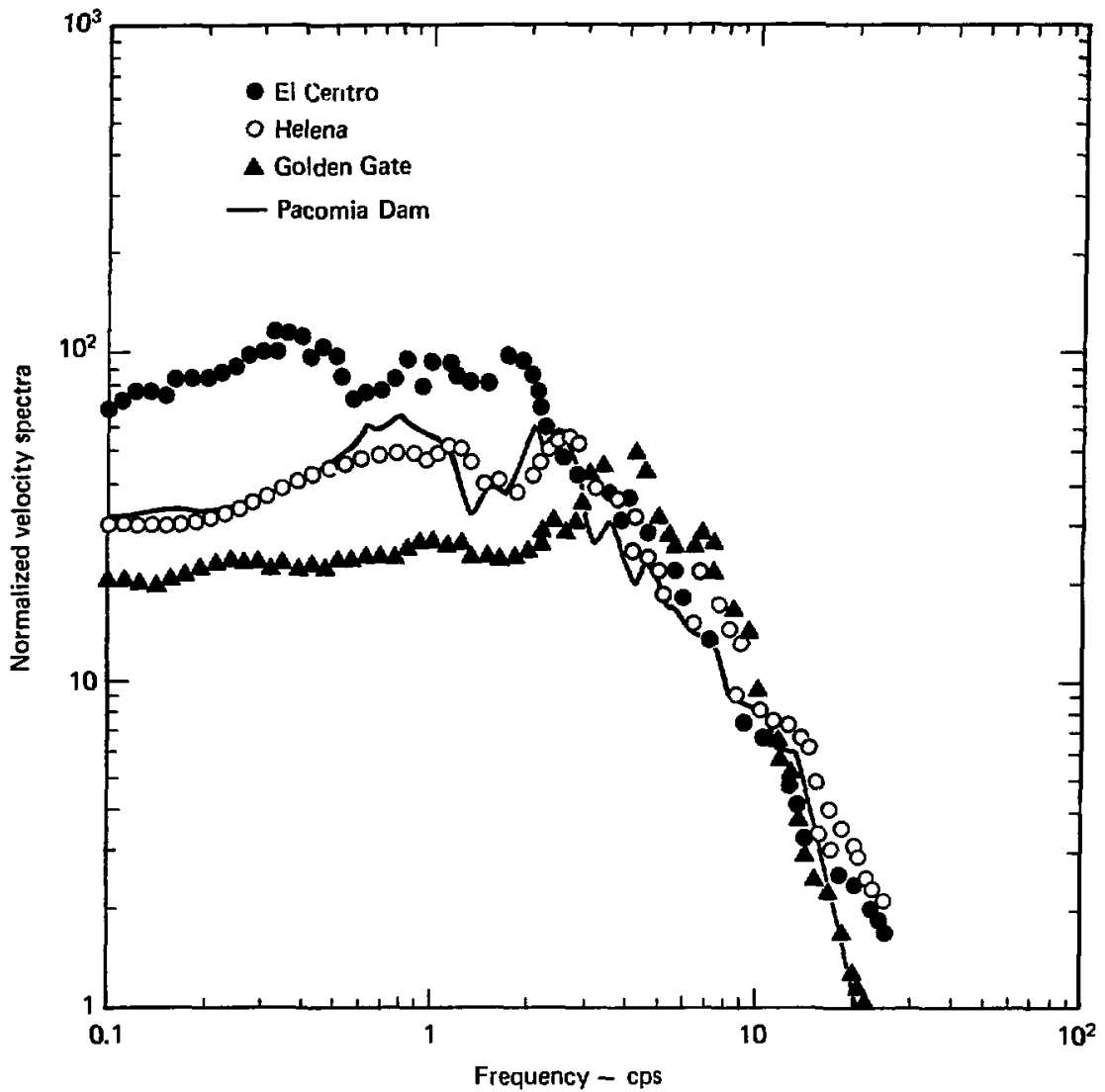

Fig. 18. Comparison of 5\%-damped normalized relative-velocity spectra for several earthquakes.

as we11. Trifunac ${ }^{1,3}$ discusses the lack of agreement between Brune's 10 model and actual Fourier spectra, suggesting that the high-frequency cutoff is a function of nonlinear attenuation. Thus, increasing source size above the magnitudes prevtously compared does not have a significant effect on the high-frequency part of the spectra. This is Illustrated on Fig. 18 where $5 \%$-damped normalized relative-velocity spectra are compared for Pacoima Dam $\left(M_{L}=6.4\right)$, Helena $\left(\mathrm{M}_{\mathrm{L}}=6\right)$, Golden Gate $\left(M_{L}=5.3\right)$, and $E 1$ Centro $\left(M_{L}=6.7\right)$. The normalization is based on acceleration, and high-frequency falloff is simflar for all records. The 
effect of the earthquakes' source sizes is evident by comparing the Golden Gate record with both the

San Fernando and the Helena records. The similarity between the Helena and the Pacoima Dam records is also evident. The differences between

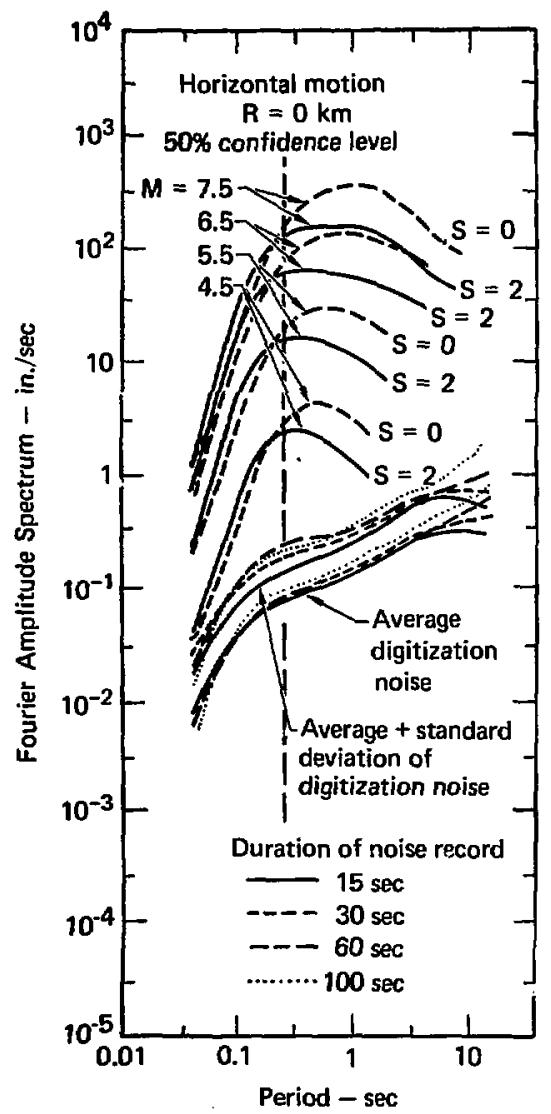

F1g. 19. Horizontal Fourier Amplitude Spectra of strong-motion acceleration for $R=0, p=0.50$, $s=0$, and 3 , and for magnitudes equal to $4.5,5.5,6.5$, and 7.5 . the E1 Centro and the Pacoima Dam records are also a function of the source parameters.

Figures 19 and 20 illustrate that the HFCF is independent of both magnitude and epicentral distance. 13 Although the HFCF remains the same

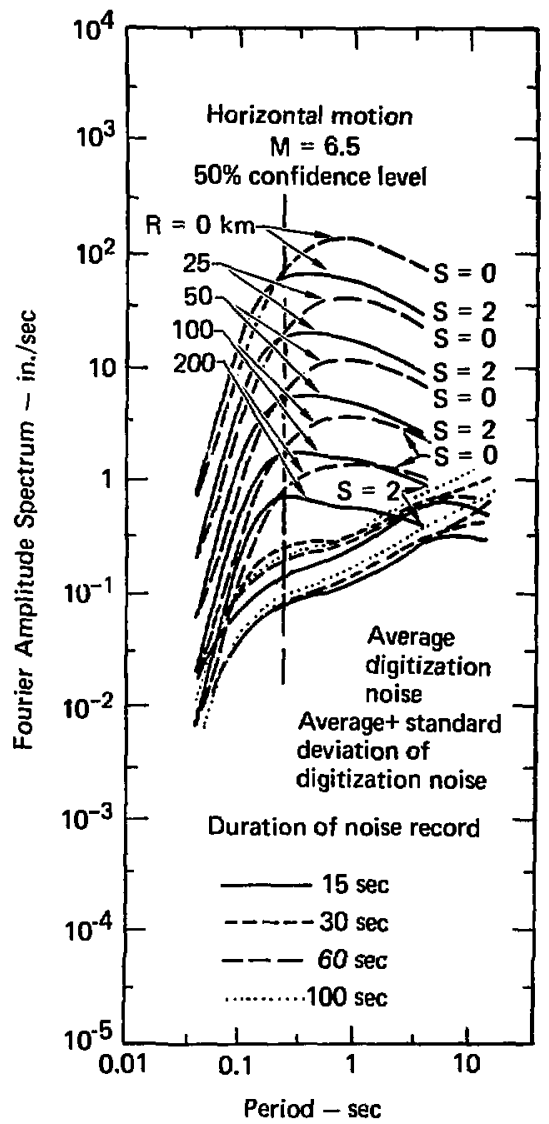

Fig. 20. Horizontal Fourier Amplitude Spectra of strong-motion acceleration for $p=0.5, s=0$ and 2 , $M=6.5$, and epicentral distances equal to $0,23,5 n, 100$, and $200 \mathrm{~km}$. 
for both changes in magnitude and epicentral distance, both the spectral level and the low-frequency corner frequency (LFCF) are definite functions of earthquake magnitude.

We are seeking a way to scale the effects of the peak relative velocity part of the spectra and the LFCF (the frequency at which the lower frequency part of the spectra drops off) as a function of earthquake source size for the Diablo Canyon Site (Figs. 18, 19. and 20).

Equation (7) is the key to scaling, but it is expressf $t$ in terms of stress drop $\sigma$ and this parameter is difficult to estimate. However, in the near field, Trifunac ${ }^{3}$ shows that $\sigma \cong \mathrm{v}_{\max }$ $\mu / B$. Thus, Eq. (7) becomes

$$
A(\omega)=\frac{v_{\max } \omega}{\left(\omega^{2}+f_{c}^{2}\right)^{1 / 2}} .
$$

Table 6 compares the normalized velocity of the earthquakes seen in Fig. 18.

The spectral level for $\mathrm{E} 1$ Centro should be a factor of two greater than Pacoima Dam and Helena spectra in the frequency range

$f_{c}<\omega<f_{H}$ and $f_{H}=3 \mathrm{~Hz}$, where $f_{H}$ is the observed highfrequency falloff. Figure 18 shows that this is true. The Golden Gate spectra is lower but the role of $f_{c}$
Table 6, Comparisons of normalized earthquake velocities.

\begin{tabular}{lcc}
\hline Earthquake & Magnitude & $\begin{array}{c}\text { V/a } \\
\text { (in./sec/g) }\end{array}$ \\
\hline E1 Centro & 6.7 & 54 \\
San Fernando & 6.4 & 27 \\
Helena & 6.0 & 28 \\
Golden Gate & 5.3 & 21 \\
Event 11 & & \\
$\quad$ San Fernando & 5.4 & 18 \\
Kern County & 7.7 & 40 \\
\hline
\end{tabular}

appears to be important because the spectral level of the Golden Gate record is lower in this frequency range than a comparison of velocities given in Table 6 would suggest.

Figure 21 shows a comparison of the 5\%-damped normalized relativevelocity spectra for the Golden Gate record and Event 11 (Trifunac ${ }^{13}$ ), a magnitude 5.4 aftershock of the San Fernanado earthquake. There is a great similarity between the two spectra. Figure 22 compares E1 Centro and Taft records from the large 1952 Kern County earthquake. Both spectra are similar but the Taft spectra is somewhat lower. It is difficult to directly compare the E1 Centro (6.7) and Kern County (7.7) earthquakes because of the extremely complex nature of $\mathbf{E} 1$ Centro earthquake mechanism (Trifunac ${ }^{15}$ ). It is important to note that similar lengths of faulting were involved but the seismic moments were different (Kern 


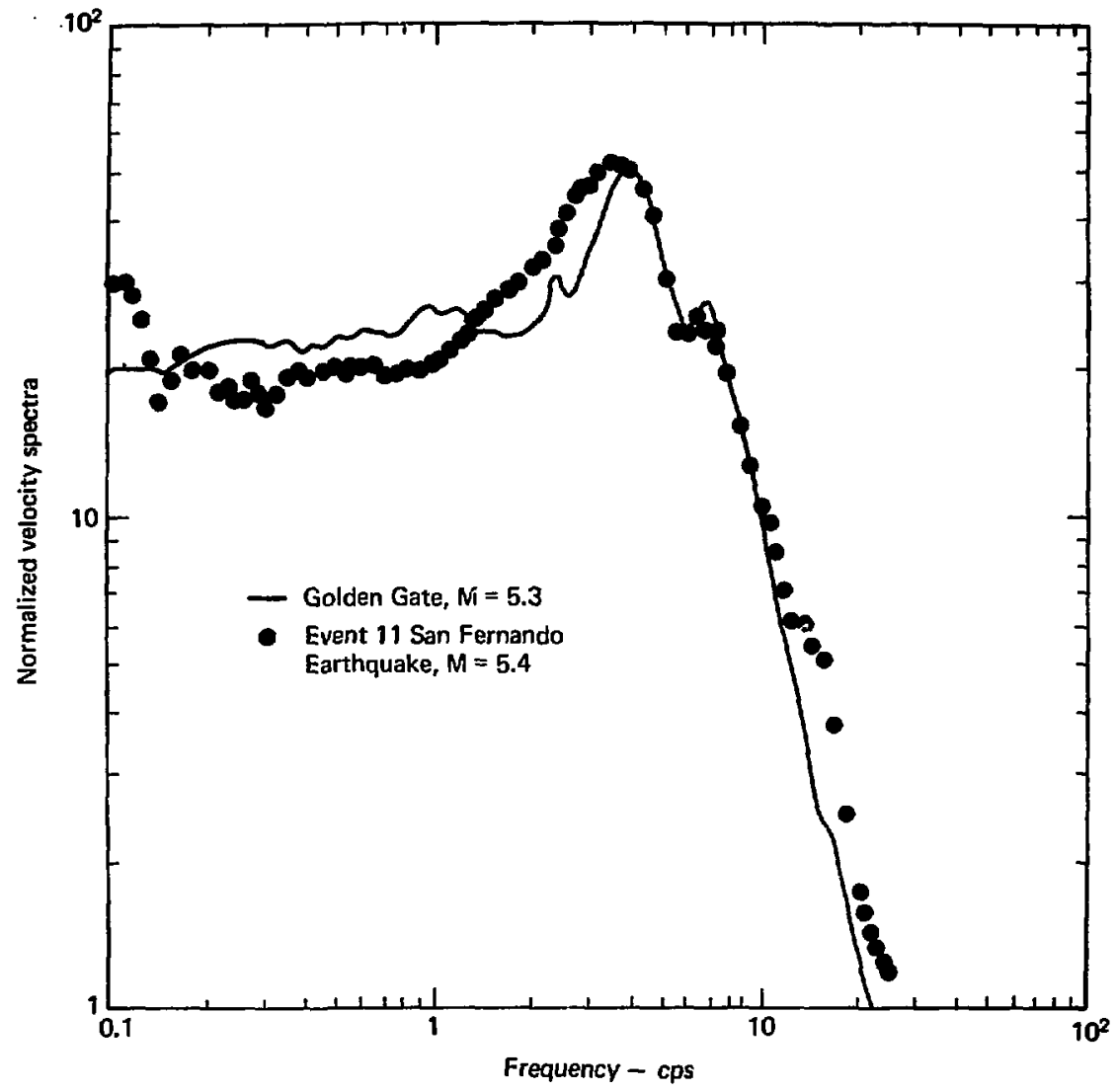

Fig. 21. Comparison of the 5\%-damped normalized relative-velocity spectra for the Golden Gate and Event 11 aftershock.

County was larger). Strong-motion accelerographs are not adequate for recording long-period waves.

Our comparisons do not completely delineate the differences between the earthquakes. The records were simply scaled to the same peak $g$ level and no attempt was made to extrapolate each earthquake bacie to its source region and estimate the peak velocity near the fault. This would be an extremely difficult task. We use the same method typically utilized for the design of nuclear power plants, 1.e., predictions of peak $g$ value and scaling based on the estimated peak 


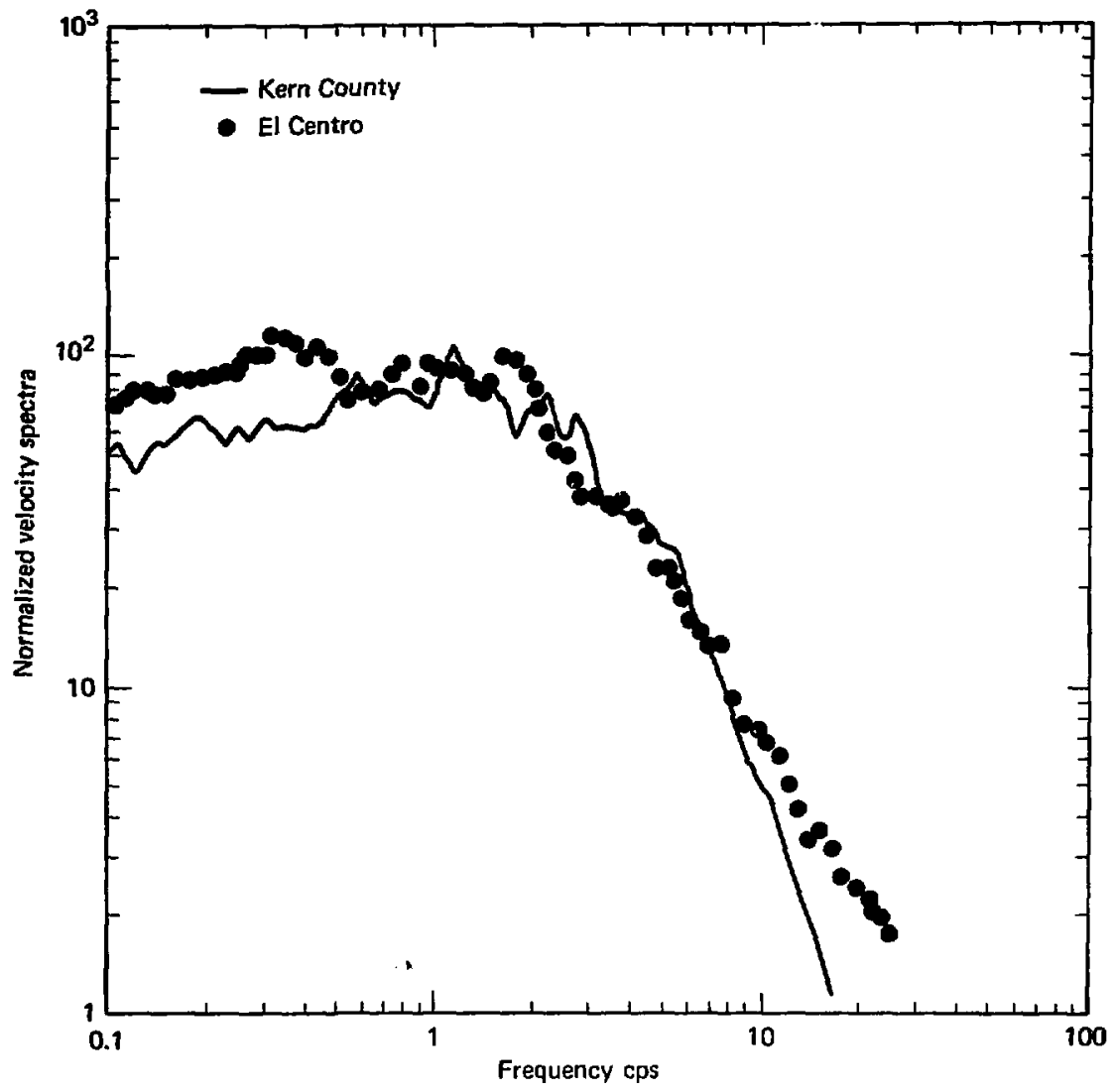

Fig. 22. Comparison of spectra from 1952 Kern County earthquake and E1 Centro records.

g value. This is a reasonable approach because nuclear power stations are stiff, high-frequency structures responding only to the high-frequency portion of the spectra that is primarily characterized by acceleration.

Although the spectra are from strong motion records, they are not all true near-field records. For the frequency band of interest to us, the effect on the predicted spectral shape based on Brung's near- or far-field model is not too important for large source sizes.

We must now consider the role of corner frequency. In Brune's model, 
the LFCF was related to the time required for the peak velocity to decay to zero. In the near field it would be a function of the size of the proximate dislocations that contribute to the strong ground motion. Thus, for very long faults and an earthquake consisting of several successive events, the near-field corner frequency would be influenced only by the nearby events and not the more distant events. In the far field, the spectral shape would be governed by values averaged over the entire fault.

Because Brune's ${ }^{10}$ near-f:.eld mode1 is inexact, it is impossible to obtain a simple expression for the appropriate value for the LFCF in the near field. However, it is possible to obtain an exact expression for the LFCF in the far field. Brune ${ }^{10}$ shows that

$A_{f f}(\omega)=\left(R_{\theta \phi}\right)=\frac{\sigma \beta}{\mu} \frac{r}{R} \frac{\omega^{2}}{\omega^{2}+\alpha^{2}}$,

where $\left(R_{\theta \phi}\right)=$ average of the radiation pattern, $r=$ dimension of equivalent circular disolation surface, $R=$ source distance, and $\alpha=2.34 \mathrm{~B} / \mathbf{r}=$ corner frequency.

Equation (9) is very similar to Eq. (7). The major difference is the decay rate of the spectral amplitude for frequencies less than the corner frequency. Spectral shape changes in the near and far fields as well as differences in spectral shapes for earthquakes of different source sizes can be compared in Eqs. (7) and (9). Because the comparison is relative to spectral shape and the effect of source size on the corner frequency, the absolute spectral level is not important, and Eqs. (7) and (9) be zome

$$
\overline{\mathrm{A}}_{\mathrm{NF}}=\frac{\mathrm{K}_{\mathrm{HF}}}{\left(w^{2}+\mathrm{f}_{\mathrm{c}}^{2}\right)^{1 / 2}},
$$

and

$$
A_{F F}=\frac{K_{F F} \omega^{2}}{\omega^{2}+\alpha^{2}},
$$

where

$$
\alpha_{:}=2.34 \frac{\beta}{r},
$$

and

$$
\mathrm{f}_{\mathrm{c}}=n \frac{\beta}{\mathrm{r}} \text {. }
$$

Figure 23 illustrates the difference in the near- (E.q. (10)) and far-field (Eq. (11)) approximations of the source model. They are then compared with the SI6E component of after shock 11 (Trifunac ${ }^{14}$ ) of the 1971 San Fernando earthquake recorded at the Pacoima Dam. This figure shows that the far-field form (Eq. (11)) matches the data better than the near-field approximation, as expected for a value of $R / r=25$, which is a far-field observation. 


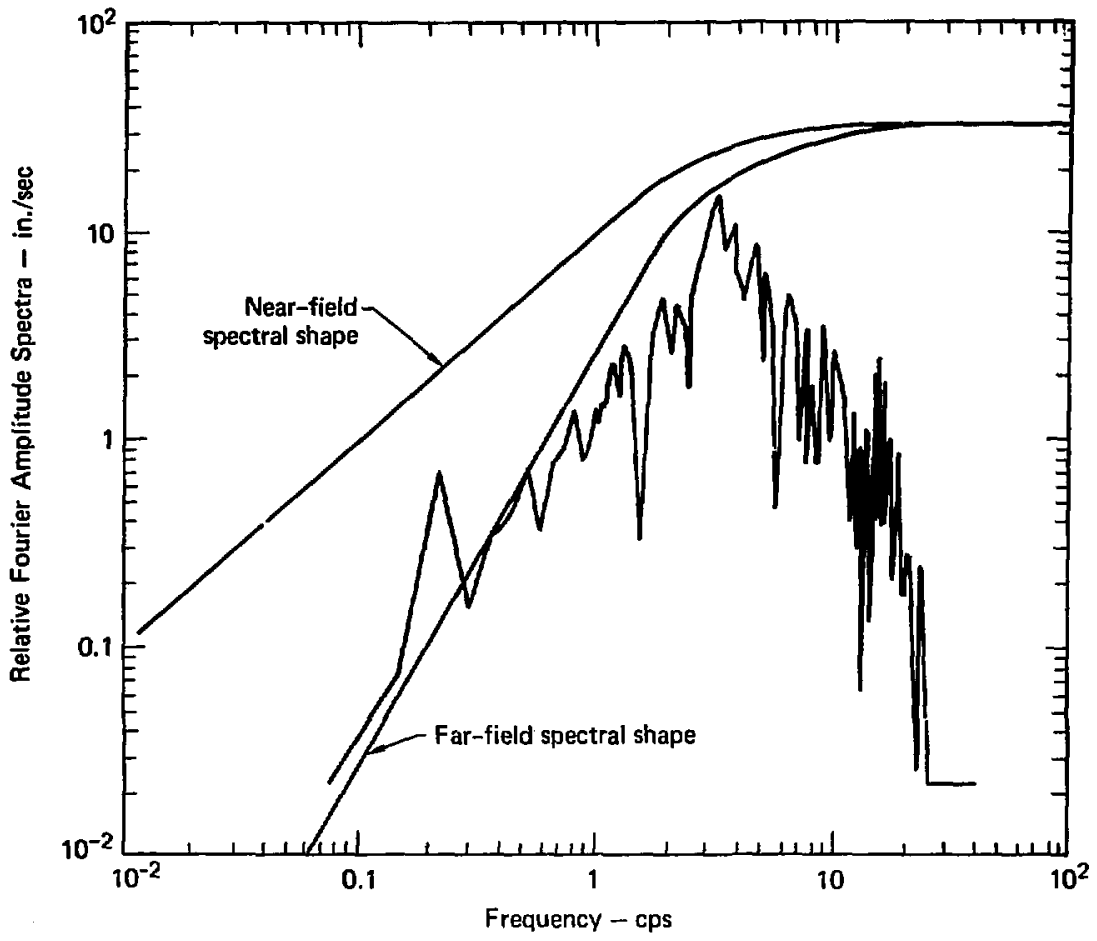

F1g. 23. Difference In near- and far-field approximations of Brune's model.

For small source sizes, the difference in near-and far-field approximations illustrated in Fig. 23 is important in the frequency range of engineering interests. However, for a larger source size, $r>10 \mathrm{~km} \alpha$ becomes less than $0.1 \mathrm{~Hz}$. This frequency is too low to be of any importance for nuclear power plants. For Fig. 23, Trifunac ${ }^{14}$ obtained the value of $\alpha$ using $I \simeq 0.45 \mathrm{~km}$ (estimated for Event 11), where $\alpha=2.34 \frac{B}{\mathrm{r}}=\frac{2.34(3.5)}{0.45} \simeq 20 \mathrm{rad} / \mathrm{sec}$.

Trifunac ${ }^{14}$ also estimated that

$\mathrm{R}=12 \mathrm{~km}$, and for an illustration we used $\mathrm{f}_{\mathrm{c}}=\alpha$.

The effect of increased source size (with cunstant stress drop) is illustrated on Fig. 24. Also shown is the S16E component of the main shock of the 1971 San Fernando earthquake, and the near-field fit using 


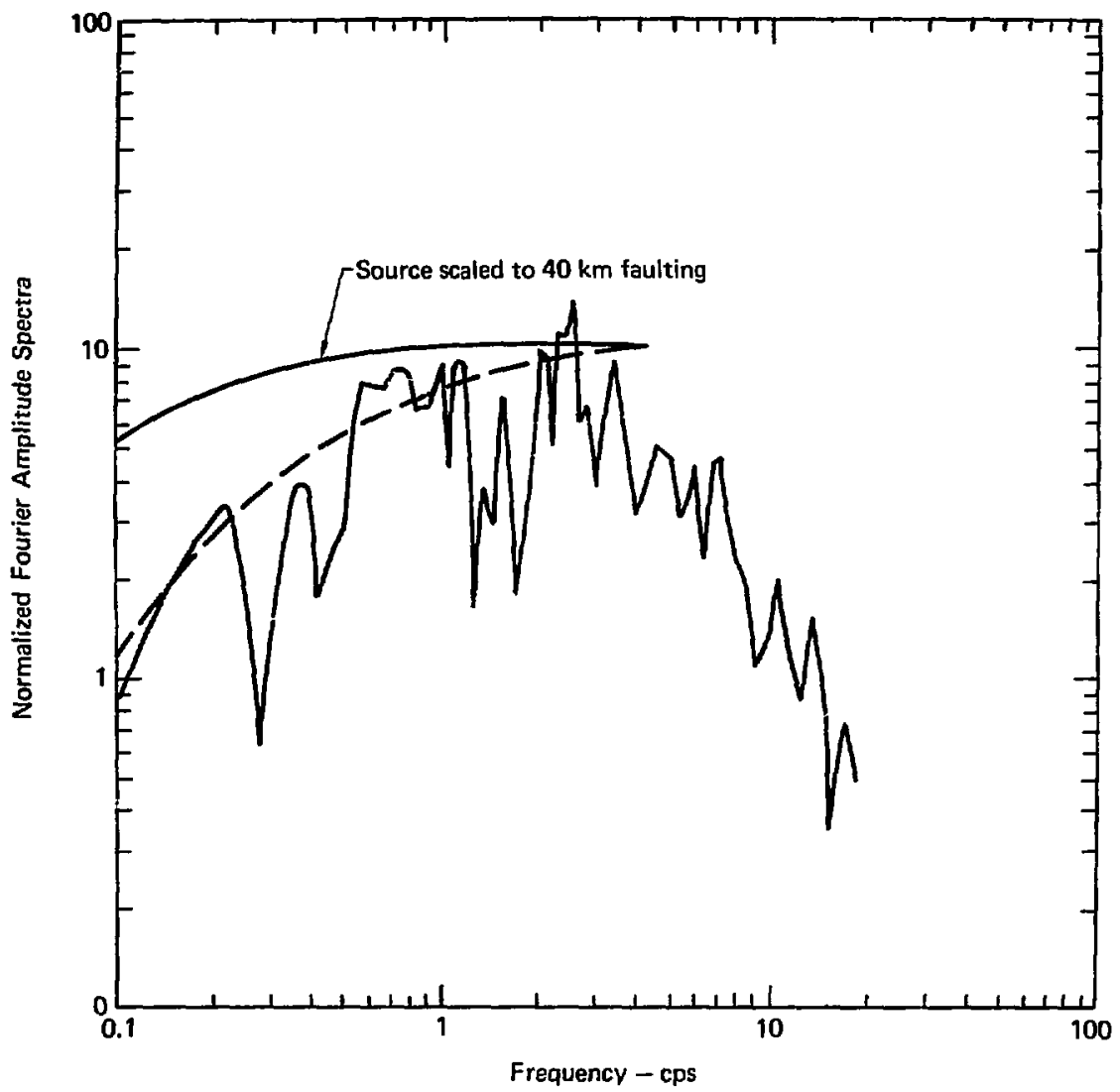

Fig. 24. Effect of increase source size with constant stress drop for Pacolma Dam record (Fourier Amplitude Spectra).

Brune's ${ }^{10}$ model (Fig. 17) for 8- and 40-km source stzes. If we use the Thatcher and Hanks ${ }^{16}$ relation,

$M_{L}=3 / 2 \log (L)+\log \Delta \sigma+3.5$,

then a change in source size of a factor of 4.5 corresponds to about one unit on the $M_{L}$ scale. This increase in magnitude (for the same stress drop) would have little influence on the design of a nuclear power plant because it is a stiff structure (Fig. 24). However, if we compare Figs. 23 and 24, we see that going from magnitude 5.4 to 6.5 
greatly affects the design of a nuclear power plant.

One problem with using either Eqs. (7) or (8) as a predictive tool is that the LFCF is not well defined, although $1 \mathrm{ts}$ value can be important. For the main shock of the 1971 San Fernando earthquake, Trifunac 14 obtalned a value of $f_{c} \tilde{x} 1 \mathrm{~Hz}$. The expression $\alpha=2.34 \beta / \mathrm{r}$ gives a value of $\alpha \approx 0.13 \mathrm{~Hz}$. This difference does not usually affect the design of nuclear power p.lants. However, for an earthquake with a smaller source size but a higher stress drop, it would be important. Generally one would expect $f_{c}$ to be higher than $\alpha$ because $\alpha$ would be influenced by the entire fault length, whereas $f_{c}$ would be governed by the region of highest stress drop near the site. For smaller magnitude earthquakes, this difference would be small (assuming here that the source size is small, unlike the Parkfield earthquake). For a very large earthquake, the difference between $\alpha$ and $f_{c}$ could be large.

Scaling for increased magnttude is complex. For example, using Eq. (12) from Thatcher and Hanks ${ }^{16}$ we see that a larger $M_{L}$ can result from either a larger dislocation size (dimension of faulting) or an increase in stress drop. An increase in $\Delta \sigma$ would correspond to an increased spectral level with the sane corner frequency.
For a constant stress drop, an increase in the source size would not affect the peak Fourier spectral amplitude, but the corner frequency would diminish. Hence, progressively lower frequencies would tave the maximum spectral amplitude associated with them. Therefore, to predict the appropriate spectrum, it is important to determine if the fault is highly stressed, i.e., whether the stress drop is likely to be greater with increased magnitude, or if the larger magnitude earthquake ts simply a result of progressively larger dislocation.

The above arguments relate the peak velocity to the stress drop, the LFCF to the fault rupture length, and the high-frequency part of the relative-velocity spectra to peak acceleration. Peak acceleration can be related to the stress drop in several ways. Trifunac ${ }^{3}$ used the statlitics of the time history and Fourier Amplitude Spectra. Hanks and Johnson 17 used a qualitative model and the basic equations of motion for an elastic medium. In addition, Figs. 3 and 4 show that peak velocity and acceleration correlate well, thus supporting these results. The scatter on these figures can be attributed to local site conditions and the constructive and destructive interference of several wave arrivals. Also as 
discussed earlier, the HFCF is relatively Independent of magnitude.

It is clear that the key to developing the design spectra for the Diabla Canyon Site is to make approprlate estimates for the stress drop and source size. If the estimated local stress drop and rock strength in the fault zone is average or below average, then the predicted ground motion at the site can be reasonably based on the least square fits of the data as discussed previously. Once the peak site acceleration and velocity are estimated, the design spectra in the near field can be obtained in the following way:

(1) In the high-frequency range, i.e., $3 \mathrm{~Hz}<\mathrm{f}<25 \mathrm{~Hz}$, the spectra should be scaled on peak acceleration. For large $g$ values one can use smaller amplifications than suggested in Regulatory Guide 1.60. Increased source size only affects the high-frequency part of the spectra slightly.

(2) In the frequency range of $f_{c} \leq f \leq 3 \mathrm{~Hz}$, the peak velocity is the Important parameter to be scaled. For rock sites, the peak velocity should either be scaled for the peak $g$ level, or It should be estimated from a separate correlation of peakvelocity attenuation and epicentral distance.
(3) For the larger magnitude earthquakes, the effect of the corner frequency is not too Important for the design of nuclear power plants, particularly for Diablo Canyon. However, scaling spectra to $\mathrm{M}_{\mathrm{L}}=7.5$ from lower magnitude earthquakes, e.g., $M_{L}=6.5$, necessitates raising the spectral amplitude in the range of $\mathrm{f}_{c}\left(\mathrm{M}_{\mathrm{L}}=7.5\right)<\mathrm{f}_{\mathrm{c}}\left(\mathrm{M}_{\mathrm{L}}=6.5\right)$ (FIg. 24). The corner frequency is extremely important for small events with high stress drops. The results show that significant decrease in spectral amplitude will occur in the frequency band of interest. This is illustrated on FIg, 25 for two earthquakes of the same magnitude but with a factor of 10 difference in stress drop. For purposes of illustration we used our fit of Eq. (9) to Event 11 (Fig. 23) and $\mathrm{Eq}$. (12) to obtain the source dimension for the higher stressdrop earthquake.

(4) In general, if the magnitude of the DBE is increased from 6.5 to 7.5 (at the same nearfield distance), It should not significantly influence the design of a nuclear power plant, provided that the increased magnitude is only caused by increased faulting dimension. 


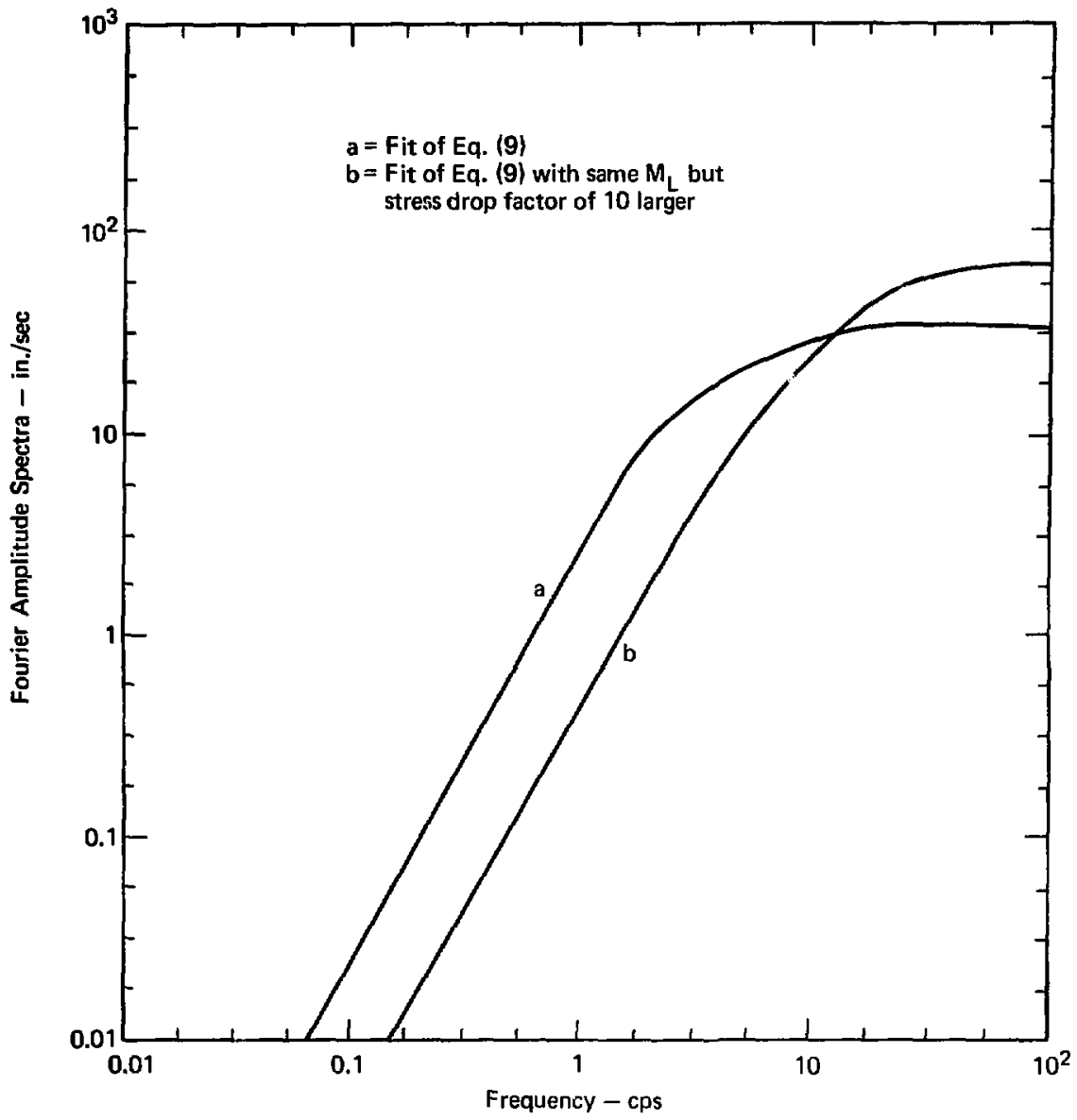

Fig, 25. Effect of increased stress drop for same magniture earthquake on Fourfer Amplitude Spectra.

\section{Soil-Structure Interaction}

We have been dealing with various aspects of the free-field seismic environment at Diablo Canyon. To more completely evaluate the seismic design Input, we must assess possible soil-structure interaction (SSI). 
Conventional SSI methods such as those contained in LUSH, are appropriate because of the proximity of the reactor to the Hosgri Fault. It is conceivable that a shallow earthquake could cause energy that propagates horizontally across the basemat of the structure. The effect of this excitation, called the traveling wave, on the structure would be very different from the effect of a vertically propagating SH wave. However, we feel there is 11ttle possibility that the reactor will experience traveling-wave excitation. It is more likely that the depth of focus will be at least $10 \mathrm{~km}$, in which case energy w111 be refracted vertica11y. For a strike-slip faulting mechanism, the majority of the energy would arrive in the SH mode. This is the basis of the conventional sSI calculative techniques.

The free-field environment from a magnitude 7.5 earthquake at Diablo Canyon would be very severe. The current design of the plant coujd possibly be challenged if the inter- action effects were small and resulted in a basemat environment comparable to the free fleld. On the other hand, significant interaction could modify the basemat environment to acceptable levels. It is the purpose of the SSI analysis to determine if the interaction effects are important enough to warrant a costly detalled study.

We have postulated two different bedrock accelerograms; one is impulsive and the other is longer duration, but they both have a peak acceleration of $0.75 \mathrm{~g}$. We calculated the response of the soll-structure system with the LUSA code by comparing these results with the free-field response from SHAKE.

We conclude that there would be significant interaction of the structure with the soil, in spite of the site stiffness ( 3000 fps shear wave velocity). The basemat spectral accelerations for frequencies between 2 and $3 \mathrm{~Hz}$ would be lfss than the free-field spectra by as much as $50 \%$ for both bedrock excitations.

\section{Lush Calculations}

Because there are few detalls avallable about the properties of the structure and the site, we performed exploratory calculations to reveal. the fundamental character of the
Interaction. Subsequent calculations would be required to model the problem in sufficient detall to permit design decisions. The Diablo Canyon site was modeled as a layer 
of $3000 \mathrm{fps}$ sandstone $250 \mathrm{ft}$ thick. We assume the sandstone density to be $150 \mathrm{pcf}$ and the water table to be at bedrock. For compatibility between LUSH and SHAKE, we also assumed bedrock to be infinitely stiff relative to the sandstone. (This model does not include the effects of the mudstone layer previ- ously discussed. Therefore, the calculated surface $g$ values presented here are higher than those already given. We feel that this simplified analysis is adequate to determine SSI, but these Iimitations should be considered when the results are interpreted.) The SHAKE and LUSH shear modulus and damping factor

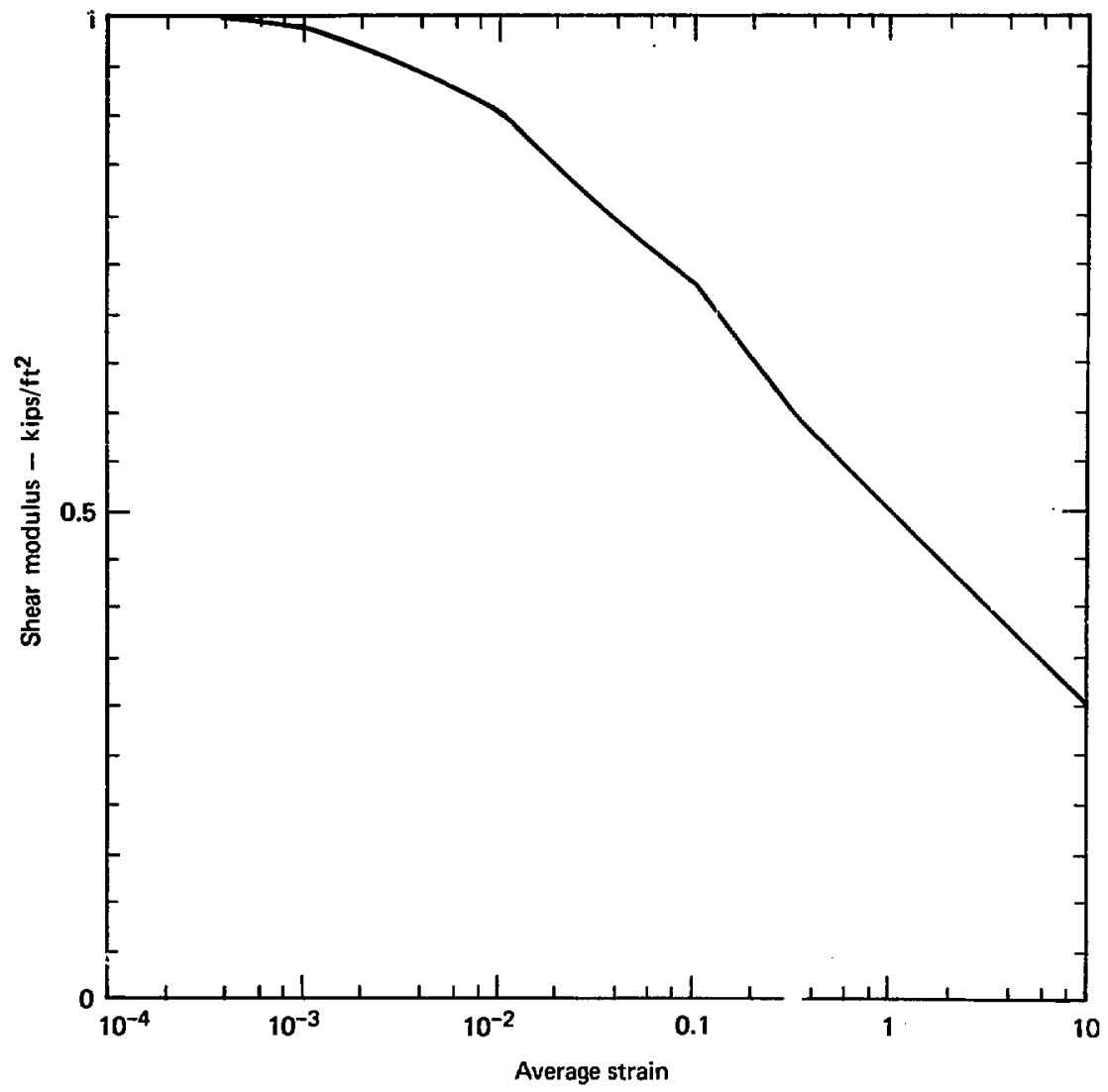

Fig. 26. Decrease in spectral amplitude for two earthquakes wit', same magnitude and different stress drops. 
relationships for sandstone are given in Figs. 26 and 27. In our calculations, we used two bedrock excitations with a peak acceleration of $0.75 \mathrm{~g}$ each. A comparison of the response spectra for the two excitations shows the difference in frequency content (Fig. 28). In Figs. 29 and 30, (keyed in Table 7), we present the free-field responses of the site in the form of overlaid response spectra. In Table 7 we give the variation of peak acceleration with depth. The differences in the site response are emphasized in Fig. 31, where the calculated surface motions are compared. These results show that the fundamental period of the site is 0.4 seconds. The structural model is simple but adequate for the SSI effects, with dimensions and mass comparable to reactor buildings, and a fixed base first mode of
$4.67 \mathrm{~Hz}$. We assume the model to be embedded 40 feet.

We developed a sol1-structure model for the LUSH calculations with several important characteristics. First, the mesh size insures that frequencies up to $20 \mathrm{~Hz}$ are preserved. Second, the lateral extent of the model is determined by trial and error until motions at the edge are free-field, Finally, we reduce the bandwidth of the problem by using the plane of symmetry. The model has 301 nodes, 260 elements, and a bandwidth of 34 . The vertical sides are on horfzontal rollers so the base moves horizontally in accordance with the bedrock time history.

The soil properties for the first LUSH 1teration were taken from the SHAKE analysis. After four iterations the solution had converged based on the criteria that the moduli

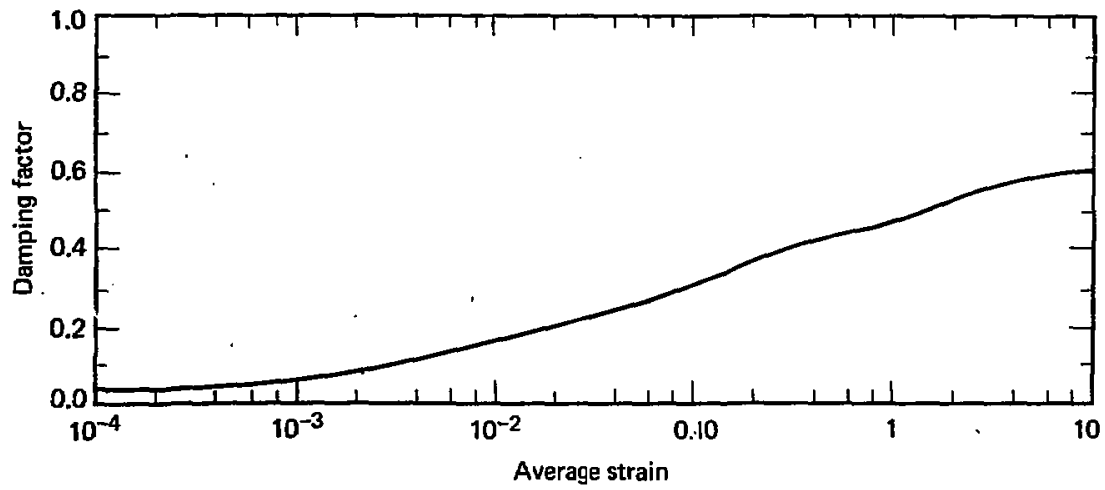

FIg. 27. The SHAKE and LUSH damping factor relationships for sandstone. 


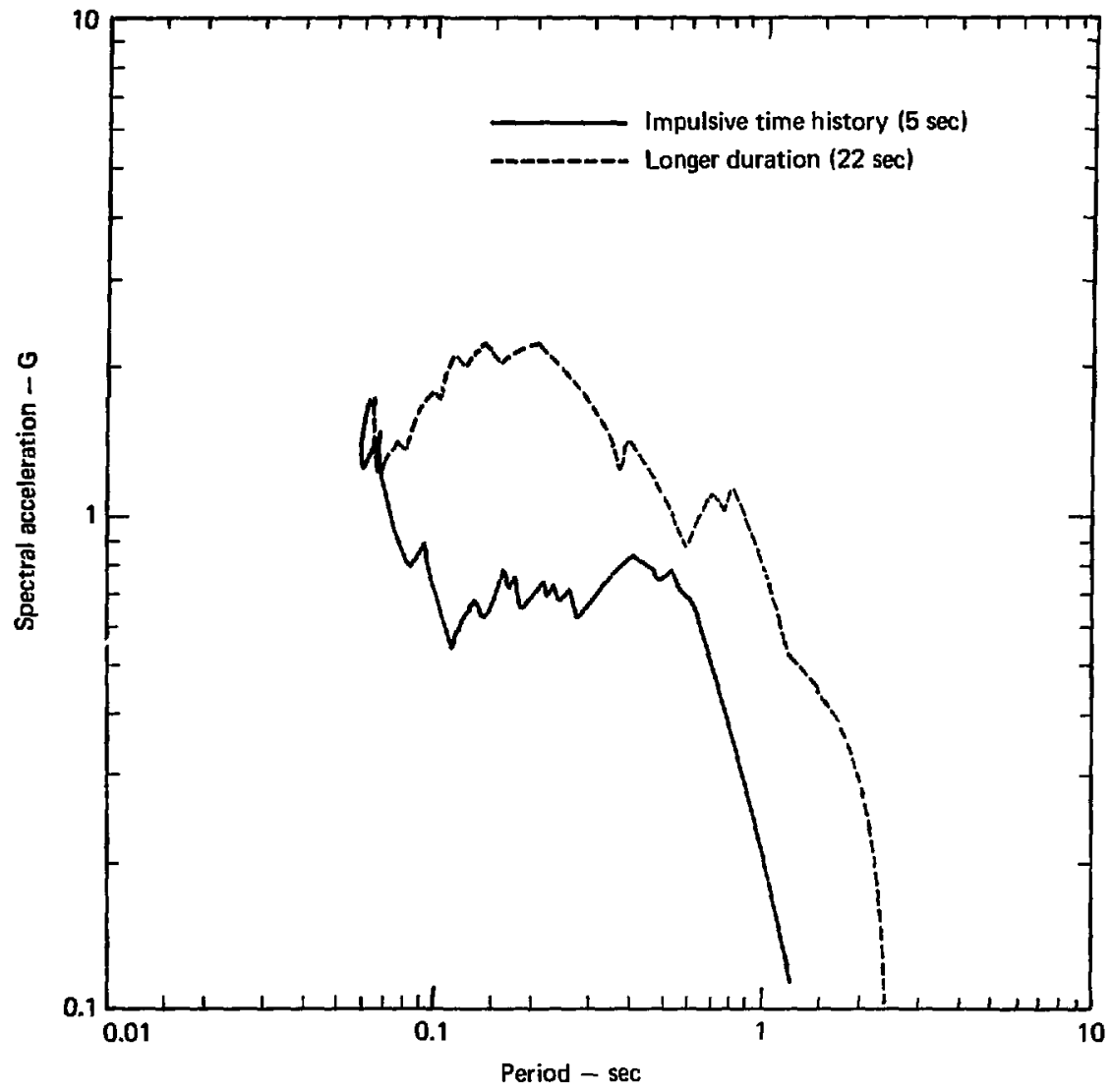

Fig. 28. A comparison of the 5\%-damped response spectra of the SHAKE and LUSH bedrock excitations.

and damping factors changed by less than $5 \%$ between iterations.

The accuracy of a LUSH calculation is determined by comparing the LUSH free-field response with the SHAKE response. A poor comparison would Indicate an inadequate model. In Figs. 32 and 33, we present a com- parison of the LUSH and SHAKE responses. The results agreed well, proving that reflections off the vertical boundaries do not influence the interaction results.

Figures 34 and 35 compare the basemat and free-field response spectra. This comparison indicates 


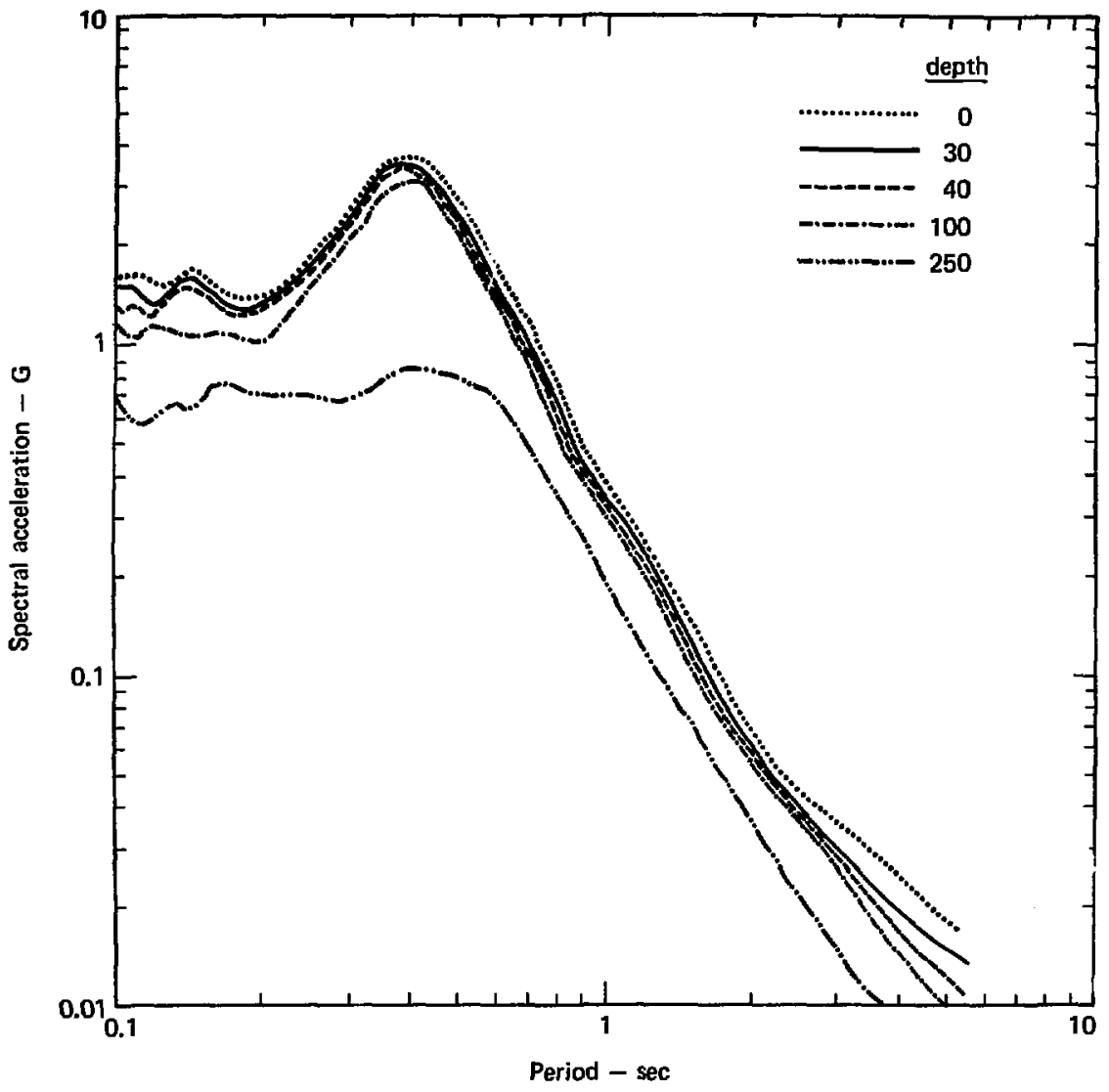

FIg. 29. Change in the 50\%-damped response spectra of the free-field with depth for the short-duration input.

that, although the shape of the basemat spectra is very similar to the free fleld, the basemat spectral accelerations are apprectably less than the free fleld. The difference Is greatest in the frequency range from 2 to $3 \mathrm{~Hz}$, suggesting that the structure act 3 as a damper on the spectral peaks. It is interesting to note that the interaction effects must be caused principally by the mass of the structure because the first structural mode is very close to the first soil mode. 


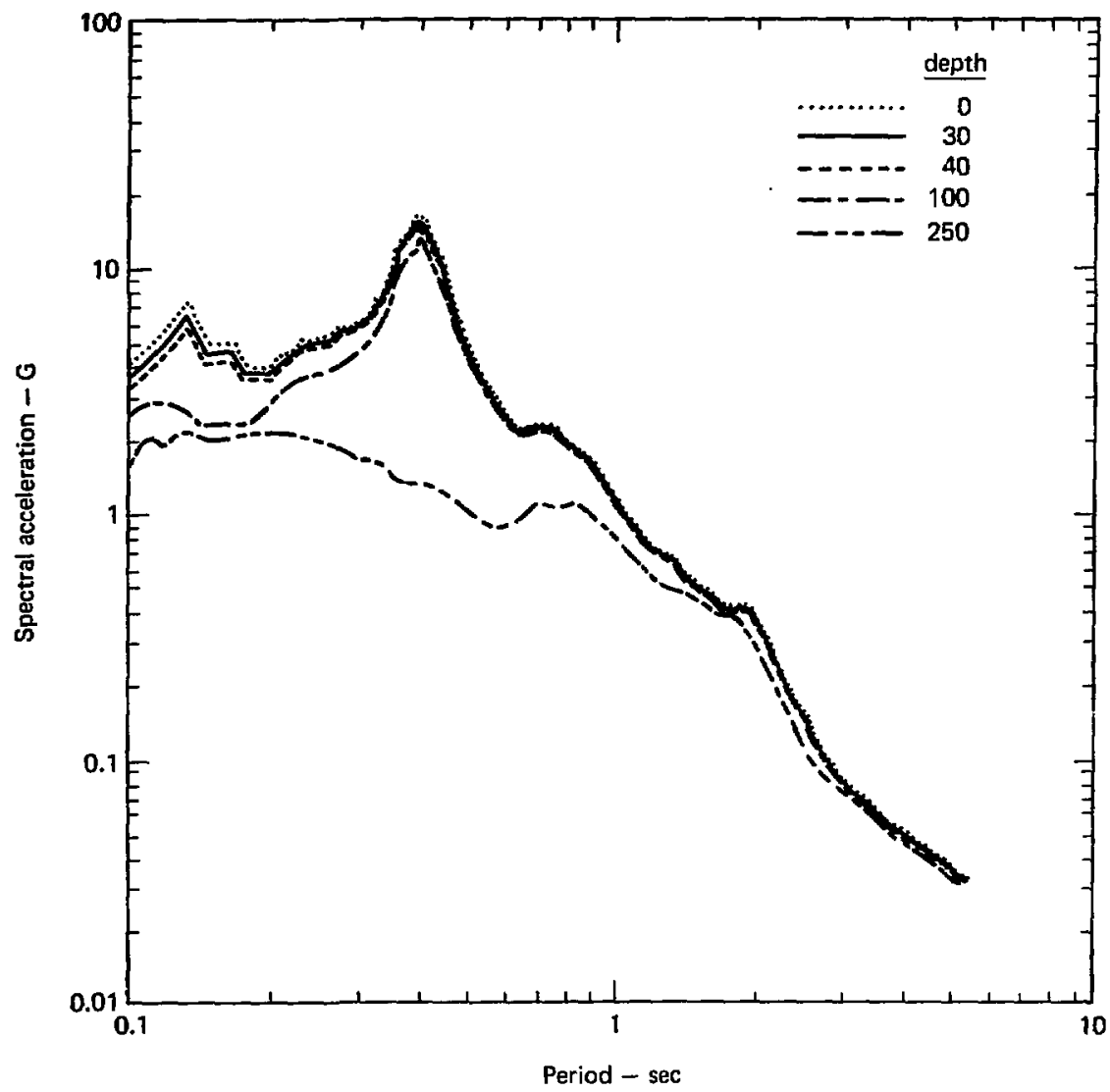

Fig. 30. Change in the 50\%-damped response spectra of the free-field for the long-duration input.

We feel that there could be signiffcant SSI at the Diablo Canyon reactor. However, this theory is speculative because of present uncertainties in site and structure modeling as well as in establishing the bedrock seismic excitation. We recommend that final conclusions be based on a further analysis that would provide parameters for the above variables. 
Table 7. Earthquake response for the Diablo Canyon sites. Acoustlc shear wave veloctty - 3000 fps.

\begin{tabular}{rcc}
\hline Depth, it & $\begin{array}{c}\text { Long-duration excitation, } \\
\text { peak acceleration, }\end{array}$ & $\begin{array}{c}\text { Short-duration excitation, } \\
\text { peak acceleration, g }\end{array}$ \\
\hline 0 & 2.6 & 1.9 \\
30 & 2.45 & 1.3 \\
40 & 2.3 & 1.17 \\
100 & 2.1 & 1.2 \\
250 & 0.75 & 0.75 \\
\hline
\end{tabular}

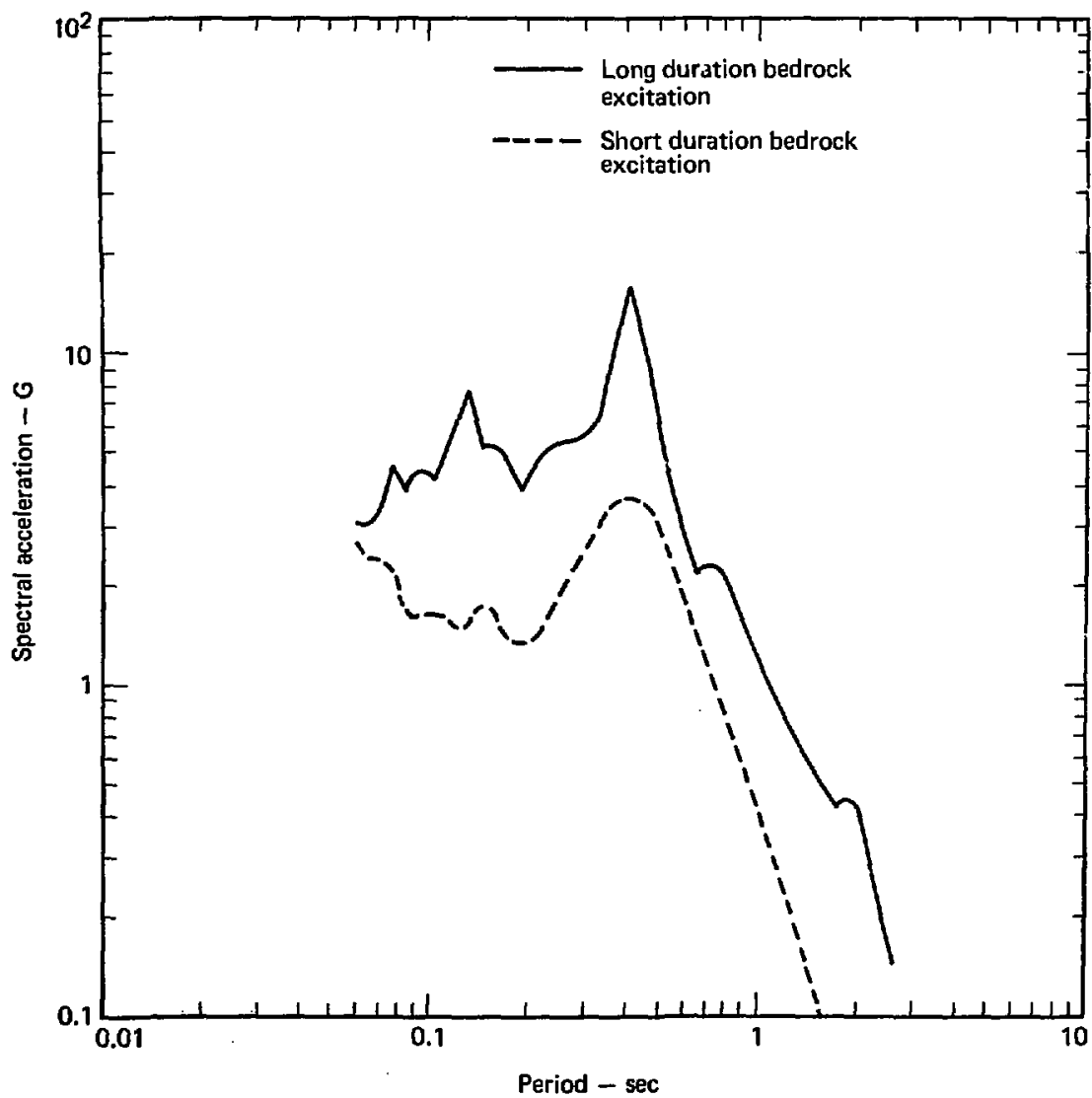

Fig. 31. Comparison of free-field, surface-motion 5\%-damped response spectra from SHARE for both bedrock excttations. 


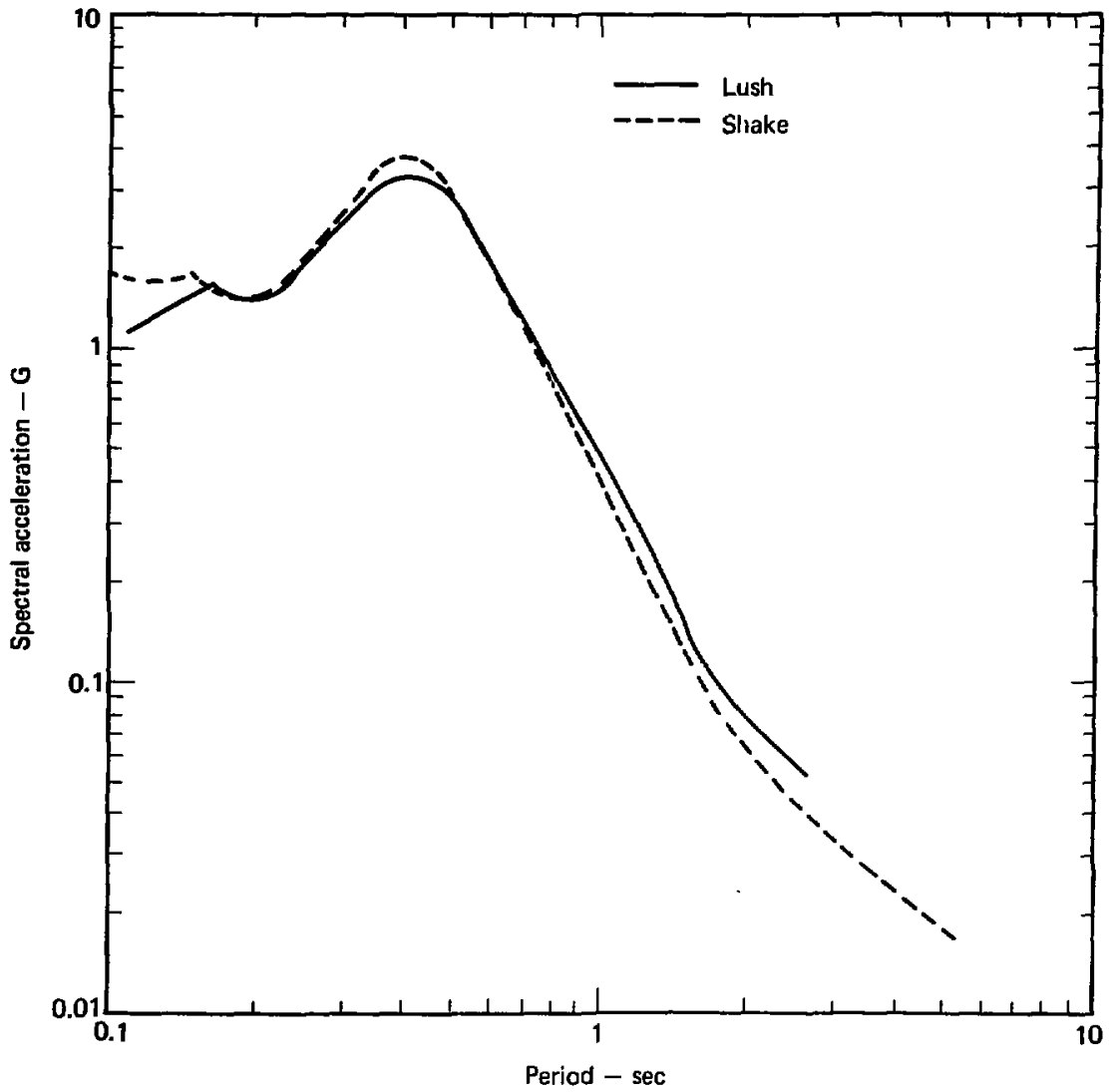

FIg. 32. Comparison of short-duration input SHAKE and LUSH free-field response spectra at the surface for $5 \%$-damping. 


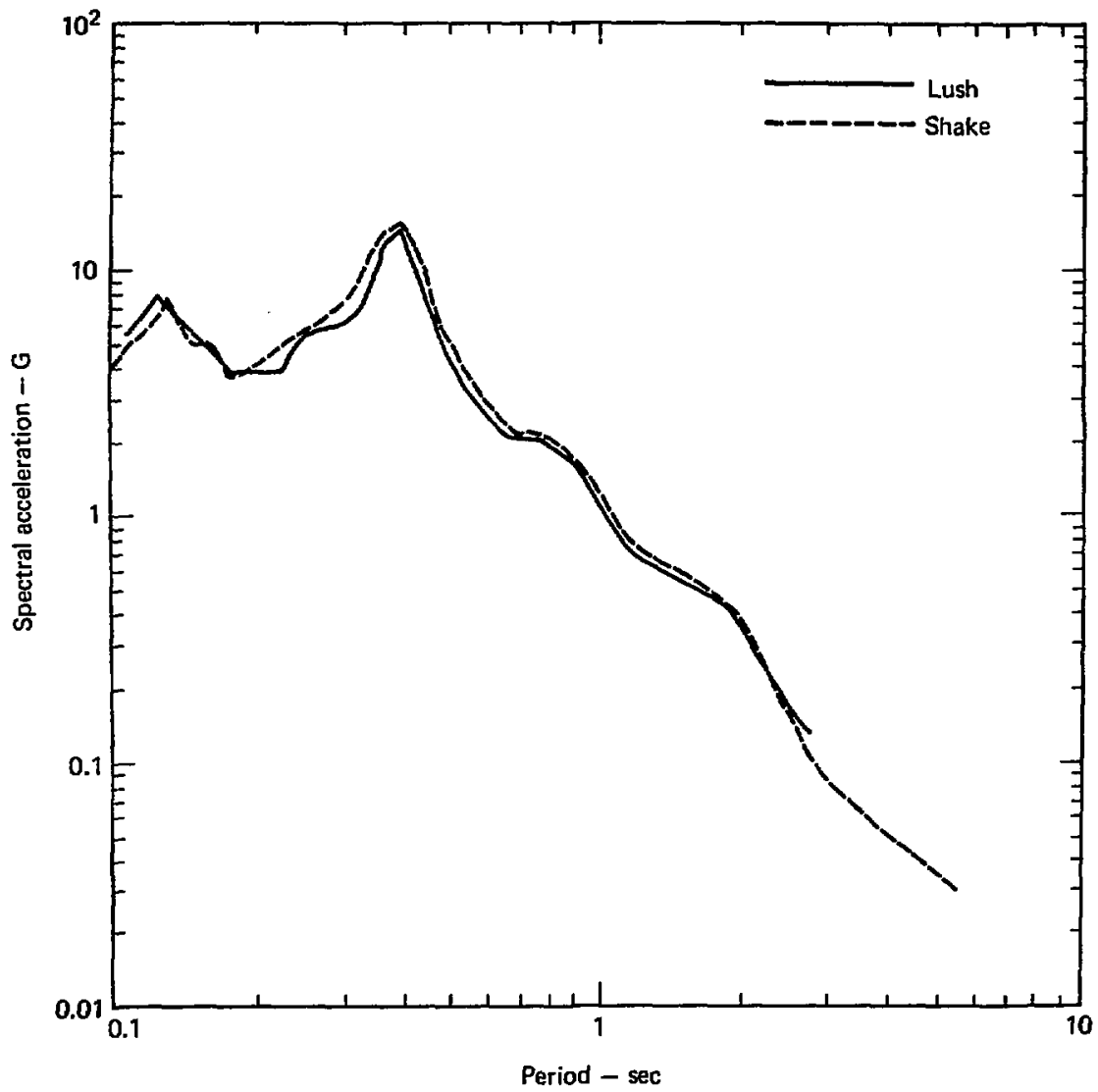

Fig. 33. Comparison of long-duration input SHAKE and LUSH free-field response spectra at the surface for $5 \%$-damping. 


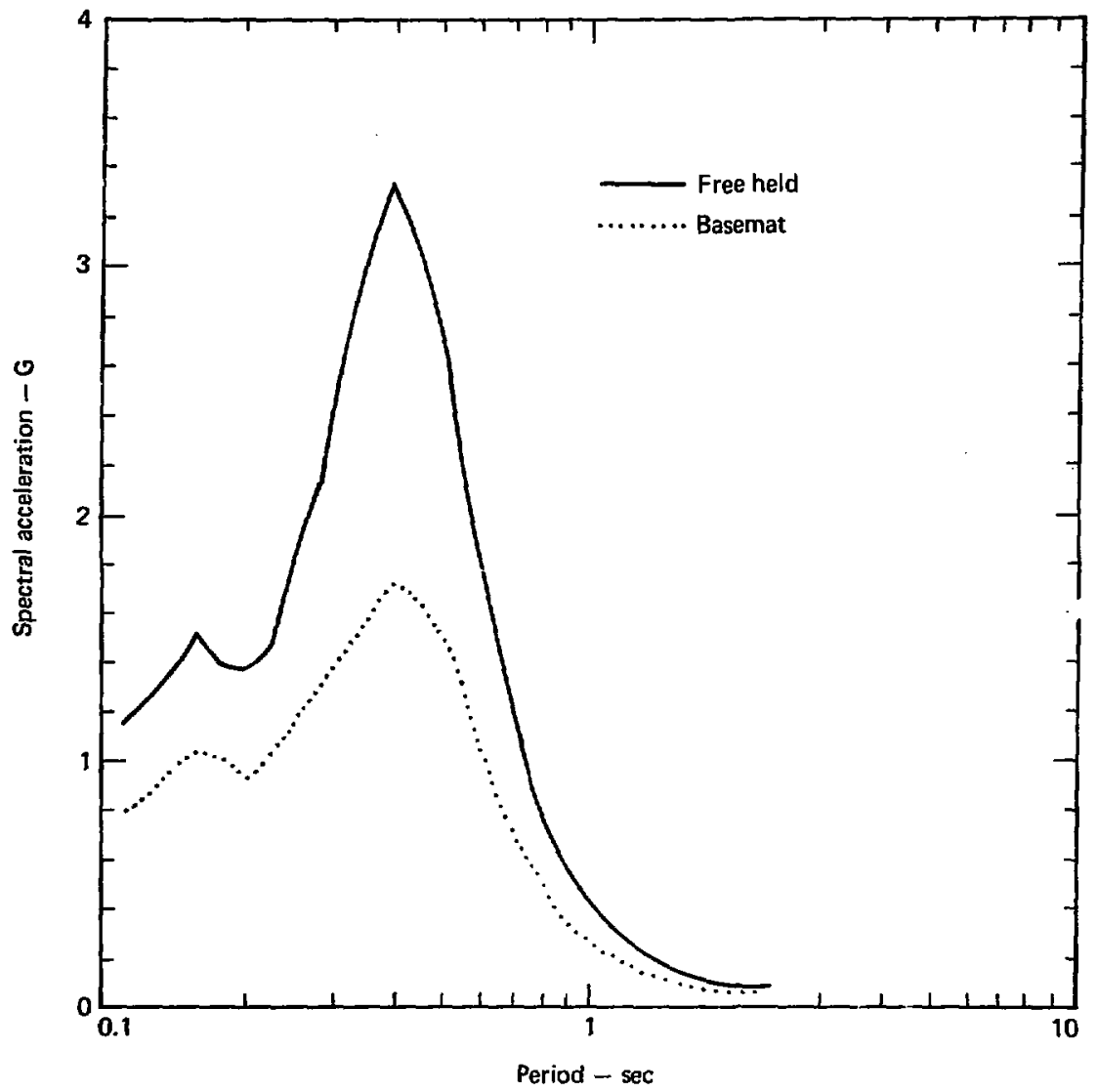

Fig. 34. Comparison of free-field (40-ft depth) and basemat spectra (5\%) for long-duration input.

$-45-$ 


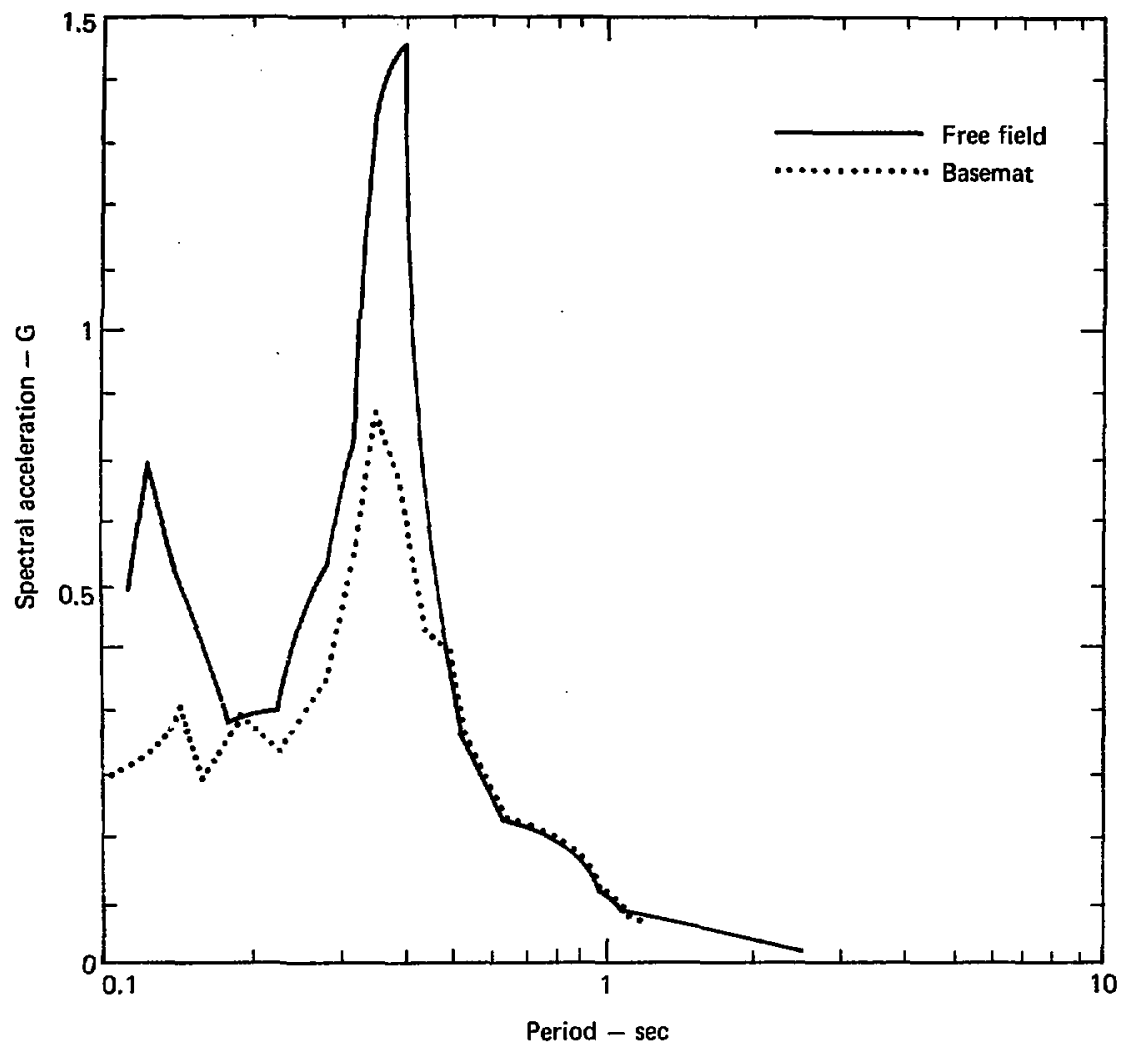

Fig. 35. Comparison of free-field (40-ft depth) and basemat (5\%) spectra for short-duration input.

\section{Effect of Seismic Wave Passage on the Response of Large Basemat Structures}

We have discussed the possible effect of a massive foundation on the modification of typical free-field records. Our conclusions are based on LUSH calculations made with the assumption that the earthquake motion
Is Identical at all spatial points at some depth beneath the reactor. However, these conditions are not typical. Various studies have shown that nonuniform earthquake motion causes self-canceling effects by 
those ground-motion components that oppose each other in a direction relative to the motion of the basemat. This is called the wave-passage effect.

Scanlan ${ }^{18}$ provides the most complete wave-passage model available and we used it to obtain estimates of the possible effects of wave passage. We then compared these estimates with the results of recorded data to determine whether the data would support the model's results. Scanlan's ${ }^{18}$ model is relatively simple. The basemat is represented by a rigid rectangular foundation that rests on and is connected to the soil by an evenly distributed set of soil springs. The seismic input is applied at the base of these springs and it is assumed that

$u(t)$

$$
=\sum A_{n} \cos \left(\omega_{n} t+\phi_{n}-\frac{\omega_{n} x}{c}\right),
$$

where

$$
\begin{aligned}
\sum A_{n} \cos \left(\omega_{n} t+\right. & \left.\phi_{n}\right) \\
= & \text { Fourier expansion } \\
& \text { of surface } \\
& \text { accelerogram, }
\end{aligned}
$$

and

$\mathrm{C}=$ appropriate wave train velocity.

The term $\omega_{n} x / C$ in Eq. (13) represents the wave train that travels across the site.
Two possible types of earthquake motion can be analyzed with this model. The first type is when the soil particle motion is in the same direction as the wave, and the second is when the soil particle motion is transverse to the direction of the wave.

Ong major problem with any such analysis is estimating appropriate average wave velocities that should be used. If the strong ground motion is caused by surface waves, then the appropriate average velocity can be obtained. However, in the reasonably near field of an earthquake, several complex arrivals cause the strong motion (Fig. 36). Thus, much of the motion recorded with two nearby instruments would travel with the high apparent wave velocities in the lower layers, while the higher freguency surface waves would travel with much lower wave velocities in the near surface layers.

Because strong-motion instruments are triggered at some threshold level, it is usually not possible to accurately estimate the appropriate velocities from available earthquake data. There are considerable data from underground nuclear explosions showing average wave velocity of the strong motion is the same as high wave velocities of the deeper layers. This high apparent wave-train velocity is recorded at a distance of at 


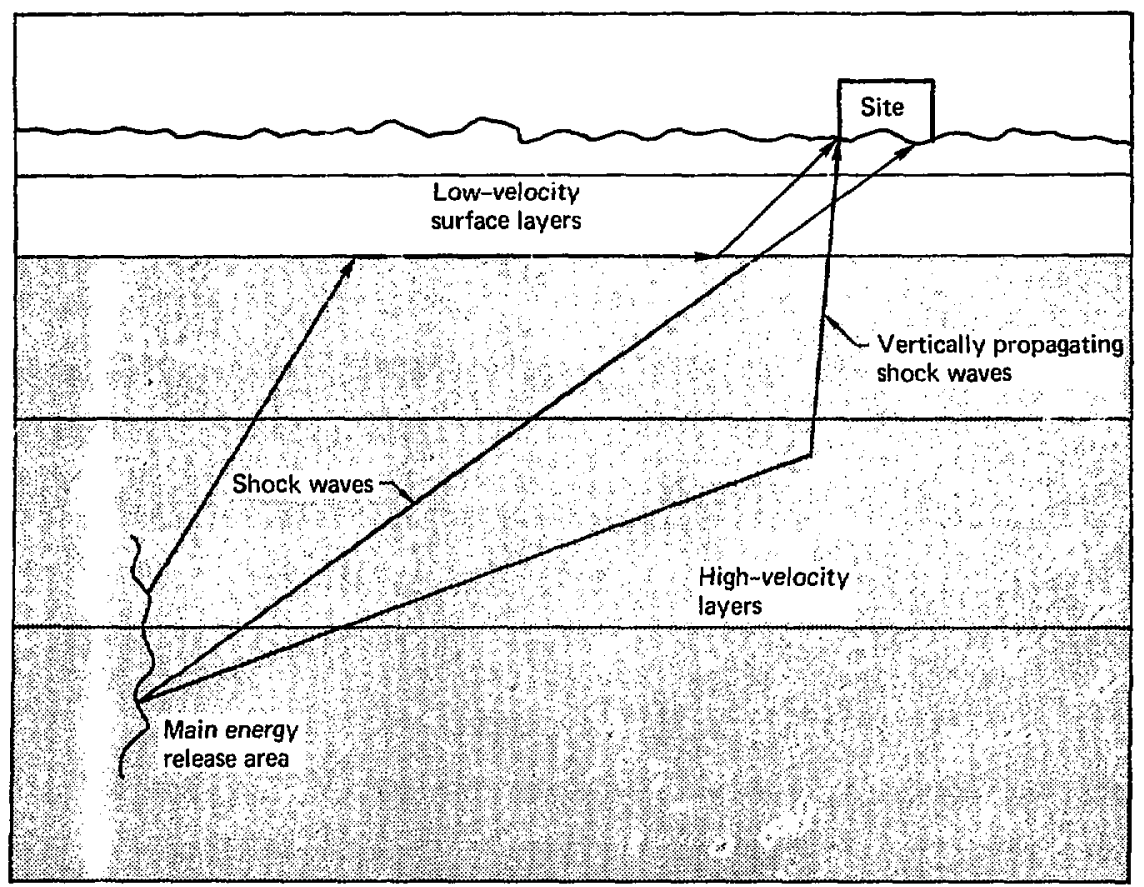

Fig. 36. Probable wave travel paths that would cause large apparent wave train velocities.

least 10 times the depth of energy release (this is about as far as the dense strong-motion arrays extend).

There have been recent studies of ground-motion recorded on closely spaced instruments. Tamura et al. 19 and Tsuchida et al, ${ }^{20}$ published results obtained from two different accel erometer arrays located on soft alluvial ground. For boti arrays, the apparent wave velocity was computed by obtalning the time lags from a cross-correlation of the data recorded by the varlous instruments. Tamura et al. 19 estimated a wave velocity of nearly $3 \mathrm{~km} / \mathrm{sec}$, while the wave velocity estimated by Tsuchida et al. ${ }^{20}$ varied from 2.6 to $5.3 \mathrm{~km} / \mathrm{sec}$. It should be noted that these velocities are much iarger than the wave velocitles of the nearsurface layers.

If we set astde these problems, it is possible to obtain provistonal results. Scanlan ${ }^{18}$ shows that the traveling wave can be replaced by an 
averaged time history applied simultaneously at the base of the soil springs. For both types of earthquake motion Scanlan ${ }^{18}$ showed

$\bar{u}(t)=\sum \bar{A}_{m} \cos \left(\omega_{n} t+\phi_{n}-\psi_{n}\right)$,

where

$$
\begin{aligned}
& \bar{A}_{n}=\left[\frac{2(1-\cos R n)}{R_{n}^{2}}\right]^{1 / 2}, \\
& R_{n}=\frac{\omega_{n}^{2}}{C},
\end{aligned}
$$

and

$$
\mathrm{T}_{\mathrm{an}} \psi_{\mathrm{n}}=\frac{1-\cos \mathrm{Rn}}{\sin \mathrm{Rn}} .
$$

where

$C=$ appropriate wave velocity and $L=$ foundation dimension.

In addition, Scanlan ${ }^{18}$ found that a torsional motton would be excited even in symmetric structures. This motion is not usually included in typical sol1-structure-interaction analysis. In symetric structures, no torsional motion is Induced when the same motion is input equally under the structure. Therefore, it is impossible to derive an expression completely equivalent to Eq. (14). However, Scanlan ${ }^{18}$ shows that

$\alpha_{n}=\left\{\left[\frac{\sin R n}{2 R n}+\frac{\cos R n-1}{R_{n}^{2}}\right]^{2}\right.$

$$
+\left(\frac{\sin R n}{R^{2}}-\frac{1+\cos R n}{2 R n}\right)^{2} \text {, }
$$

which is very similar to the $\bar{A}_{n}$ in Eq. (2). Plots of $\bar{A}_{n} / A_{n}$ and $\alpha n$ are shown on Fig. 37. This figure also shows that the net effect of the traveling wave is the reduction of the amplitude of the Fourler coefflclents at higher frequencies. In this case, high frequencies are defined relative to the average traveling wave-train velocity and the foundation dimension $L$.

Several assumptions were made in this analysts and their validity is difficult to determine, suggesting that it would be useful to assess the overall effect of wave passarce on structural response. This $\theta$ an be done by qualitatively comparing the overall structural response to real traveling waves to the response predicted qualitativeiy by Eq. (14). This is ideally artileved by comparing free-fleld measurements with measurements obtained in a building. However, Wecause there are so few cases is strong motion recorded both in trildings and nearby in the free rield, we can also compare the response of an accelerometer located in the basements of closely grouped buildings with different basemat areas. In this way, we should be able to determine the importance of the effect. 

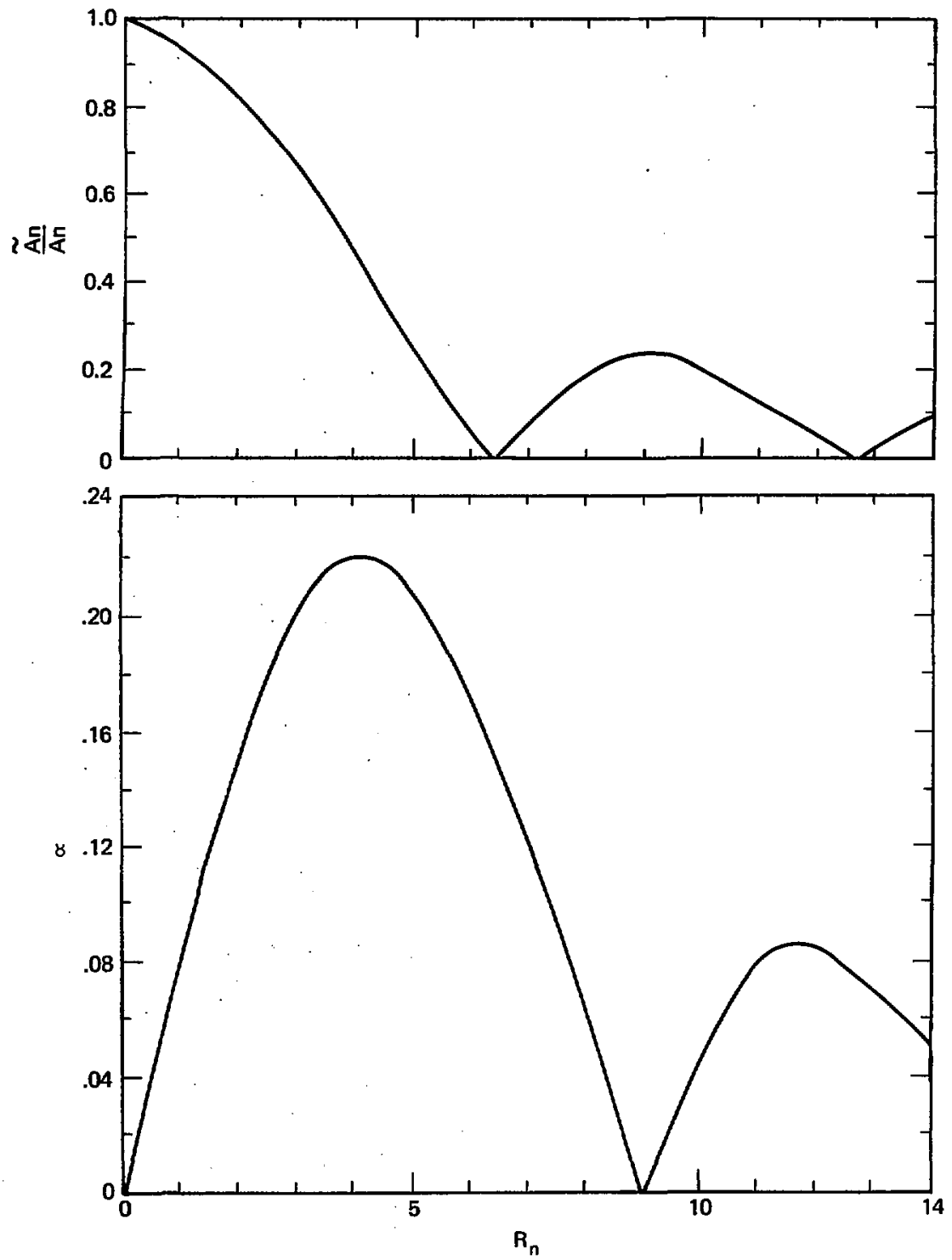

Fig. 37. Effect of the traveling wave on the Fourier Amplitude Spectra at higher frequencles. 
One such recorded case compared data from a parking lot and the Hollywood Storage Building du -ing the San Fernando earthquake. Newmark et al. ${ }^{21}$ used this example as evidence for wave-passage effects. Figure 38 gives a plot of the ratio of the Fourier Spectral Amplitude recorded in the parking lot divided by the motion recorded in the basement of the Hollywood Storage Build- ing. Newmark et al. ${ }^{21}$ was able to predict the difference in the two spectra by using a wave velocity of $0.6 \mathrm{~km} / \mathrm{sec}$. The value of wave velocity used by Newmark et al. 21 is very low when compared to the experimentally obtained wave velocities previously discussed.

We can use Eq. (14) to obtain the probable effect on various basemat areas. Figure 39 illustrates the

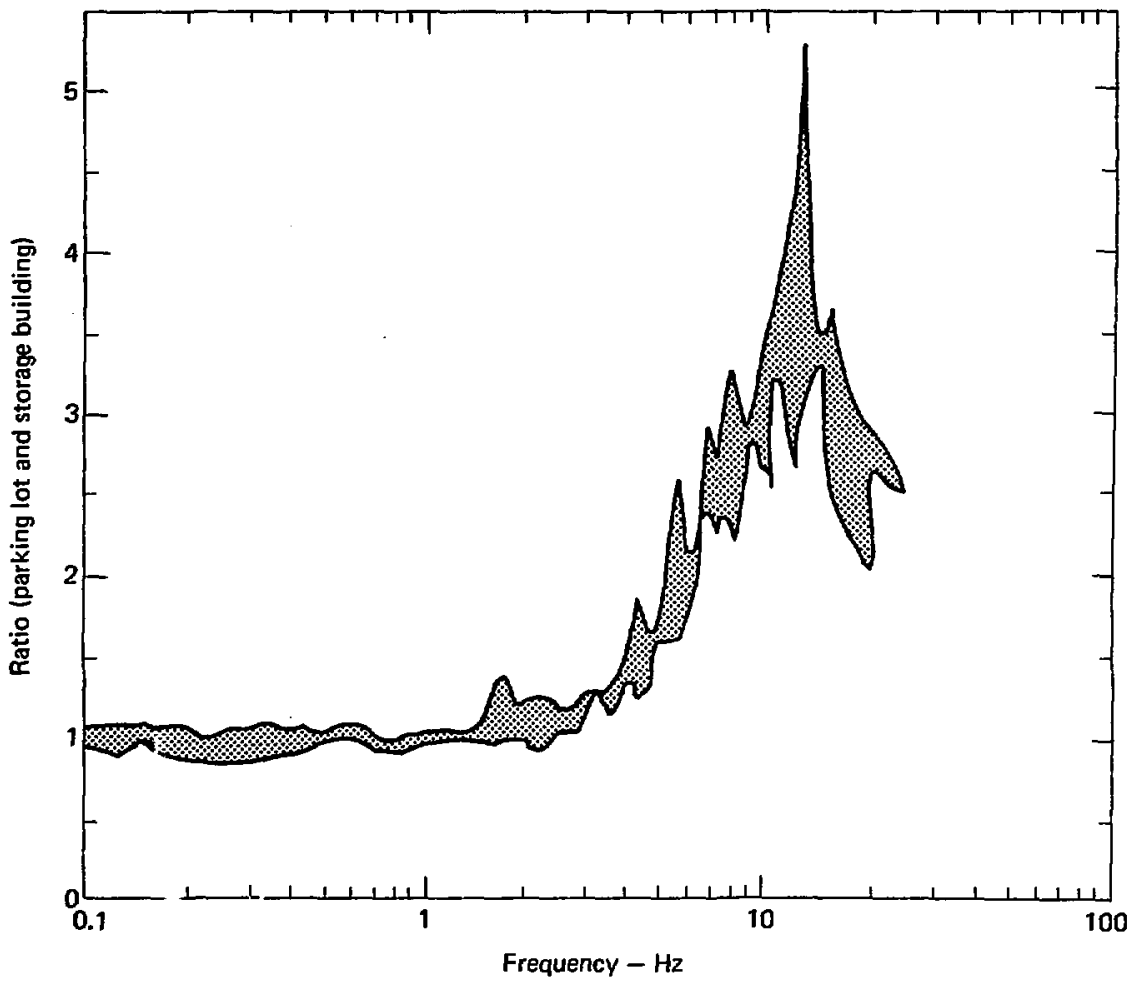

Fig. 38. Ratio of 2\%-damped relative-velocity spectral amplitude for the parking lot and Hollywood Storage Bullding. Only the envelope of the two components is shown. 
averaging as a function of frequency expected for a wave velocity of $\mathrm{C} \simeq 0.6 \mathrm{~km} / \mathrm{sec}$ and $3 \mathrm{~km} / \mathrm{sec}$ in structures with an effective length of 100 and $300 \mathrm{ft}$. The ratio of the Fourier coefficients for the effective time histories of two different structures is shown and we see that the cholce of $\mathrm{C}$ is very important. If, as indicated previous1y, the appropriate wave velocity is that of the deeper layers $(>3 \mathrm{~km} / \mathrm{sec})$, then wave passage is not very Important. However, if the value of $\mathrm{C}$ used by Newmark is appropriate, then wave passage effects are important and should be discernable.
Figure 40 gives the locations of the buildings we studied, Figure 41 shows a comparison of the Fourier amplitude spectra recorded at ground level in the 6430 sunset Building to that recorded in the parking lot at the Hollywood storage Building and we see that the two spectra are almost Identical. The building at 6430 Sunset has 14 storles and seems to show no evidence of averaging. However, a comparison of 6430 Sunset to an 11-story building at 6464 Sunset shows a considerable difference in the basemat response of both buildings (Fig. 42). This suggests that the differences in the recording from the

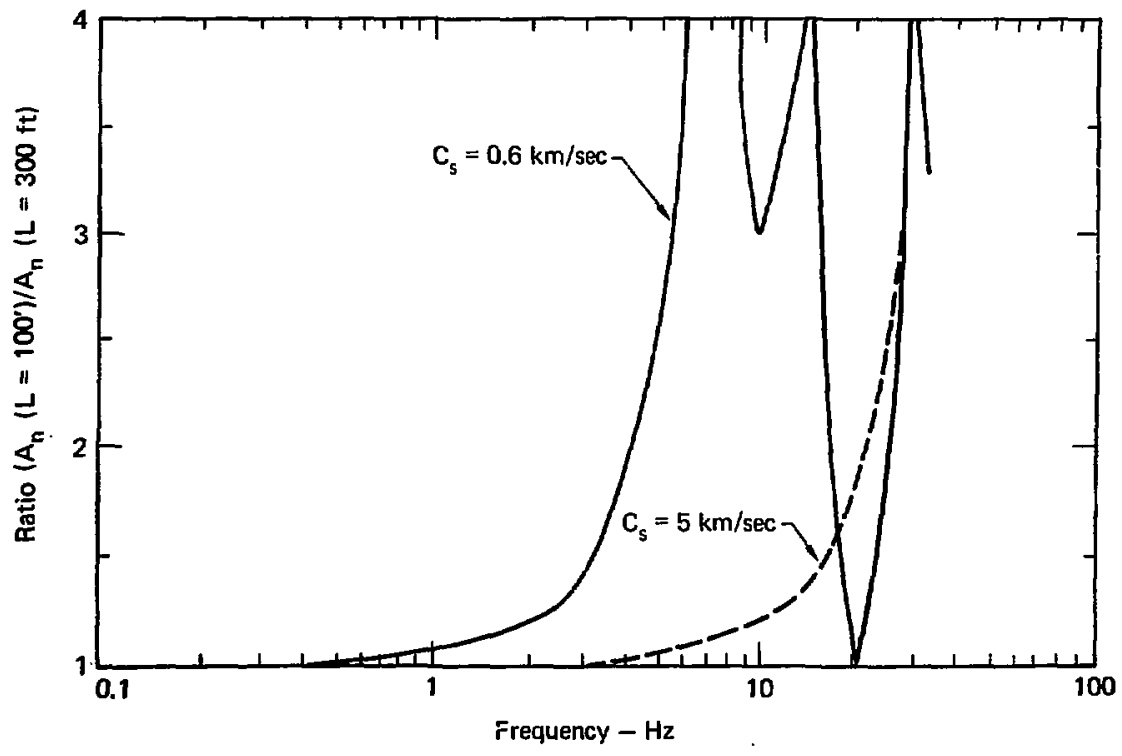

Fig. 39. Predicted effect on the ratio of the Fourier Amplitude Spectra for a building $100 \mathrm{ft}$ long divided by a $300-\mathrm{ft}$ long building. 


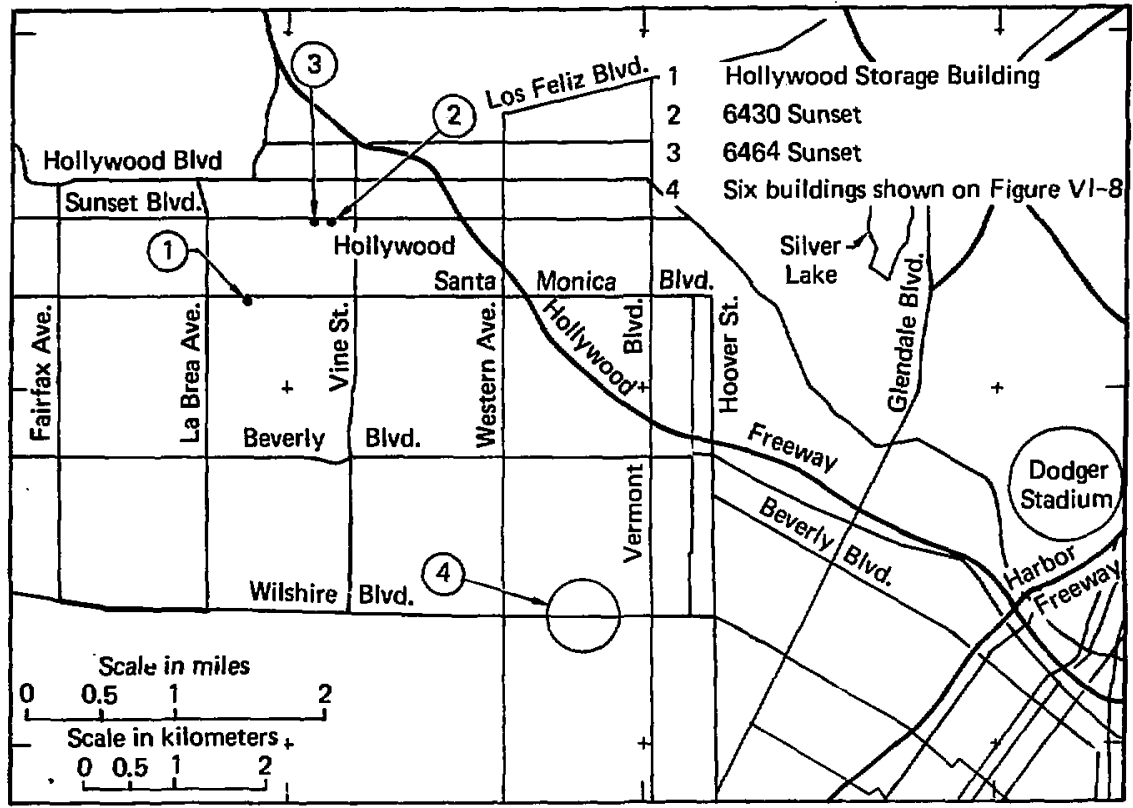

Fig. 40. Relative locations of all buildings studied.

parking lot and the basemat of the Hollywood Storage Building may be caused by factors other than wave passage.

Figure 43 shows the location of a group of buildings in the Hollywood area, thelr basemat areas and the ratio of the basemat area to 3411 Wilshire. Figure 44 compares the $2 \%$-damped relative velocity spectral amplitude of each building to that of the largest basemat at 3411 Wilshire. There are only slight differences in the two components recorded at each site. Only the envelope of the data of the components is shown because we are primarily interested in the overall trend of the data rather than the fine structure of the spectral ratlo. The $2 \%$-damped spectra was chosen to swooth out some of the violet fluctuations observed in the Fourier spectra and simplify interpretation.

In the high-frequency end (greater than $3 \mathrm{~Hz}$ ), we would expect that the ratio would be much larger than unity if Newmark's choice of $0.6 \mathrm{~km} / \mathrm{sec}$ for the wave velocity is correct (Fig. 39). But this is not the case, because the 


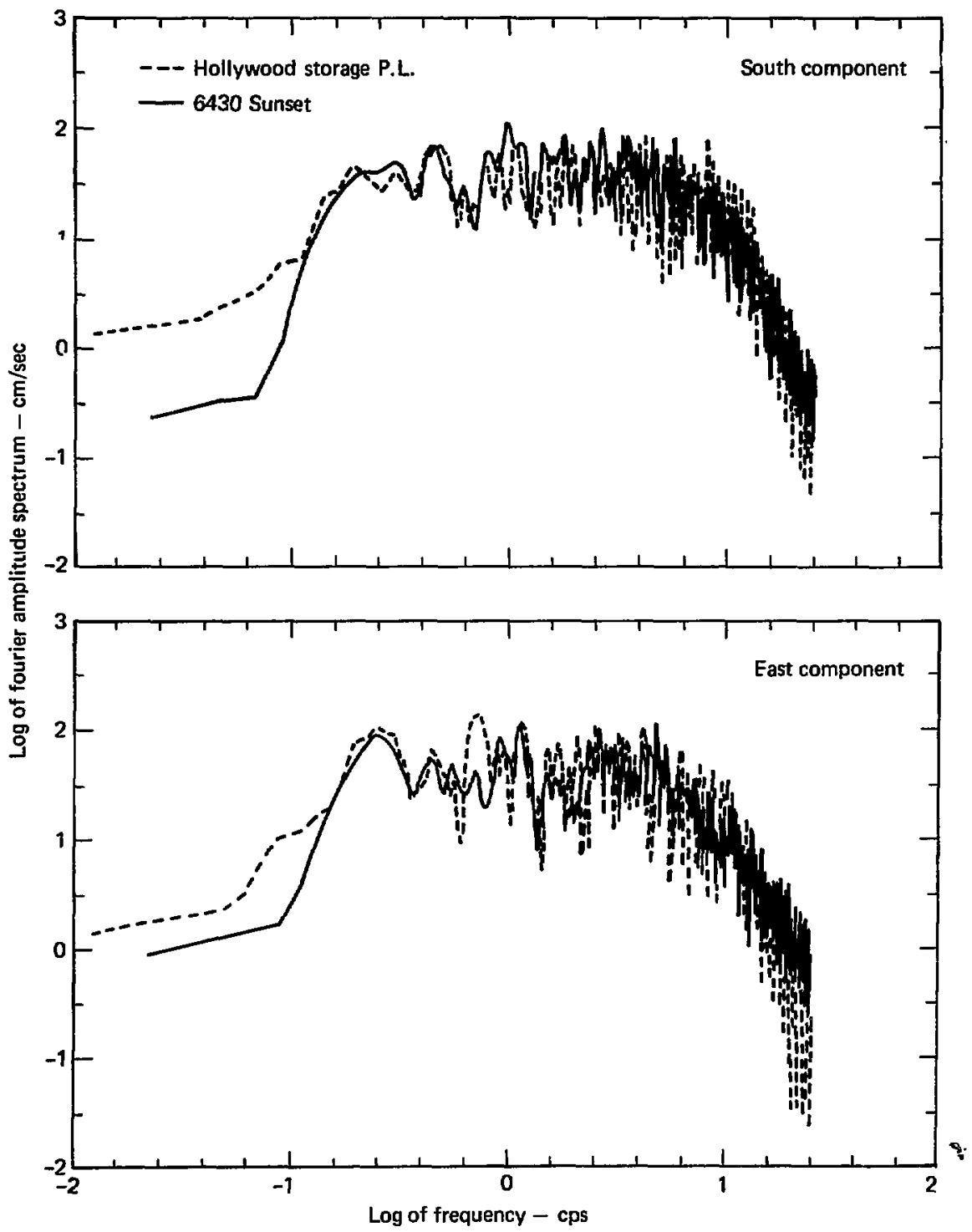

F1g. 41. Comparison of ground-level Fourler amplitude spectra recorded at 6430 Sunset Blvd, and parking lot of Hollywood Storage Building (south and east components). 


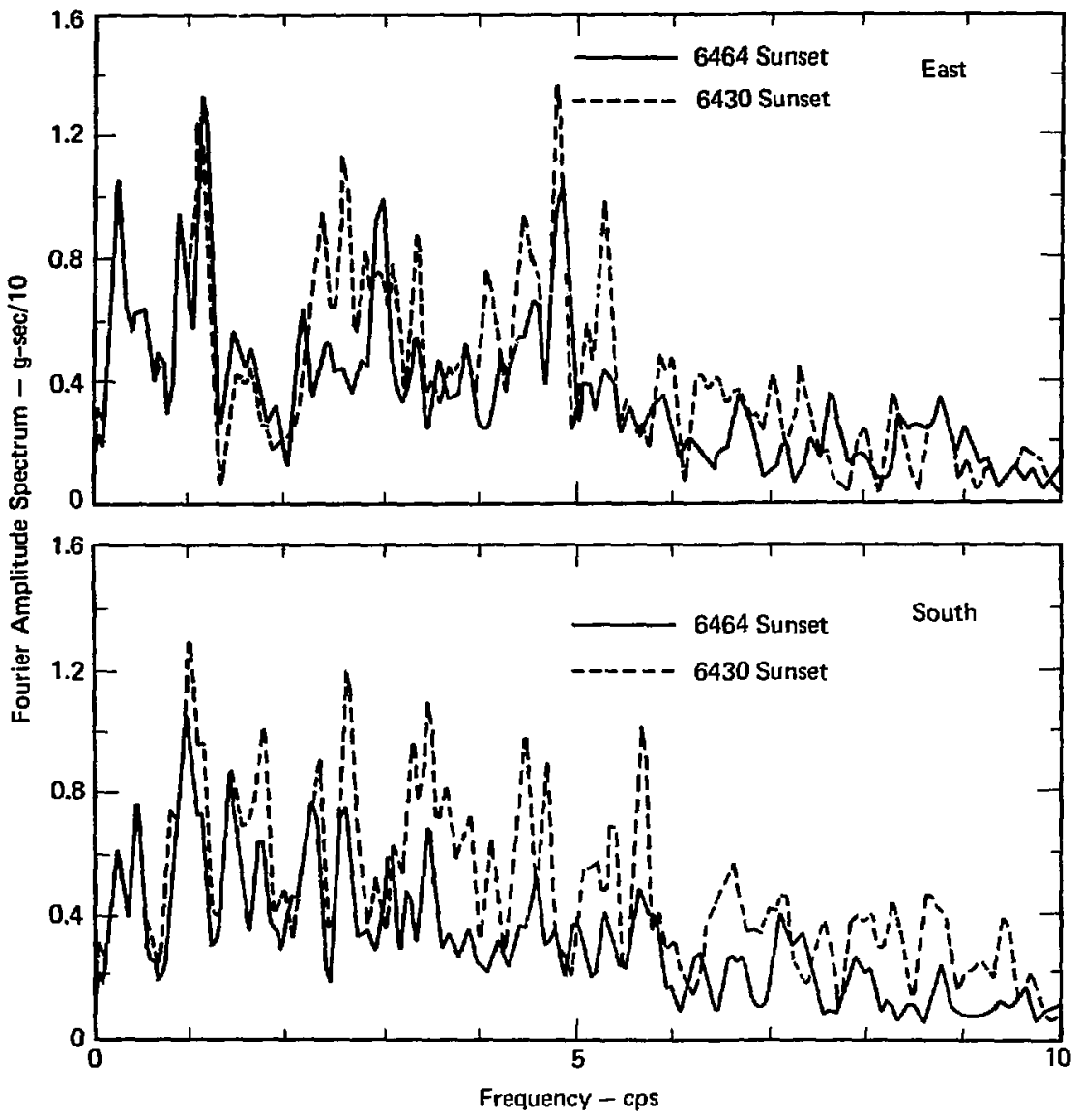

Fig. 42. Comparison of ground-level Fourier Amplitude Spectra recorded in buildings at 6430 and 6464 sunset Blvd. 


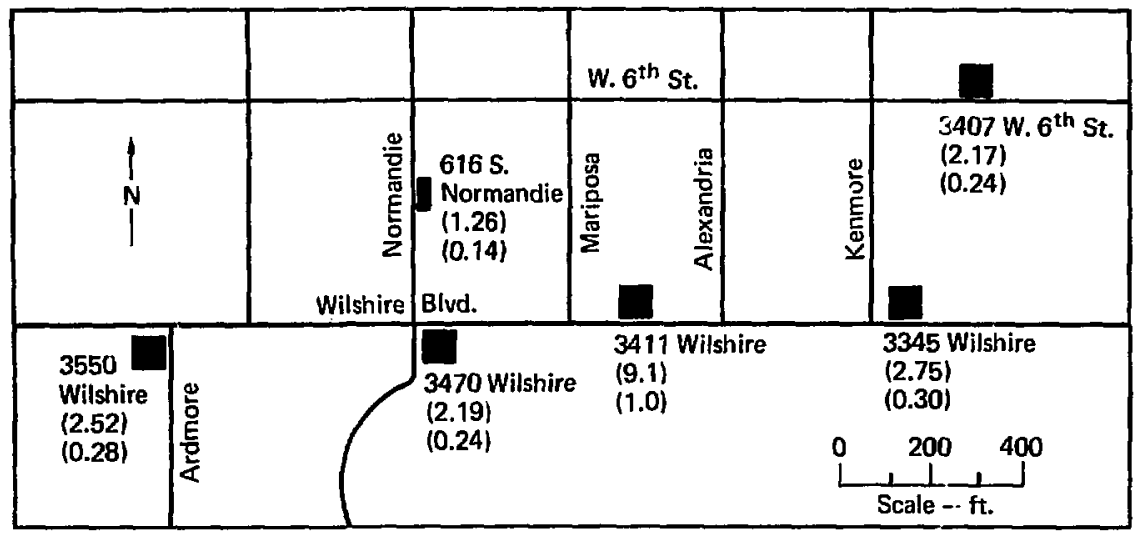

Fig. 43. Relative locations and basenat areas of accelerograph stations. Top number in parenthesis represents basemat area X1000. Bottom number in parenthesis represents ratto of basemat area to 3411 Wilshire.

only significant change in the ratio is between 1 and $3 \mathrm{~Hz}$. However, the response shown on Fig. 44 is consistent with the choice of a higher wave velocity for frequencies greater than $3 \mathrm{~Hz}$. The bullding at 3411 wilshire seems to have filtered the ground motion between 1 and $3 \mathrm{~Hz}$.

We conclude that the apparent wave veloctty is extremely important and added measurements of the average wave velocity are needed. The available data seems to suggest that this velocity is much larger than the wave velocity of the near-surface layers. In addition, when theoretical predictions are compared with actual recordings, some cases appear to support the theory while others do not. However, any interpretation is difficult because the wave velocity is unknown and has such an important effect on the phenomenon. It appears that the response of structures to the passing seismic wave is very complex and cannot be lumped together in a simple averaging scheme. 

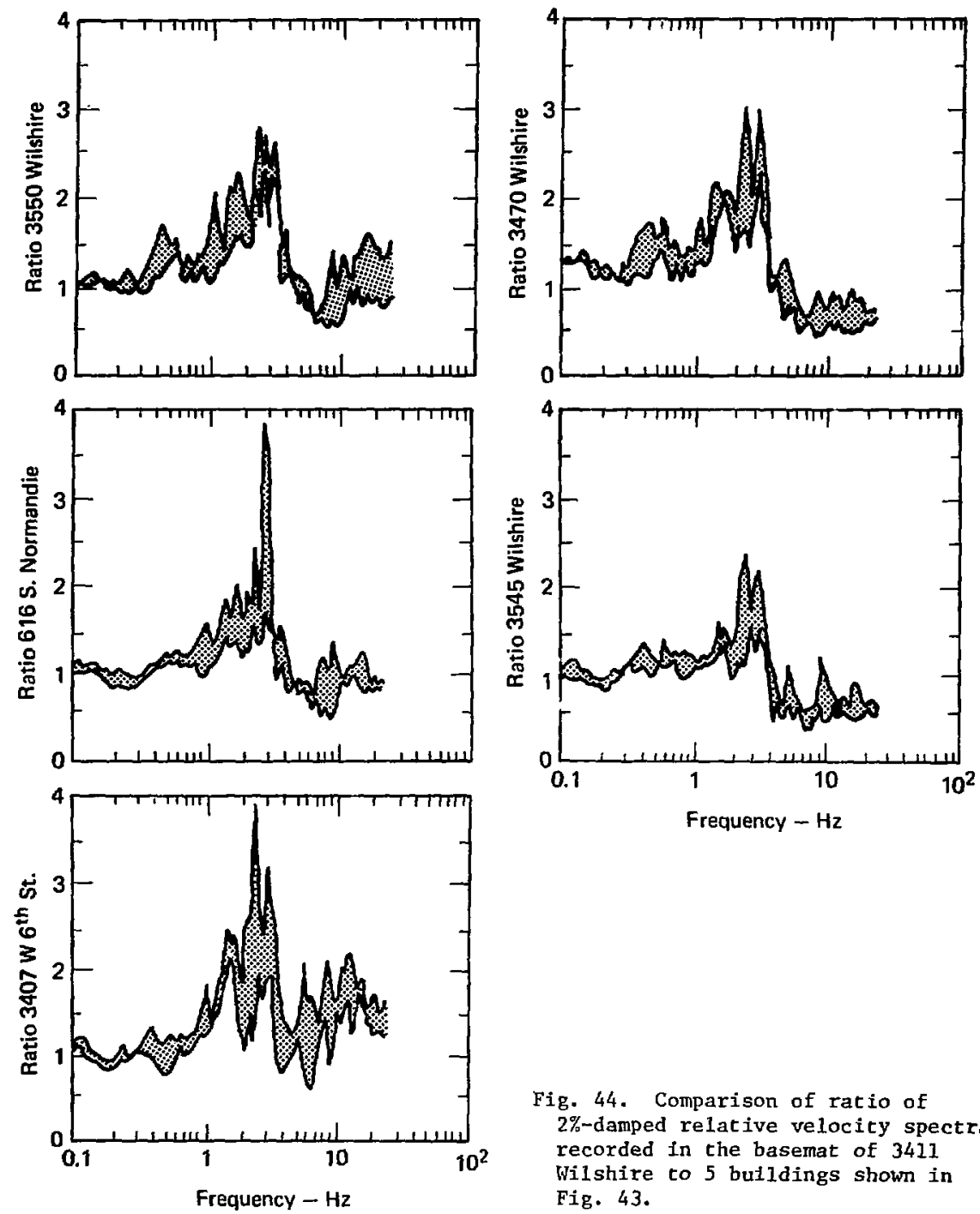

Fig. 44. Comparison of ratio of 2\%-damped relative velocity spectra recorded in the basemat of 3411 Wilshire to 5 bulldings shown in Fig. 43. 


\section{Conclusion}

Our study has provided added confirmation that the ratio of peak velocity to peak acceleration is much smaller at a rock site than at a soil site. We have also shown that the level of ground motion (recorded response spectra) that would occur at Diablo Canyon from a major nearby earthquake would have lower amplification factors than those specified in Regulatory Guide 1.60. The appropriate $g$ value should be in the average to low average range of values predicted by accepted correlations; the reduction is caused by the affect of the mudstone layex and the SSI at the site. Finally, we have shown that the present Diablo Canyon Nuclear Power Plant should not be seriously affected by an earthquake of increased magnitude that is the result of an increased fault rupture length rather than increased stress drop.

\section{Acknowledgments}

The authors express their appreciation to V. N. Karpenko, Division Leader during this study and to C. E. Walter, Deputy Leader, Nuclear Test Engineering Division, Mechanical Engineering Department, for their encouragement and support of this project. The attention and encouragement given by $J$. C. Stepp of the office of Nuclear Reactor Regulation have been most helpful and appreciated. Project funding from the U.s. Nuclear Regulatory Commission is acknowledged. 


\section{References}

1. N. M. Newmark and Associates, "A Study of Vertical and Horizontal Earthquake Spectra," USAEC, Wash-1255 (1973).

2. R. McGuire, "Seismic Structural Rerponse Risk Analysis, Incorporating Peak Response Regressions on Earthquake Magnitude and Distance," Ph.D thesis, Massachusetts Institute of Technology, Cambridge, Mass. (1974).

3. M. D. Trifunac, "Preliminary Analysis of the Peaks of Strong Earthquake Ground Motion-Dependence of Peaks on Earthquake Magnitude, Epicentral Distance and Recording Site Conditions," BSSA 66 (1976).

4. P. B. Schnabel, J. Lysmer, and H. B. Seed, SHAKE, A Computer Program for Earthquake Response and of Horizontally Layered Sites, University of California, Berkeley, Calif., Rept. EERC 72-12 (1972).

5. H. L. Wong, and P. C. Jennings, "Effects of Canyon Topography on Strong Ground Notion," BSSA 65, 1239-1257 (1975).

6. M. D. Trifunac and F. E. Udwadia, "Comparison of Earthquake and Micrometer Ground Motions in El Centro, California," BSSA 63 (1973).

7. H. Kanamori, and D. L. Anderson, "Theoretical Basis of Some Empirical Relations In Seismology," BSSA 65, 1073-1095 (1975).

8. K. Aki, "Earthquake Mechanism," Tectonophysics, 13, 423-446 (1972).

9. J. N. Brune, "Seismic Sources, Fault Plane Studies and Tectonics," Thans. Am. Geophys. $\underline{\mathrm{U}} \underline{52}$ (5) 178-187 (1971).

10. M. D. Trifunac, "Analysis of Strong Earthquakes Ground Motion for Prediction of Response Spectra," Int. J. of Earthquake Engineeming and Structural Dynomica, 2, 59-69 (1973).

11. D. E. Hudson, "Some Problems in the Application of Spectrum Techniques to Strong-Motion Earthquake Analysis," BSSA 52, 417-430 (1962).

12. M. D. Trifunac, "Preliminary Empirical Model for Scaling Fourier Amplitude Spectra of Strong Ground Accelerations in Terms of Earthquake Magnitude, Source-to-Station Distance and Recording Site Conditions," BSSA 63 , 1323-1342 (1976).

13. M. D. Trifunac, "Stress Estimates for San Fernando, California Earthquake of 9, Feb. 1971: Main Event and Thirteen After Shocks," BSSA 62, 721-750 (1972).

14. M. D. Trifunac, "Tectonic Stress and Source Mechanism of the Imperial Valley Earthquake of 1940," BDSA 62, 1283-1302 (1972). 
15. J. N. Brune, "Tectonic Stress and the Spectra of Seismic Shear Waves," J. Geophys. Res. 75, 4997-5009 (1970).

16. W. Thatcher, and T. C. Hanks, "Source Parameters of Southern California Earthquakes," J. Geophys. Res. 78, 8547-8576 (1973).

17. T. C. Hands, and D. A. Johnson, "Geophysical Assessment of Peak Accelerations," BSSA 66, 959-968 (1976).

18. R. H. Scanlan, "Seismic Wave Effects on Soil-Structure Interaction," Inter. J. of Earthquake Fingineering and Structural Dynamics 4, 379-388 (1976).

19. C. Tamura, T. Noguch1, and K. Kato, "Earthquake Observation Along Measuring Lines on the Surface of Alluvial Soft Ground," in Proc. 6th World Conference on Earthquake Engineering, vo1. 2 (1977).

20. H. Tsuchida, E. Kurata, and S. Hayashi, "Observation of Earthquake Response of Ground with Horizontal and Vertical Seismometer Arrays," in Proc. 6th World Conference on Earthquake Engineering, vol. 2 (1977).

21. N. M. Newmark, W. J. Hall, and J. R. Morgan, "Comparison of Building Response and Free Fleld Motion in Earthquakes," in Proc. 6th Worid Conference on Exrthquake Engineering, vol. 3 (1977).

$\mathrm{DLB} / \mathrm{ml} / \mathrm{vt}, \mathrm{mg} / \mathrm{jf}$ 